Historic, Archive Document

Do not assume content reflects current scientific knowledge, policies, or practices. 

aHV4701

. A95

no.

2000-01

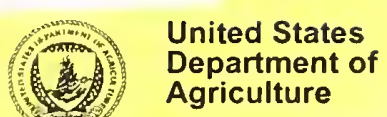

ISSN: 1049-202X

$025 \begin{aligned} & \text { Agricultural } \\ & \text { Research } \\ & \text { Service }\end{aligned}$

1. National

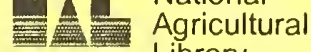
Library

Beltsville

Maryland

20705-2351

March 2000

\section{Audio-Visuals Relating to Animal Care, Use, and Welfare}

AWIC Series No. 2000-01

Animal Welfare Information Center Series

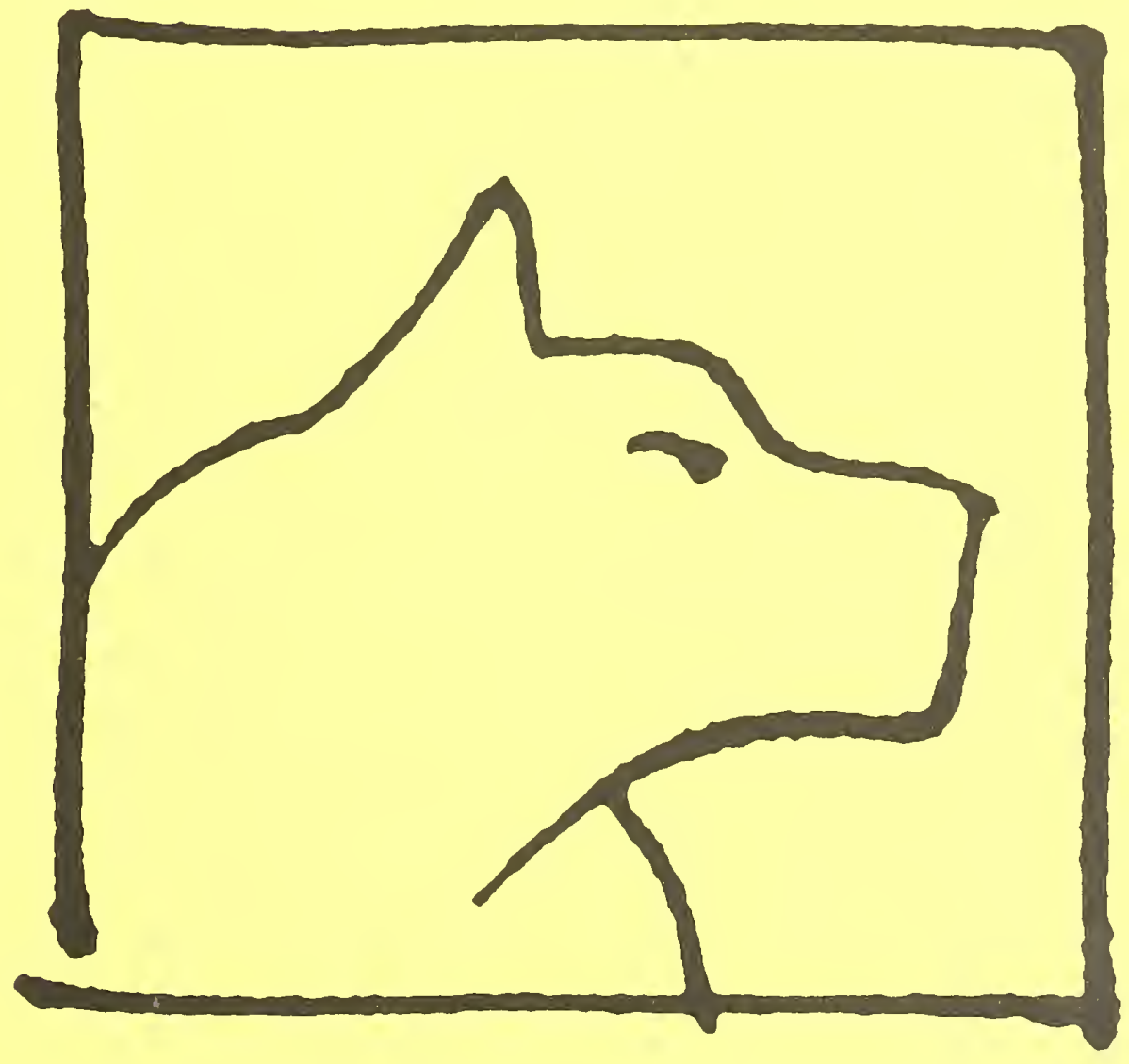


United States

Department of

Agriculture

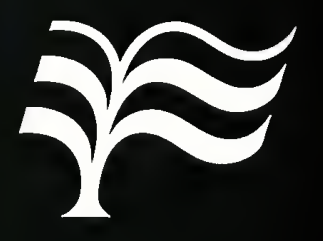

NATIONAL Agricultural LIBRARY

Advancing Access to Global Information for Agriculture 


\section{Audio-Visuals Relating to Animal Care, Use, and Welfare}

AWIC Series No. 2000-01

Updates AWIC Series No. 96-01

Jean A. Larson and D'Anna J.B. Jensen Animal Welfare Information Center

National Agricultural Library Agricultural Research Service U.S. Department of Agriculture 10301 Baltimore Avenue Beltsville, MD 20705

Website - http://www.nal.usda.gov/awic

E-maill - awic@nal.usda.gov

Phone - 301-504-6212 


\section{National Agricultural Library Cataloging Record:}

Larson, Jean A., Jensen, D'Anna J. B.

Audio-visuals relating to animal care, use, and welfare.

(AWIC series ; no. 2000-01)

1. Animal welfare-Audio-visual aids-Bibliography-Catalogs.

2. Animals-Audio-visual aids-Bibliography-Catalogs.

I. II. Title.

aHV4701.A95 no.2000-01

The United States Department of Agriculture (USDA) prohibits discrimination in all its programs and activities on the basis of race, color, national origin, sex, religion, age, disability, political beliefs, sexual orientation, or marital or family status. (Not all prohibited bases apply to all programs.)

Persons with disabilities who require alternative means for communication of program information (Braille, large print, audiotape, etc.) should contact USDA's TARGET Center at 202-720-2600 (voice and TDD).

To file a complaint of discrimination, write USDA, Office of Civil Rights, Room 326-W, Whitten Building, 1400 Independence Avenue, SW, Washington, DC 20250-9410 or call 202-720-5964 (voice or TDD). USDA is an equal employment opportunity provider and employer. 


\section{Table of Contents}

How to Use this Document $\ldots \ldots \ldots \ldots \ldots \ldots \ldots \ldots \ldots$

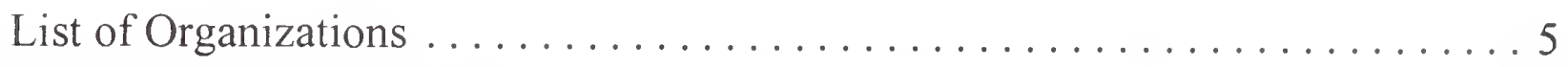

Alphabetical Listing of Titles $\ldots \ldots \ldots \ldots \ldots \ldots \ldots \ldots \ldots \ldots$

Audio-Visual Listing...$\ldots \ldots \ldots \ldots \ldots \ldots \ldots \ldots$

Loan Information . .......................... 107

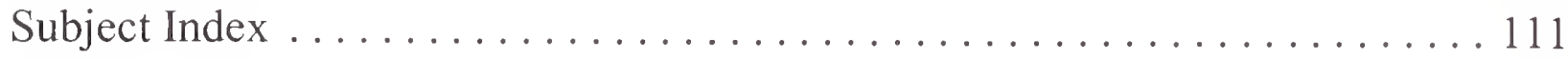




\section{How to Use this Document}

This document is a listing of audiovisuals related to animal care that are currently in the National Agricultural Library (NAL) collection. All audio visuals are available to others on an interlibrary loan basis (see page 109 of this document for more information). They cannot be purchased from NAL. If the reader would like copies of the materials, please contact the producer.

There are several ways to access the listed titles. There is a quick alphabetic listing by title and an extensive index. The body of the document includes a complete bibliographic citations in the same order as the title listing. The citations include the title, author, publisher, place of publication, date, format, length of time, keyword, a short descriptive note/abstract, and the NAL call number. Please note that the call number field includes terms such as--filmstrip, videocassette and slide and a number. Please include all this information when requesting them on loan from NAL. 


\section{List of Organizations}

AAALAC - Association for Assessment and Accreditation of Laboratory Animal Care International

AALAS - American Association for Laboratory Animal Science

ACUC - Animal Care and Use Committee

AKC - American Kennel Club

ALF $\quad-\quad$ Animal Liberation Front

APHIS - Animal and Plant Health Inspection Service.

ARS - Agricultural Research Service

ASPCA - American Society for the Prevention of Cruelty to Animals

AWIC - Animal Welfare Information Center

CAAT - Johns Hopkins Center for Alternatives to Animal Testing

FBR - Foundation for Biomedical Research

FDA $\quad-\quad$ Food and Drug Administration

FRAME - Fund for the Replacement of Animals in Medical Experiments

HSUS - Humane Society of the United States

IACUC - Institutional Animal Care and Use Committee

iiFAR - Incurably Ill for Animal Resource

ILAR - Institute for Laboratory Animal Resources

NABR - National Association for Biomedical Research

$\mathrm{NIH} \quad-\quad$ National Institutes of Health

PETA - People for the Ethical Treatment of Animals

SCAW - Scientists Center for Animal Welfare

USDA - United States Department of Agriculture 


\section{Alphabetical Listing of Titles}

1. A Challenge to Care: Careers in Laboratory Animal Science

2. A Feminist View of Human-Animal Relations

3. A Guide to Foal Handling

4. A New Leash on Life

5. A New Way: A Presentation of Lincoln Park Zoo

6. A Question of Life

7. A Question of Respect

8. A Question of Safety: The Importance of Product Safety Testing

9. About Animals, The Question Is...

10. Advanced Training of the Western Horse

11. AKC and the Sport of Dogs

12. All About Llamas

13. Alternatives in Animal Research

14. AMDUCA Regulations

15. America's Pork Producers: Stewards of the Land

16. Among the Wild Chimpanzees

17. Amphibians: Medicine and Husbandry

18. An Introduction to Zoonoses

19. Anatomy of the Dog: Male Genitilia

20. Anatomy of the Dog

21. Anesthesia Matters: An Instructional Video on the Use of Anesthesia in Small Laboratory Animals

22. Animal Agriculture: Myths and Facts

23. Animal Behavior in the Wild

24. Animal Bite Prevention for Children and Adults: Two Defensive Maneuvers to Prevent Serious Injuries from Dog Attacks

25. Animal Care and Use: Policy Issues in the 1990's

26. Animal Care Matters

27. Animal Research: The Cost of Hope

28. Animal Rights/Animal Welfare

29. Animal Rights: The Issues, the Movement

30. Animal Training

31. Animal Welfare: Implications for Agricultural Research

32. Animal Welfare Information Center: Resources Today for the Research of Tomorrow

33. Animal Welfare: The Farmers' Story

34. Animals in Biomedical Research

35. Animals in Research: A Complex Issue

36. Animals in Research: Breaking the Habit

37. Animals in Zoos: Issues and Concerns

38. Animals, Nature and Religion

39. Animals that Live in Groups

40. APHIS M\&B Recruitment Video

41. Artificial Insemination in Swine

42. Aseptic Surgery of Rodents

43. Avian Depredation of Southern Aquaculture 
44. Baiting Techniques

45. Bandaging and Splinting

46. Bam Construction

47. Basic Herding

48. Basic Horse Training

49. Basic Horse Care: Farnam Video Collections

50. Basic Horseshoeing Principles

51. Basic Sterile Cell Culture

52. Basic T.E.A.M. with Llamas

53. Bear Necessities

54. Beating Muscle Injuries in Horses

55. Beef Cattle Judging

56. Biology and Management of the Domestic Ferret

57. Biomethodology of the Cat

58. Biomethodology of the Dog

59. Biomethodology of the Guinea Pig

60. Biomethodology of the Laboratory Mouse

61. Biomethodology of the Primate

62. Biomethodology of the Rabbit

63. Biomethodology of the Rat

64. Biosecurity in Aquaculture

65. Biotechnology, Food, \& Agriculture

66. Biotechnology: On the Cutting Edge

67. Biovideo: Animal Senses

68. Blood Collection from Birds

69. Bovine Restraint

70. Breaking Barriers

71. Breaking Yearlings

72. Britches

73. Broodmare Management

74. Brookfield Zoo: Keeper Orientation

75. BST \& Milk: Issues \& Answers

76. BST: Continuing a Dairy Tradition

77. BST Debate: Biotechnology and the Dairy Case

78. Caesarean Birth

79. Cage Culture: Raising Fish in Ponds

80. Cage Sanitation: Use of Chemical Disinfectants

81. Caging Systems, Bedding Materials \& Environmental Considerations for Laboratory Rodents

82. Calving Time Management/Equipment

83. Canine Control Officer/Kennel Worker

84. Care and Management of Caged Birds

85. Careers in the Horse Industry: Unbridled Opportunities

86. Careers in Veterinary Medicine: a Rainbow of Choices

87. Careers in Veterinary Medicine

88. Caring for Life

89. Carnivore Restraint and Handling

90. Carnivores: Basic Needs, Handling and Care

91. Cat Care: A Video Guide to Successful Cat Care 
92. Catfish Farming in the South

93. Cats: Caressing the Tiger

94. Cattle Handling and Transportation

95. Cattle Handling

96. Cell Wars:The Life Revolution

97. Changing Relationship Between Humans and Animals

98. Channel Catfish Spawning \& Hatchery Management

99. Chicken for Dinner? (also called Sentenced for Life)

100. Cleveland City Club Forum Debate: Animals in Medical Research

101. Commensal Rodents: Biology \& Behavior

102. Common Ground: Farming and Wildlife

103. Composting for Pork Producers

104. Composting Poultry Mortality

105. Conformation

106. Connections: Animals, People and Biotechnology

107. Control of the Horse : "The Art of Restraint" in Horsemanship

108. Control of Ventilation: Effects of Chemo and Mechano Receptors

109. Controlling Grass Tetany

110. Cow Handling

111. Cryptosporidium and Cryptosporidiosis: The Parasite and the Disease

112. Dairy Calf Management University of Idaho

113. Dance of Death

114. Dehorning Cattle

115. Development and Reproduction of Mice in a Laboratory Setting

116. Diseases of Laboratory Animals as Complications of Biomedical Research

117. Diseases of Warmwater Fish

118. Dissection \& Anatomy of the Crayfish

119. Dissection \& Anatomy of the Clam

120. Dissection and Anatomy of the Shark

121. Dissection and Anatomy of the Eye

122. Dissection and Anatomy of the Heart

123. Dissection and Anatomy of the Fetal Pig

124. Dissection and Anatomy of the Brain

125. Dissection and Anatomy of the Rat

126. Dissection and Anatomy of the Cat

127. Do Animals Reason?

128. Do Animals Think and Feel?

129. Dog Lab: An Unnecessary Exercise

130. Dogsteps: A Study of Canine Structure and Movement

131. Don't Kill the Animals

132. Early Age Neutering of Puppies and Kittens

133. Early Learning: The Complete Training of the Newborn Foal During its Imprinting and Critical Learning Periods

134. Early Spay/Neuter

135. Educating Your Foal

136. Elephant Care and Handling

137. Elephant

138. Elephants in Need: Action Alert 
140. Emu Farming: A Guide to Hatching and Raising Emu

141. Environmental Assurance Program: America's Pork Producers--Dedicated to Conserving the Environment

142. Environmental Enrichment: Advancing Animal Care

143. Equine Euthanasia: Peaceful Death in the Hospital or in the Home Pasture

144. European Pork Production: Animal Welfare Concerns

145. Every Link in the Chain

146. Exodus at Yellowstone: The Second Catastrophe

147. External Parasites of Dogs and Cats

148. External Physical Exam of the Dog

149. Facing the Animal Rights Challenge

150. Fancy Footwork

151. Farm Animal Behavior Research

152. Farm Animal Welfare

153. Farm Animals with Care

154. Farming a New Fish: Hybrid Striped Bass

155. Feeding Broodmares

156. Feeding Management of Horses

157. Feeding Performance Horses

158. Feeding Young Horses for Sound Growth and Development

159. Feeds for Horses

160. Feedyard

161. Ferret Keeping

162. Fish Tales

163. Fleas: Biology and Control

164. Foal Management

165. Foaling Fundamentals: A Video Handbook for Healthy Foaling

166. Foaling Your Mare

167. Foaling

168. Food Safety and Animal Drugs: Testing, Testing, Testing

169. Footcare in Cattle: Hoof Structure and Trimming

170. Foundation for Biomedical Research PSA: Use of Animals in Medical Research

171. Fundamentals of Blood Gas Analysis: Collection, Measurement and Interpretation

172. Gait

173. Gnotobiotic Pig Production

174. Gnotobiotics in Production of Experimental Animals

175. Goat Breeding and Kid Rearing

176. Gorilla

177. Granby's Primates

178. Ground Handling Horses Safely

179. Haltering a Foal without Trauma with T.E.A.M. Educational Horse Videos

180. Handling and Restraining Laboratory Rodents

181. Handling and Restraints of the Canine Patient

182. Handling And Sexing Some Common Laboratory Animal Species

183. Handling Hoofed Stock

184. Handling Livestock Naturally

185. Hands-on Horse Care : An Owners' Guide for Relieving Colic, Illness \& Performance Stress 
186. Hidden Crimes: A Film on Animal Experimentation

187. Hope: A Story that Highlights the Critical Importance of Animal Research in Medical Progress through the Eyes of Three Families

188. Horse Training (Intermediate)

189. Horses, Kids and Ethics

190. Hot Branding

191. How to Housebreak Your Puppy

192. Human/Pig Behavior

193. Humane Care and Use of Laboratory Animals

194. Humane Care and Use of Laboratory Animals for Technicians (Cuidado y Uso Humanitario de Animales de Laboratorio para Tecnicos)

195. Humane Educator/Obedience Trainer

196. Humane Principles and Procedures in Animal Research

197. Hunter's TiterMax

198. IBBA "How To" Segment: Tattooing; Showtime

199. Imprint Training the Foal "Palomine's Blue Ribbon Series"

200. In Defense of Animals: A Portrait of Peter Singer

201. In Vitro Research: An Introduction

202. Injection Techniques for Swine: Your 4-H Market Hog Project

203. Injection Vaccination of Fish

204. Inspection and Labeling Aspects of Genetically Engineered Food Animals

205. Inspection for Commensal Rodents

206. Integrated Pest Management

207. Intercultural Views of Animals

208. Introduction of Foreign Genes into Livestock

209. Introduction to Chimpanzee Behavior

210. Introduction to Rotational Grazing

211. Investigational New Animal Drug

212. Jane Goodall: A Life in the Wild

213. Joint Manufacturing for Iinvestigational and Licensed Biologics

214. Keeping Ducks: Beautiful Comical Things

215. Keeping Nature in Balance

216. Killing the Crisis, Not the Animals

217. Kiss the Animals Goodbye

218. Knowledge Now in Experimental Biology: The Model Organisms Series Sampler

219. Konrad Lorenz: Science of Animal Behavior "Animal behavior series

220. Laboratory Animal Medicine: What It is and How It Relates to Veterinary Medicine

221. Laboratory Animal Technician Training Course: Part 16, Veterinary Pharmacology, Anesthesiology and Euthanasia

222. Laboratory Animals: Toxicology and the Public

223. Laboratory Dogs

224. Lamb Evaluation: Ewe Evaluation

225. Lamb Survival

226. Leakey

227. Licensing Veterinary Biologics: Traditional \& Recombinant Vaccines

228. Licensing Veterinary in vitro Diagnostic Kits

229. Life Force: Animal Welfare

230. Line in the Sand 
231. Livestock in Transit - Handle with Care

232. Llama Training with Bobra Goldsmith: What Every Llama Should Know

233. Man's Best Friends

234. Management Practices for Beef Cattle, Tape \#208

235. Management Practices for Beef Cattle, Tape \#209

236. Managing Giants

237. Manipulation of Mouse Embryos

238. Marine Mammals Handling and Restraint

239. Marsupial Care and Handling

240. Mechanical Control

241. Medication Handling and Storage

242. Metro Washington Park Zoo: Environmental Enrichment Program

243. Milking Methods

244. Miss Goodall and the Wild Chimpanzees

245. Modern Veal Production: A Mixture of Technology and the Family Farm

246. Molecular Modeling for Biological Systems

247. Monkey Island

248. Monkeys, Apes, and Man

249. MoorComfort Gestation System

250. Mystery of Animal Behavior

251. National Anti-Vivisection Society Public Service Announcements

252. Neuromuscular Blocking Agents

253. New Creation - Genetic Engineering Biotechnology: Ethical (Animal Welfare), Economic and Environmental Concerns

254. New Rangeland Compact

255. Non-human Primates: Basic Needs, Handling and Care

256. Nonhuman Primates

257. Normal and Abnormal Behavior in Domestic Livestock Used for Research

258. Northwest Sheep Growers: Benefitting Man and the World He Lives In

259. Nuisance Wildlife Trapping

260. Nutrition and Feeding Methods for Laboratory Animals

261. Ocean Ranching

262. Open Heart Valve Replacement in the Dog

263. Orangutans of the Rain Forest

264. Orientation to Small Animal ICU

265. Ostrich Processing

266. Ostriches and Emus: And on this Farm; \#7

267. Our Side of the Fence

268. Ovariohysterectomy of the Rabbit

269. Parasites of the Horse

270. Partners in Progress: Growing \& Testing for Healthy Poultry

271. Partners with Nature

272. PAWS

273. Pfiesteria and the Factory Farm

274. Pinniped Identification

275. Plan for Survival (Lincoln Park Zoo)

276. Plum Island Animal Disease Center

277. Pork Quality Assurance: FDA and Your Farm 
278. Poultry at Home

279. Practical Methodology: Endotracheal Intubation of the Rabbit

280. Practical Methodology: Endotracheal Intubation of the Rat and Hamster

281. Practical Methodology: Endotracheal Intubation of the Guinea Pig

282. Practical Methodology: Humane Handling and Laboratory Techniques for the Hamster

283. Practical Methodology: Humane Handling and Laboratory Techniques for the Guinea Pig

284. Practical Methodology: Humane Handling and Laboratory Techniques for the Rabbit

285. Practical Methodology: Humane Handling and Laboratory Techniques for the Mouse

286. Practical Methodology: Humane Handling and Laboratory Techniques for the Rat

287. Practical Methodology: Nonhuman Primates Part II - Special Laboratory Techniques

288. Practical Methodology: Nonhuman Primates Part I - Personnel Safety, Primate Handling and Restraint

289. Practical Methodology: Reptiles Part II - Special Laboratory Techniques

290. Practical Methodology: Reptiles Part I - Humane Handling, Restraint and Husbandry

291. Practical Outdoor Pig Production

292. Preserving our Livestock Heritage

293. Primates

294. Principles of Rodent Control

295. Proceptivity Patterns in Captive Lowland Gorillas, Orangutans, and Celebes Macaques

296. Professional Advice for Healthy, Happy Birds

297. Professional Advice for the Care of Cage-dwelling Pets, Including Gerbils, Hamsters, Rabbits, Guinea Pigs, Rats, and Mice

298. Progress Without Pain

299. Proper Pig Handling for Markets \& Packers: Manejo Correcto de Cerdos para los Mercados y las Empresas Empaquetadoras

300. Protecting Endangered Animals

301. Quality Assurance: A Term Used by Animal Agriculture Which Refers to the Production of High Quality, Safe, and Wholesome Food!

302. Quality Assurance for 4-H Swine Producers

303. Question of Ethics

304. Questions \& Answers about BST and Milk

305. Rabbits: Bacterial and Mycotic Diseases

306. Rabbits: Biology

307. Rabbits: Care and Management in a Laboratory Setting

308. Rabbits: Introduction to Use in Research

309. Rabbits: Noninfectious Disease

310. Rabbits: Parasitic, Protozoal, and Viral Diseases

311. Raising Emus \& Rheas

312. Recognition and Alleviation of Pain and Distress

313. Reducing Residues in the Main Causes of Violations: The Cull Dairy Cow and the Bob Veal Calf

314. Reptiles: Bacterial Diseases of Captive Reptiles

315. Research Animals: A Realistic View

316. Research Methods for Studying Animal Behavior in a Zoo Setting

317. Responsible Care and Use of Canine in Research

318. Restraining/Injecting

319. Restraint and Handling of the Bird

320. Restraint and Handling of the Dog 
321. Restraint and Handling of the Cat

322. Restraint and Handling of the Reptile--Snakes

323. Restraint and Handling of the Reptile-- Crocodilians, Chelonians, and Lizards

324. Reverence for Life: Rights and Responsibilities

325. Rhea Intensive Farming: Reference Guide to the Exotic Bird Production from Egg to Breeder

326. Riding with Awareness

327. Rodents: Basic Needs, Handling and Care

328. Safely Handling Breeding Stallions \& Mares with T.E.A.M. Educational Horse Videos

329. Safety \& Regulatory Issues in Transgenic Production of Biopharmaceuticals

330. Sales Preparation

331. Science in Agriculture

332. Search for the Great Apes

333. Searching the Literature for Alternatives

334. Sentenced for Life (Also called "Chicken for Dinner")

335. Separating Fact from Myth: The Veal Industry Challenge

336. Share the Care: Humane Education

337. Sheep Management Practices, Tape \#214

338. Sheep Management Practices, Tape \#215

339. Shiverer Mouse

340. Shoeing the Horse

341. Signs of Enrichment

342. Signs of the Apes, Songs of the Whales

343. Silent World: Genetic Engineering-Ethical, Environmental and Animal Welfare Concerns

344. Silver Spring Monkeys

345. Small Animal Anesthetic Induction Technique

346. Small Mammals Restraint and Handling

347. Some Preferred Techniques for the Laboratory Rat

348. Some Preferred Techniques for the Laboratory Guinea Pig

349. Some Preferred Techniques for the Laboratory Rabbit

350. Some Preferred Techniques for the Laboratory Rat

351. Some Preferred Techniques for the Laboratory Mouse

352. Sorry, Charlie

353. Sources of Information on Animal Research Legislation and Animal Welfare

354. Speaking of Harvey

355. Spirits of the Forest

356. Sportsmedicine Therapies and Treatments

357. Stallion Management

358. Starting a Young Horse

359. Siep Beyond: A Question of Ethics

360. Stimulus Response

361. Suffer the Animals

362. Superanimals, Superhumans? The Life Revolution

363. Surgery Preparation

364. Surgical Instruments and Their Use

365. Surgical Procedures on Swine

366. Swine Handling and Transportation

367. Swine Handling for Pork Producers

368. Swine Handling for Transporters 
369. Swine Health Care

370. Swine Management Practices I

371. Swine Management Practices II

372. Swine Respiratory Disease

373. Symposium: Animal Welfare Compliance for Study Directors

374. Systemic Anatomy of the Cat

375. T.E.A.M. Learning Exercises, part 2: Obstacles and Groundwork

376. T.E.A.M. Learning Exercises, Part 1: Awareness Movements.

377. Take Time? Training Your Dog from Farm Work to Trailing

378. Teaching the Touch

379. Teaching the Yearling

380. Techniques with Guinea Pigs

381. Tellington TTouch for Happier, Healthier Dogs

382. Tellington TTouch for Happier, Healthier Cats

383. Terrorism in Dixon

384. The American Mule: Yesterday and Today

385. The Americas' View of Animals

386. The Animal Welfare Act: Philosophy and Intent

387. The Animals Are Crying

388. The Animals Film

389. The Ascent of the Chimps

390. The Avian Physical Examination and the Handling of Various Avian Species

391. The Bear Necessities: Environmental Enrichment for Captive Polar Bears

392. The Challenge of Animals in Research

393. The Control of Feral Cat Colonies

394. The Dog and Cat in Research

395. The Dog and Cat

396. The Dog Owner's Manual

397. The Down Side of Livestock Marketing

398. The Family of Chimps

399. The Frog Inside-Out

400. The Future of Human-Animal Relations

401. The Guinea Pig and Rabbit

402. The Guinea Pig: Biology

403. The Guinea Pig: Diseases

404. The Guinea Pig: Introduction and Husbandry

405. The Guns of Autumn

406. The Hamster: Biology and Diseases, Part 2

407. The Hamster: Introduction and Husbandry, Part 1

408. The Heart of the Matter

409. The Image of Animals Today

410. The Laboratory Rat: Biology, Husbandry, and Research Methodology

411. The Laboratory Rat: Diseases

412. The Laboratory Rat: Introduction

413. The Mongolian Gerbil, Meriones Unguiculatus

414. The Mongolian Gerbil

415. The Mouse: Bacterial and Parasitic Diseases

416. The Mouse: Biology and Use in Research 
417. The Mouse: Handling, Restraint, and Other Techniques

418. The Mouse: Husbandry

419. The Mouse: Neoplastic, Non-Infectious and Miscellaneous Diseases

420. The Mouse, Rat and Hamster

421. The Mouse: Viral Diseases

422. The Nature of Change

423. The New Research Environment

424. The Nonhuman Primates

425. The Other Side of the Fence

426. The Physical Exam

427. The Principles of Horseshoeing: The Sound Horse

428. The Rhino War: A Desperate Fight to Save an Endangered Species

429. The Soviet Circus

430. The T Touch That Teaches, Part I: Head and Neck

431. The T Touch That Teaches, Part II: Body, Legs, and Tail

432. The Tellington TTouch for Happier, Healthier Cats

433. The Ultimate Test Animal

434. The Value of Animal Research in the Betterment of Health

435. Think Like a Horse

436. Thoracotomy and Lung Lobectomy in the Dog

437. Tips for Safe Horse Handling

438. TiterMax: An Adjuvant Update

439. To be a Gorilla: The Management of Lowland Gorillas in Captivity

440. To Hunt or Not to Hunt

441. Tools for Research: Questions About Animal Rights

442. Touch for Dogs

443. Training Corral-Living Rhesus Monkeys for Fecal and Blood Sample Collection

444. Training Game

445. Training Medical Behaviors in Orangutans at Brookfield Zoo

446. Transgenic Animals: Food Sources--FDA, FSIS, Industry and Future Perspectives

447. Transgenic Animals in the Production of Biopharmaceuticals

448. Transgenic Farm Animals

449. Transgenic Technologies

450. Triploid Oyster Production

451. Trout Diseases

452. Ttouch for Horses

453. Tuberculin Testing Exotic Animals

454. Understanding Dairy Cattle Behavior to Improve Handling \& Production

455. Understanding Farm Animal Behavior

456. Unlocking Nature's Secrets

457. Unnecessary Fuss

458. USDA Slaughter

459. Using Animals in Research: Guidelines for Investigators

460. Veal Farming is Special

461. Veterinary Medicine \& Human Health

462. Video Guide to Recording Marine Mammal Stranding Data

463. Vitamin E for Beef Cattle

464. Voices I Have Heard 
465. Watching Animals

466. We Are All Noah

467. Weaning

468. Welfare Parameters in Veal Calf Production Facilities

469. What's The Beef?

470. When Should I Call the Vet?

471. Whither Biogenetics? The Life Revolution

472. Who Cares Anyway

473. Who Speaks for the Animals?

474. Why I Should Stay Awake in Science Class

475. Will I Be Alright Doctor?

476. Within Striking Distance

477. World Congress Awards Luncheon

478. Youth and Dairy Cattle: A Safe Partnership

479. Zoo Careers: A Look Behind the Scenes at a Modern Zoo

480. Zoos of the World 


\section{Audio-Visual Listing}

A Challenge to Care: Careers in Laboratory Animal Science. Cordoba, TN: American Association for Laboratory Animal Science; 1988; 1/2" VHS, 16 min.

Keyword: Vocational guidance, technicians, research, experimental psychologists.

Note: After a brief argument for the use of laboratory animals in medical research, the program discusses the careers available in the production, care, and management of laboratory animals.

NAL Call No: Videocassette No. 711.

A Feminist View of Human-Animal Relations. Minneapolis, MN: University of Minnesota; 1986; 1/2" VHS, $45 \mathrm{~min}$.

Keyword: Animal welfare, feminists, ethics.

Note: The concepts of "victim" and "distribution of powers" are discussed in reference to interactions between males and females, and humans and animals. A historical perspective expressed through art is used to portray the connection between animal and child abuse.

NAL Call No: Videocassette No. 324.

A Guide to Foal Handling. Betsy Beineke. Clovis, Calif:: The Discovery Trail ; Powder Springs, GA : Distributed by Betsy Beineke, c1990. 1 VHS videocassette (ca. 34 min.).

Keywords: Horses, foals, handling, imprinting, training

Note: Betsy Beineke presents her method of foal handling. This involves imprinting the foal's nervous system and bonding with the foal.

NAL Call No: Videocassette no.2053.

A New Leash on Life. Charlotte, NC: W.J. Klein Company; Presented by the Humane Society of the United States; 1987; 1/2" VHS, 15 min.

Keyword: Dogs, pets, pounds, adoption, pet care.

Note: Presents the benefits and costs of owning a dog. Addresses the issues of pet abandonment, pound adoption, pet care, and living with pets in apartments.

NAL Call No: Videocassette No. 904.

A New Way: A Presentation of Lincoln Park Zoo. Integrated Pest Management. Chicago: Lincoln Park Zoo; c1990; 1/2" VHS, $13 \mathrm{~min}$.

Keyword: Lincoln Park Zoo, pests, integrated control, zoos.

Note: Describes how the Lincoln Park Zoo developed and manages its pest management program. The goal of this program is to control the pests, because eradication is an unrealistic goal. Communication, cooperation and vigilance makes this program successful.

NAL Call No: Videocassette No. 1560.

A Question of Life. Berkeley, CA: California Biomedical Research Association; 1984; 1/2" VHS, 15 $\min$.

Keyword: Medical research, animal models, animal welfare, ethics.

Note: The role of laboratory animals in the advancement of medicine is examined. The program lists medical benefits for humans and animals resulting from animal research. 
NAL Call No: Videocassette No. 193.

A Question of Respect. New York: American Society for the Prevention of Cruelty to Animals (ASPCA); 1988; 1/2" VHS, 12 min.

Keyword: Animal welfare, laboratory animals, animal experimentation, livestock, pets.

Note: The ASPCA looks at the inter-relationship between earth, animals, and man. The video discusses man's responsibility toward animals with respect to research, product testing, and pets.

NAL Call No: Videocassette No. 801.

A Question of Safety: The Importance of Product Safety Testing. Washington, DC: Foundation for Biomedical Research; 1988; 1/2" VHS, $14 \mathrm{~min} .30 \mathrm{sec}$.

Keyword: Toxicity, animal models, product safety, alternative testing methods.

Note: This film discusses the use of laboratory animals in providing product safety assurance.

The program stresses the importance of data from toxicity studies using animals to determine product safety under normal conditions, and toxicity treatment in cases of accidental poisoning. It briefly discusses the concept of "acceptable risk" and the use of alternatives to live animals.

NAL Call No: Videocassette No. 340.

About Animals, The Question Is.... Lynnwood, WA: Progressive Animal Welfare Society; 1987; 1/2" VHS, 22 min.

Keyword: Intensive livestock farming, laboratory animals, animal welfare, ethics.

Note: A historical exploration of Western culture's beliefs and practices regarding animals. Two practices are emphasized: the use of animals for food and for experimentation. The views of both critics and supporters of these practices are presented in order to stimulate questions and discussion by the audience. A study guide accompanies the videocassette.

NAL Call No: Videocassette No. 332.

Advanced Training of the Western Horse. Edmonton, Alberta: Alberta Agriculture, Food and Rural Development, c1984. 1 VHS videocassette (30 min.).

Keywords: Horses, training, advanced level, techniques, horse behavior.

Note: Information on training a horse for western style riding and competition.

NAL, Call No: Videocassette no.2680.

AKC and the Sport of Dogs. New York, NY: The American Kennel Club; 1986; 1/2" VHS, 34 min.

Keyword: Guide dogs, police dogs, hunting dogs, sport.

Note: This American Kennel Club production demonstrates the history of man's use of dogs. It contains an in-depth discussion of the current uses of guide, police, and sporting/hunting dogs and the role of the AKC.

NAL Call No: Videocassette No. 1351.

All About Llamas. Bozeman, MT: Taylor/Gavin Communications; 1986; 1/2" VHS, 45 min. (each video).

Keyword: Care, handling, management, history, uses, behavior, breeding, birthing, packing, hiking.

Note: This series consists of three videotapes. Tape \#1 - Llama Basics discusses the history, care, and handling of llamas. Tape \#2 - Breeding, Birthing and Newborn Care covers the 
basics of breeding, natural delivery, delivery assisting, and newborn care. Tape \#3 - Let's Go Packing discusses the use of llamas as pack animals for hiking and outdoor adventures.

NAL Call No: Videocassette No. 1330.

Alternatives in Animal Research. Peter Doris and Kathy Watson: Texas Tech University Health Science Center; 1989; 1/2" VHS and U-matic (listed as video no. 810), $60 \mathrm{~min}$.

Keyword: Animal models, biomedical research, alternatives, animal welfare, animal rights, history, the 3 R's.

Note: Gives the history of man's use of animals, and what the benefits to man have been and could be. A comprehensive discussion of the uses of animals in research today, along with guidelines and regulations. Covers the issue of animal rights and its effects on research. Discusses alternatives to using animals by using techniques in Refinement, Reduction, and Replacement.

NAL Call No: Videocassette No. 811.

AMDUCA Regulations. (Animal Medicinal Drug Use Clarification Act Regulations).

American Veterinary Medical Association; Center for Veterinary Medicine (U.S.); CDRH Television [Rockville, MD?] : CDRH Television, [1997]. 1 VHS videocassette (161 min.).

Keywords: Drugs, labeling standards, veterinary drugs, U.S. laws and legislations.

Note: Mark Barnett (FDA), Steve Sundlof (director, FDA Center for Veterinary Medicine), Mary Beth Leininger (president, AVMA) and a panel of experts discuss the Animal Medicinal Drug Use Clarification Act (AMDUCA) and its implications for veterinarians.

NAL Call No: Videocassette no.2624.

America's Pork Producers: Stewards of the Land. National Pork Producers Council (U.S.); National Pork Board (U.S.). Des Moines, Iowa : The Council, [1995] 1VHS videocassette (ca.16 min.).

Keywords: Pork industry and trade, environmental aspects, agricultural conservation.

Note: Presents interviews with several pork producers who have excelled in their efforts to conserve and protect the environment.

NAL Call No: Videocassette no.2364.

Among the Wild Chimpanzees. Washington, DC: National Geographic video and WQED of Pittsburgh. Distributed by Vestron Video of Stanford, CT; c1987; 1/2" VHS, 59 min. ISBN: 0805104402.

Keyword: Jane van Lawick Goodall, biographic information, chimpanzees, behavior, social structure, tool use, East Africa,

Note: This film, authored by Alexander Scourby, is a videocassette of a 1984 film by the Society, WQED/ Pittsburgh and Vestron, Inc. It documents Jane Goodall's twenty-two year field research on the wild chimpanzees of East Africa. Shows the Chimpanzees' nomadic behavior, their family structure, and their ability to hunt and make and use tools. Also looks at discoveries of warfare and cannibalism.

NAL Call No: Videocassette No. 1100.

Amphibians: Medicine and Husbandry. Ann Arbor, MI: University of Michigan; 1975; 64 slides, audiocassette, $23 \mathrm{~min}$.

Keyword: Frogs, salamanders, newts, tadpoles, axolotl, veterinary medicine, husbandry, laboratory animals.

Note: History of laboratory use, taxonomy, husbandry, sources of amphibians, and water 
quality parameters are addressed. Also covered are the signs, etiology, and treatment of "red leg syndrome"; Lucke renal adenocarcinoma; mycobacterial infection; pigmented

fungal infection; and parasites. A script accompanies the slide set.

NAL Call No: Slide No. 226.

An Introduction to Zoonoses. Manhattan, KS: Kansas State University. College of Medicine; 1991; 1/2" VHS, 18 min.

Keyword: Zoonoses, Q fever, Psittacosis, preventative measures.

Note: Defines zoonoses and illustrates transmission vectors. Q-fever from dairy cows and Psittacosis from birds are given as examples of zoonotic diseases with symptoms exhibited by humans. Preventative measures of disease avoidance are discussed.

NAL Call No: Videocassette No. 1661.

Anatomy of the Dog: Male Genitilia. [Raleigh, N.C.]: North Carolina State University, College of Veterinary Medicine, c1985. 1 VHS videocassette (20 min.)

Keywords: Dogs, male, reproductive structures.

Note: A description, diagram and photos of the male dog reproductive tract and genital system. NAL Call No: Videocassette no.1833.

Anatomy of the Dog. Subtitle on cassette label and container: "The female genitalia." Raleigh, NC: North Carolina State University, College of Veterinary Medicine; c1985; 1/2" VHS, 22 min.

Keyword: Dogs, bitches, reproductive anatomy.

Note: Illustrates and describes the anatomy of the reproductive system of the dog by dissection of a cadaver. There are brief explanations of the structure and function of the various structures.

NAL Call No: Videocassette No. 1832

Anesthesia Matters: An Instructional Video on the Use of Anesthesia in Small Laboratory Animals. [Cambridge, Mass.]: Massachusetts Institute of Technology, c1995. 1 VHS videocassette (21 min., 18 sec.).

Keywords: Veterinary medicine, anesthesia, laboratory animals.

Note: This video is designed to aid institutions in providing effective education to animal research personnel as required by government regulations and guidelines. It covers topics concerning use of anesthesia in small laboratory animals.

NAL Call No: Videocassette no.2363.

Animal Agriculture: Myths and Facts. Arlington, VA: Animal Industry Foundation; 1990; 1/2" VHS, $18 \mathrm{~min}$.

Keyword: Factory farming, cattle, animal welfare, production.

Note: Farmers dispel the myths about cow/calf and feedlot cattle production, as well as turkey, hog, veal, and egg production. They emphasize that the care and well-being of their animals is very important for them and the continuation of their farms.

NAL Call No: Videocassette No. 1131.

Animal Behavior in the Wild. Minneapolis, MN: University of Minnesota; 1986; 1/2" VHS, 45 min. Keyword: Elk, musk oxen, cats, horses, behavior.

Note: University of Minnesota professors Richard Phillips and David Smith discuss and illustrate aspects of animal behavior and communication using examples recorded on 
film.

NAL Call No: Videocassette No. 368.

Animal Bite Prevention for Children and Adults: Two Defensive Maneuvers to Prevent Serious Injuries from Dog Attacks. 2nd ed. J. Michael Cornwall.Columbus, Ohio: Glencoe Animal Hospital, c1992. 1 VHS videocassette (ca. 15 min.). 1 teacher's guide +1 parent's guide +1 poster.

Keywords: Dog bite prevention, dog behavior, human-animal interactions.

Note: Dr. Cornwell teaches animal safety to children in a fun and non-threatening manner. Also titled "Animal Safety is Fun."

NAL Call No: Videocassette no.2511.

Animal Care and Use: Policy Issues in the 1990's. Katie McCabe; 1989; 1/2" VHS, 40 min.

Keyword: Animal rights, animal models, animal welfare, research, political activists.

Note: The video is a taping of a conference luncheon addressed by Katie McCabe on the animal rights movement and its effects on biomedical research today and the overall effect it will have on the world in the future.

NAL Call No: Videocassette No. 903.

Animal Care Matters. Massachusetts Institute of Technology. [Cambridge, Mass.] : Massachusetts Institute of Technology, c1993. 1 VHS videocassette (24 min., $33 \mathrm{sec}$.).

Keywords: Animal experimentation, United-States, laboratory animals, animal rights movement, animal care committee.

Note: Explores the issues surrounding experimentation on animal subjects through interviews with veterinarians, researchers, and animal rights activists, and provides an introduction to community oversight of animal research.

NAL Call No: Videocassette no.2194.

Animal Research: The Cost of Hope. Michael Criley; 1985; 1/2" VHS (No. 151), U-Matic 3/4" (No. 149), $20 \mathrm{~min}$.

Keyword: Animal welfare, animal research, laboratory animals, ethics.

Note: This videocassette examines the animal research vs. animal rights debate. The contribution of animal research to the advancement of human health care is illustrated with animal and human heart patients. The acquisition of pound animals (dogs) for biomedical research is discussed.

NAL Call No: Videocassette Nos. 149 and 151.

Animal Rights/Animal Welfare. Des Moines, IA: National Pork Producers Council; 1990, 1/2" VHS, 20 $\min$.

Key words: Animal rights, animal welfare, factory farming, animal husbandry, farming.

Note: Discussion of animal rights and animal welfare in relation to factory farming. The video displays perceived myths by the animal rights movement on factory farming. Discusses animal rights groups, their agendas, and their tactics. Gives advice on how people in the farming industry can deal with the issues and groups.

NAL Call No: Videocassette No. 901.

Animal Rights: The Issues, the Movement. Westport, CT: Animal Rights Network, Inc.; 1982; 35 mm, $17 \min$.

Keyword: Veal calves, chickens, laboratory animals, farm animals, animal welfare, ethics, 
vegetarianism, trapping.

Note: This filmstrip introduces the viewer to the animal rights philosophy. The animal rights perspective as it relates to the use of animals for experimentation and food production is discussed. A script accompanies the filmstrip.

NAL Call No: Filmstrip No. 191.

Animal Training. Toledo, Ohio: Toledo Zoological Society, 1993. 1 VHS videocassette (15 min., 30 sec.).

Keywords: Zoo animals, training techniques.

Note: Two video segments, approximately eight minutes each, demonstrate how zoo animals are trained to allow and assist zoo staff in moving them, monitoring their health and providing for their general care. Some examples presented in the first segment also appear in the second.

NAL Call No: Videocassette no.209.

Animal Welfare: Implications for Agricultural Research. Washington, DC: U.S. Department of Agriculture; 1990; 1/2" VHS, 22 min.

Keyword: Law, legislation, guidelines, impact, Russell and Birch, religion, behavior.

Note: Joy Mench, Doctor of Philosophy professor, discusses the religious and historical aspects of animal welfare and animal rights, the guidelines and standards established for treatment of animals in a research setting, and the effect of the animal rights movement on both biomedical and agricultural research. She closes by emphasizing the need for more research in animal behavior, in order to maintain and improve the care of agricultural animals.

NAL Call No: Videocassette No. 905.

Animal Welfare Information Center: Resources Today for the Research of Tomorrow. Washington, DC: Video \& Teleconference Division, USDA; 1989; 1/2" VHS, 11 min. $37 \mathrm{sec}$.

Keyword: Library, information, animal welfare, research, laboratory animals.

Note: This video describes the resources and services offered by the Animal Welfare Information Center (AWIC) at USDA's National Agricultural Library, including computer literature searching, production of bibliographies, identification of current research, and referrals. The film details how scientists and others can access information regarding laboratory animal care and use.

NAL Call No: Videocassette No. 559.

Animal Welfare: The Farmers' Story. Park Ridge, IL: The American Farm Bureau Federation; 1981; 1/2" VHS, 3/4 U-Matic, $28 \mathrm{~min} .30 \mathrm{sec}$.

Keyword: Dairy cows, hogs, poultry, intensive livestock farming, animal welfare.

Note: This film explores the economic and animal husbandry aspects of current animal farming practices through onsite interviews with farmers. The film equates proper animal management practices with satisfactory animal welfare practices.

NAL Call No: Videocassette Nos. 399 and 483.

Animals in Biomedical Research. Minneapolis, MN: University of Minnesota; 1986; 1/2" VHS, 45 min.

Keyword: Alternatives, animal welfare, ethics, medical research, laboratory animals.

Note: A lengthy panel discussion of the need for animals in biomedical research. Examples of advances in medicine through animal research are presented. Alternatives to and 
methods of reducing the use of animals in research, the limitations of animals in research, and the use of animals in teaching are discussed.

NAL Call No: Videocassette No. 326.

Animals in Research: A Complex Issue. Springfield, IL: Southern Illinois University School of Medicine; 1983; 3/4" U-Matic, 6 min. $25 \mathrm{sec}$.

Keyword: Medical research, laboratory animals, regulation.

Note: A brief introduction to issues concerning the use of animals in research. The film mentions the benefits of animal research and discusses painful procedures performed by biomedical researchers. The film also suggests that the need for regulating animal research be weighed against the costs and benefits to all of society.

NAL Call No: Videocassette No. 341.

Animals in Research: Breaking the Habit. The Nature of Things Series. David T.Suzuki, Mark A. Bisby, and Andrew W. Rowan. [Toronto, Ont.] Canadian Broadcasting Corporation, c1993. 1 VHS videocassette (58 min.).

Keywords: Animal experimentation, animal models, primates, laboratory animals, debate.

Note: David Suzuki leads a debate over the validity of the animal model in medical research. Primate footage includes an infant baboon (Papio) shown in the test of a ventilator; chimpanzees (Pan troglodytes) at the Southwest Foundation for Biomedical Research; rhesus monkeys (Macaca mulatta) in Harry Harlow's work on maternal deprivation; and Debbie the baboon shown in a restraining device in a Canadian lab. Following this rerun, Dr. Mark Bisby and Dr. Andrew Rowan discuss whether this program presents its case fairly.

NAL Call No:Videocassette no.2265.

Animals in Zoos: Issues and Concerns. Minneapolis, MN: University of Minnesota; 1986; 1/2" VHS, $45 \mathrm{~min}$.

Keyword: Animal breeding, artificial insemination, genetics.

Note: Dr. Thomas Foose of the American Association of Zoological Parks and Aquariums, Carrol Henderson of the Minnesota Department of Natural Resources, and Harriet Lykken of the Sierra Club discuss the role of zoos in maintaining genetic diversity in captive animal populations. The panelists respond to audience questions.

NAL Call No: Videocassette No. 369.

Animals, Nature and Religion. Old Saybrook, CT: Connecticut Video Productions; 1980; 1/2" VHS, 38 $\min$.

Keyword: Animal welfare, philosophy, American Indians, Hinduism, Buddhism, Christianity, Judaism, Taoism, sustainable agriculture, behavior, farm animals.

Note: Dr. Michael W. Fox surveys a wide spectrum of religious and philosophical thought to encourage respect for animals and nature. Fox emphasizes the need to change mankind's world view from one of self-centered domination (exemplified in the video by animal research, biotechnology, and modern agricultural practices) to a more holistic, interconnected concept of nature. The film ends with a plea for a more gentle, communal, and harmonious approach to life. A script accompanies the video.

NAL Call No: Videocassette Nos. 418, 466, and 467 (three copies).

Animals that Live in Groups. Washington, DC: National Geographic Society; c1989; 1/2" VHS, 15 min. 
Includes 2 identical teacher's guides.

Keyword: Animal societies, advantages of groups.

Note: Briefly describes several of the wide variety of animals which band together in a common effort to find food and shelter, to raise young, and to protect themselves from enemies.

NAL Call No: Videocassette No. 1155.

APHIS M\&B Recruitment Video. Also called "APHIS, an investment in your future." Washington, D.C. United States Animal and Health Inspection Service. Distributed by Initram Communications; 1990?; 1/2" VHS, 12 min.

Keyword: United States Animal and Health Inspection Service, careers, vocational guidance, veterinary medicine, horticulture, meat inspection.

Note: Provides an overview of the various career opportunities in animal health, plant health and quarantine, animal diseases, and animal inspection that the United States Animal and Plant Health Inspection Service can offer.

NAL Call No: Videocassette No. 1369.

Artificial Insemination in Swine. East Lansing, Mich: Instructional Media Center, Michigan State University; c1981; 1/2" VHS, 15 min. 50 sec.

Keyword: Swine, artificial insemination, breeding, methods, equipment.

Note: Demonstrates the current methods and equipment for artificially inseminating swine.

NAL Call No: Videocassette No. 1726.

Aseptic Surgery of Rodents. Raleigh, NC: Laboratory Animal Training Association; 1989; 1/2" VHS, 30 min.

Keyword: Sterilization, disinfection, guinea pigs, hamsters, gerbils, veterinary training, biomedical techniques.

Note: This training module provides instruction on how to conduct aseptic surgery on laboratory rodents in accordance with Public Health Service policy and USDA regulations. The video covers pathogen-free surgical preparation of operating surfaces, instruments, personnel, and animal subjects. Quality control in sterilization and the administration of anesthetics and antibiotics are also discussed.

NAL Call No: Videocassette No. 561.

Avian Depredation of Southern Aquaculture. Mississippi State, MS:

Information Services, Division of Agriculture, Forestry, and Veterinary Medicine, Mississippi State University; c1992; 1/2" VHS, 25 min.

Keyword: Control of bird pests, U.S. Southern states, diseases, pests, catfish, aquaculture industry.

Note: $\quad$ Since the 1980's bird depredation has been a problem for the aquaculture industry. This video discusses economic losses and costs to the industry to protect ponds from fish eating birds. Successful techniques such as visual scare devices, noise stimuli, and physical barriers are illustrated.

NAL Call No: Videocassette No. 1479.

Baiting Techniques. National Pest Control Association (NPCA) rodent control series; 5. Dunn Loring, VA: NCPA; c1990; 1/2" VHS, 10 min. Includes 1 training manual (16 leaves)

Keyword: Rodenticides, rodent control, baiting techniques, training. 
Note: This National Pest Control Association Rodent Control Training Program (one of six videos) covers baiting techniques and bait placements. The program, authored by Edward Marshall, is designed to aid pest control service technicians in selecting proper bait material to control rodents with rodenticides. The accompanying manual includes practical training tips, program presentation recommendations, a pretest and a post test (with answers), suggested reference materials, and a commensal rodent pictorial identification key.

NAL Call No: Videocassette No. 1122.

Bandaging and Splinting. Davis, CA: The University of California at Davis; October 1977; U-Matic 3/4", $55 \mathrm{~min}$.

Keyword: Dogs, veterinary medicine, coaptation splints, aluminum rod splints, plywood splints.

Note: Using the dog as a model, a veterinarian demonstrates proper methods of making and applying bandages and splints using a variety of materials.

NAL Call No: Videocassette No. 206.

Barn Construction. Lexington, KY: Blood-Horse Productions; c1984; 1/2" VHS, ca. 30 min.

Keyword: Stables, design, barns, construction, costs.

Note: Tours of several horse barns demonstrate factors such as fire safety, appearance, durability, function and cost which influence barn design.

NAL Call No: Videocassette No. 1896.

Basic Herding. Burton J. Smith. Kamuela, HI: Graziers Hui, c1993. 1VHS videocassette (ca. 50 min.), 1 manual +1 booklet.

Keywords: Cattle, handling and restraint, herding behavior, practice exercises.

Note: Discusses stockmanship, herding, and handling of cattle. Includes practice sessions and practical exercises.

NAL Call No: Videocassette no.2166.

Basic Horse Training. Bill Collins. Edmonton, Alta. : Alberta Agriculture, Food and Rural Development, c1981. I VHS videocassette (15 min.).

Keywords: Horse training, methods, basic level.

Note: Information on the basic training of horses and how to use the proper equipment.

NAL Call No: Videocassette no.2678.

Basic Horse Care: Farnam Video Collections. Odette Larson. Horseman Video Showcase. Omaha, Neb.: Farnam Companies, c1986. 1 VHS videocassette ( $80 \mathrm{~min})$.

Keywords: Horses, handling, feeding, feeds, grooming, training.

Note: Odette Larson covers the fundamentals of horse care and handling, including proper feeding, grooming, safety, horse psychology, and selection of tack. She demonstrates how to give medication and the loading and trailering of horses.

NAL Call No. Videocassette no.2594.

Basic Horseshoeing Principles. LaPorte, CO: Butler Publishing and Tools; c1992; VHS format, 55 min.

Keyword: Horseshoeing, hoof trimming, cold shoeing.

Note: Dr. Doug Butler demonstrates cold shoeing and hoof trimming techniques that are used in shoeing horses. 
NAL Call No.: Videocassette No. 1904.

Basic Sterile Cell Culture. Logan, UT: Taped Technologies; c1992; 1/2" VHS, 14 min.

Keyword: Cell culture, techniques.

Note: Describes the various techniques used in growing sterile cell cultures.

NAL Call No.: Videocassette No. 1867.

Basic T.E.A.M. with Llamas. Olympia, WA: Juniper Ridge Press; c1990; 1/2" VHS, 112 min.

Keyword: Llamas, training, Linda Tellington-Jones, techniques.

Note: Presents the basics of the Tellington-Jones Equine Awareness Method (T.E.A.M.) as a way to train llamas.

NAL Call No.: Videocassette No. 1770.

Bear Necessities. Countrywise Communication (Firm); Universities Federation for Animal Welfare. Potters Bar, Herts [England]: Universities Federation for Animal Welfare, c1992. 1 VHS videocassette (20 min).

Keywords: Polar bears, behavior, environmental enrichment in zoos.

Note: Repetitious, invariant behaviors without apparent goal are typical of captive polar bears. This video illustrates such behaviors and offers practical suggestions for reducing them and creating an environment which offers the bears greater opportunites for a variety of activities.

NAL Call No: Videocassette no. 1438.

Beating Muscle Injuries in Horses. West Bath, ME: Diamond Video Productions; 1981; 1/2" VHS, 72 $\min$.

Keyword: Wounds and injuries, physiological aspects.

Note: Care and prevention of equine muscle injuries is detailed by the author Jack Meagher.

NAL Call No.: Videocassette No. 1934.

Beef Cattle Judging. Video Programs for Education, Business, Industry. Iowa State University, Cooperative Extension Service; RMI Media Productions. Shawnee Mission, KS: Distributed by RMI Media Productions, [198-?] 1 videocassette (40 min.).

Keywords: Beef cattle, competitions, judging, carcass characteristics.

Note: Program examines growth, reproduction, and carcass desirability, which are the three important factors in judging beef cattle.

NAL Call No: Videocassette no. 1562.

Biology and Management of the Domestic Ferret. Manhattan, KS: College of Veterinary Medicine; Kansas State University; 1991; 1/2" VHS, 17 min.

Keyword: Ferrets, pets, care, handling, feeding.

Note: Carol L. Jantzi describes the history and husbandry of the domestic ferret. Nutrition, housing, reproduction, and handling are discussed.

NAL Call No.: Videocassette No. 1571.

Biomethodology of the Cat. Manassas, VA: MTM Associates, Inc.; 1987; 1/2" VHS, 14 min. $50 \mathrm{sec}$. Keyword: Cats, restraint, drug administration, blood collection, euthanasia, veterinary training.

Note: This film demonstrates to animal technicians basic techniques for handling, restraining, and manipulating cats for research. Covers removal from caging, injection routes, blood 
collection, and euthanasia. Laboratory Manual For Basic Biomethodology of Laboratory Animals: Vol. II Dogs, Cats, and Primates accompanies the videotape.

NAL Call No: Videocassette No. 337.

Biomethodology of the Dog. Manassas, VA: MTM Associates, Inc.; 1987; 1/2" VHS, 14 min. 16 sec.

Keyword: Dogs, restraint, drug administration, blood collection, euthanasia, veterinary training.

Note: This film demonstrates for animal technicians the safe and humane techniques for manipulating dogs in research, including removal from caging, injection routes, blood collection, and euthanasia. Laboratory Manual For Basic Biomethodology of Laboratory Animals: Vol. II Dogs, Cats, and Primates accompanies the videotape.

NAL Call No: Videocassette No. 335.

Biomethodology of the Guinea Pig. Silver Spring, MD: MTM Associates; 1987; 1/2" VHS, 13 min. 27 sec.

Keyword: Laboratory animals, biomedical techniques, restraint, veterinary training.

Note: A demonstration of basic techniques involving guinea pigs, including identification, restraint, injection, blood withdrawal, and euthanasia.

NAL Call No: Videocassette No. 200.

Biomethodology of the Laboratory Mouse. Silver Spring, MD: MTM Associates; 1987; 1/2" VHS, 15 $\min$.

Keyword: Laboratory animals, biomedical techniques, restraint, veterinary training.

Note: A demonstration of basic techniques involving laboratory mice, including identification, restraint, injection, blood withdrawal, and euthanasia.

NAL Call No: Videocassette No. 200.

Biomethodology of the Primate. Manassas, VA: MTM Associates, Inc.; 1987; 1/2" VHS, 15 min. 48 sec.

Keyword: Rhesus monkeys, restraint, tattooing, injection, stomach tube, nasal gastric gavage, blood withdrawal, euthanasia.

Note: This film demonstrates basic techniques for manipulating primates for research. It includes manual and chemical restraint, identification, injection routes, blood collection, and euthanasia. Laboratory Manual For Basic Biomethodology of Laboratory Animals: Vol. II Dogs, Cats, and Primates accompanies the videotape.

NAL Call No: Videocassette No. 336.

Biomethodology of the Rabbit. Silver Spring, MD: MTM Associates, Inc.; 1987; 1/2" VHS, 14 min. 49 sec.

Keyword: Laboratory animals, biomedical techniques, restraint, veterinary training.

Note: A demonstration of basic techniques involving laboratory rabbits, including identification, restraint, injection, blood withdrawal, and euthanasia.

NAL Call No: Videocassette No. 200.

Biomethodology of the Rat. Silver Spring, MD: MTM Associates; 1987; 1/2" VHS, 16 min. $33 \mathrm{sec}$.

Keyword: Laboratory animals, biomedical techniques, veterinary training.

Note: A demonstration of basic techniques involving laboratory rats, including identification, restraint, injection, blood withdrawal, and euthanasia. 
NAL Call No: Videocassette No. 200.

Biosecurity in Aquaculture. Practical Steps for Healthy Fish. Orono, Me.: University of Maine Cooperative Extension and the Public Affairs Department., c 1994. 1 VHS videocassette (15 min., $38 \mathrm{sec}$.) and 1 booklet.

Keywords: Fish hatcheries, pathogen control, management techniques.

Note: Demonstrates common-sense, cost effective steps that can be taken in the hatchery and at the grow-out site to keep contamination by parasites, bacteria, and viruses as low as possible. The program was produced with funding by: Northeast Regional Aquaculture Center, USDA with support from: Me/NH Sea Grant Marine Advisory Program.

NAL Call No: Videocassette no.2015.

Biotechnology, Food, \& Agriculture. University of Wyoming, Cooperative Extension Service. Washington State University, Cooperative Extension. Washington State University. Information Dept. [Pullman, Wash.] : Washington State University Information Department, 1995. 1 VHS videocassette (23 min.).

Keywords: Agricultural biotechnology, food biotechnology, genetic engineering, risks, benefits.

Note: Explores biotechnology applications in food production and processing, addressing the benefits and risks of agricultural biotechnology.

NAL Call No: Videocassette no.2652.

Biotechnology: On the Cutting Edge. An Interview with Geneticist Richard Burgess. Richard Burgess. Madison, WI: Hawkhill Video, c1991. 1 VHS videocassette (ca. 34 min.), 1 information sheet +1 booklet $(17$ p. ; $22 \mathrm{~cm}$.).

Keywords: Genetic engineering, biotechnology, societal concerns.

Note: Geneticist Richard Burgess discusses advances in biotechnology and contemporary social perceptions of continuing research in the field.

NAL Call No: Videocassette no. 1971.

Biovideo: Animal Senses. Burlington, NC: Carolina Biological Supply Company; 1987; 1/2" VHS, 30 min.

Keyword: Stereoscopic vision, echolocation, pheromone, wild animals.

Note: An instructional program appropriate for high school and college science students, it explains how the major senses work and their importance to animal behavior and environmental adaptation. The anatomy and physiology of sight, hearing, smell, taste, touch, feeling, and balance are clearly illustrated using animations, diagrams, and live animals. Vertebrates and insects are emphasized. A manual accompanies the videocassette.

NAL Call No: Videocassette No. 427.

Blood Collection from Birds. Madison, WI: National Wildlife Health Research Center (U.S.); 1989; 1/2"VHS, 19 min., $10 \mathrm{sec}$.

Keyword: Birds, physiology, blood collection and preservation.

Note: Joshua F. Dein shows how to draw blood samples from birds and discusses factors to be considered when collecting the blood such as anatomic location, animal restraint and positioning, site identification and preparation, and how much blood to draw per bird.

NAL Call No.: Videocassette No. 1286. 
Bovine Restraint. East Lansing, Michigan: Michigan State University; c1976; 1/2" VHS, 12 min., 20 sec. Keyword: Cattle, handling, restraint.

Note: Demonstrates a number of ways to restrain cows including the use of the rope halter, nose lead, and burley casting methods.

NAL Call No: Videocassette No. 2042.

Breaking Barriers. Washington, DC: People for the Ethical Treatment of Animals (PETA); 1986; 1/2" VHS, 16 min.

Keyword: Environmental enrichment, macaques, chimpanzees, marmosets, medical research, laboratory animal facilities.

Note: This videotape contains footage of laboratory animal facilities at SEMA, Inc.; in Rockville, MD. Primates, infected with human pathogens, are housed in isolation or in stimuli-deprived environments. The film cites abnormal behaviors exhibited by the caged primates, including stereotypic behaviors and unusual vocalizations, as proof that the primates are housed and managed inhumanely.

NAL Call No: Videocassette No. 558.

Breaking Yearlings. Lexington, KY: Blood-Horse Productions; c1985; 1/2" VHS, $38 \mathrm{~min}$.

Keyword: Horses, yearlings, breaking, training for racing.

Note: Shows step by step procedures that professionals have found successful in breaking yearlings and developing race horse potential.

NAL Call No.: Videocassette No. 1895.

Britches. Washington, DC: People for the Ethical Treatment of Animals (PETA); 1986; 1/2" VHS, 16 $\min$.

Keyword: Laboratory animals, primates, ALF, stress, medical research, macaques.

Note: On April 20, 1985, the Animal Liberation Front (ALF) broke into a research facility at the University of California at Riverside. Activists removed cats, rabbits, pigeons, mice, opossums, and a young macaque identified as "Britches." This video documents the "rescue" of the primate from the research facility. The film concludes by encouraging viewers to protest government-funded animal research.

NAL Call No: Videocassette No. 554.

Broodmare Management. Lexington, KY: Blood-Horse Productions; c1984; 1/2/" VHS, $32 \mathrm{~min}$.

Keyword: Thoroughbred horse breeding, mares, management.

Note: Describes a management program for the breeding of thoroughbred horses, with emphasis on the care and preparation of the mare. Discusses the use of artificial lighting, a teasing program, rectal palpation, use of hormones, diagnostic ultra-sound examination, endoscopic examination, clinics for infertile mares, breeding sheds, and the shipping of foaling mares. The intended audience for this program is thoroughbred horse breeders.

NAL Call No.: Videocassette No. 1891.

Brookfield Zoo: Keeper Orientation. Chicago, IL: Brookfield Zoo; 1990; 1/2" VHS, 22 min.

Keyword: Training, maintenance, care, handling, behavior.

Note: This introductory training videotape describes keeper duties and responsibilities from the 
start of their day to the end. Emphasis is placed on maintenance, cleaning, feeding, medicating, observation, and animal behavior.

NAL Call No: Videocassette No. 1289.

BST \& Milk: Issues \& Answers. Image Base (Firm); American Medical Television.; American Medical Association. [S.1.]: Image Base, c1993. 1 VHS videocassette (20 min., $30 \mathrm{sec}$.).

Keywords: Bovine somatotropin, composition of milk, use in dairy cattle, societal concerns, animal health..

Note: Explores the issues surrounding the use of bovine somatotropin (BST) in cows to increase milk production. Program explores how BST works to stimulate milk production, and supports the argument that its safe for humans to consume milk with BST. Features statements by leading experts, including M. Roy Schwarz, Dennis M. Bier, Sanford A. Miller, Ronald E. Kleinman, Richard H. Phipps and Dennis Avery. NAL Call No: Videocassette no.1715.

BST: Continuing a Dairy Tradition. St. Louis, MO: Monsanto Company; 1988; 1/2" VHS, 11 min. Keyword: Bovine somatotropin, biotechnology, milk.

Note: Experts in animal science, human health, and agricultural economics answer important questions from Wisconsin dairy farmer Greg Mell. The film serves as a general overview of the nature of bovine somatotropin, including its use and safety.

NAL Call No: Videocassette No. 458.

BST Debate: Biotechnology and the Dairy Case. A Supermarket Insights Special Report. Monsanto Agricultural Company. Stamford, CT: Retail Insights, 1990. 1 VHS videocassette (14 min.).

Keywords: Bovine somatotropin. agricultural biotechnology, milk products, U.S..

Note: Bovine somatotropin or BST is enhancing the way milk is produced. This video report focuses on how BST fits into the overall biotechnology picture, what possibilities it's likely to present at the retail level and offers some special tactics retailers can use in addressing questions shoppers may have on BST.

NAL Call No: Videocassette no.1461.

Caesarean Birth. Davis, CA: University of California; 1977; U-Matic 3/4", 25 min.

Keyword: Dogs, Caesarean section, surgery, veterinary training.

Note: A training film for students of veterinary medicine, this program illustrates proper procedures and techniques involved in performing a Caesarean operation. A dog is used as a model.

NAL Call No: Videocassette No. 218.

Cage Culture: Raising Fish in Ponds. Maryland Sea Grant College; University of Maryland (System). Office of Institutional Advancement. [College Park, Md.?]: Maryland Sea Grant College, c1990. 1VHS videocassette (25 min.).

Keywords: Aquaculture, Chesapeake Bay, production techniques, stocking density.

Note: Discusses history of aquaculture in the Chesapeake Bay, when to use cages for aquaculture, how to make and design various cages onesself, how to measure pond water quality, how to clean cages, and how to calculate number of fish per species to stock per cage per pond and how much to feed.

NAL Call No: Videocassette no.1221. 
Cage Sanitation: Use of Chemical Disinfectants. Seattle, WA: University of Washington; 1984; 56 slides, audiocassette, 13 min.

Keyword: Disinfection, sterilization, laboratory animal facilities, cages, veterinary training.

Note: Presents information on how the three classes of disinfectants are used in animal facilities. A complete cycle of small cage sanitation is demonstrated for a large facility using automatic cage-washing equipment.

NAL Call No: Slide No. 230.

Caging Systems, Bedding Materials \& Environmental Considerations for Laboratory Rodents. Seattle, WA: University of Washington; 1985; 53 slides, audiocassette, 22 min.

Keyword: Cages, laboratory animal facilities, environmental factors, veterinary training.

Note: This program presents the rationale for the selection of cage style and bedding materials for laboratory rodents. Also discussed is the importance of controlling factors in the immediate environment, including temperature, humidity, light cycle, and noise.

NAL Call No: Slide No. 237.

Calving Time Management/Equipment. Part of the series "Video programs for education business industry." Ames IA: Iowa State University. Cooperative Extension Service; RMI Media Productions; and WOI-TV (Television station). Distributed by RMI Media Productions, of Shawnee Mission, KS; 1980?; $1 / 2^{\prime \prime}$ VHS, $24 \mathrm{~min}$.

Keyword: Cattle parturition, birthing.

Note: Basics management of the calving process. Descriptions of needed equipment and basic techniques are discussed.

NAL Call No.: Videocassette No. 1440.

Canine Control Officer/Kennel Worker. Mahwah, NJ: Troll Associates; 1975; 35 mm, 7 min.

Keyword: Pets, vocational guidance, juvenile films.

Note: Made for the Humane Society of the United States, this film focuses on careers related to kennels and on the control of pet populations. Intended for elementary grades.

NAL Call No: Filmstrip No. 199.

Care and Management of Caged Birds. S. Kruckenberg. [Manhattan, Kan.]: Kansas State University, The College of Veterinary Medicine, c1992. 1 VHS videocassette (51 min.).

Keywords: Aviculture, pet birds, care and housing.

Note: Provides information on the sources, types, diets, care, housing and breeding of the more popular caged birds.

NAL Call No: Videocassette no.2104.

Careers in the Horse Industry: Unbridled Opportunities. Washington, DC: Colorado State University, Public Relations Department, Equine Sciences Program, Extension Horse Program; 1990; 1/2" VHS, 24 $\min$.

Keyword: Interviews, industry, vocations, youth, education.

Note: Designed for youth interested in horses and seeking careers and opportunities within the horse industry. It features interviews with people in all aspects of the industry, including trainers, veterinarians, sales agents, advertisers, photographers, computer specialists, lawyers, and journalists.

NAL Call No: Videocassette No. 1318. 
Careers in Veterinary Medicine: a Rainbow of Choices. Raleigh, NC: North Carolina State University, College of Veterinary Medicine; c1992; 1/2" VHS, 20 min.

Keyword: Veterinary medicine, career opportunities, vocational guidance.

Note: Discusses various opportunities in the field of veterinary medicine in the fields of small animal, large animal, equine, zoo animal practice; public health; and research. Does not mention careers in state or federal regulatory positions or in the pharmaceutical industry.

NAL Call No.: Videocassette No. 1771.

Careers in Veterinary Medicine. CA:State University. School of Veterinary Medicine. Insight Productions. Research Triangle Park, NC: North Carolina State University, School of Veterinary Medicine: Insight Productions, Inc. [distributor], [1985?] 1 VHS videocassette (17 min.).

Keywords: Veterinary medicine, career opportunities, vocational guidance.

Note: Discusses various opportunities in the field of veterinary medicine

NAL Call No: Videocassette no.1772.

Caring for Life. Washington, DC: Foundation For Biomedical Research; 1985; 1/2" VHS, U-Matic 3/4", $10 \mathrm{~min} .30 \mathrm{sec}$.

Keyword: Careers, veterinary nurse, laboratory animals, veterinary medicine, vocational education.

Note: A description of the varied job role of a veterinary nurse. Two certified veterinary nurses working at a laboratory animal rescue facility discuss various aspects of their job and their reasons for entering this field. Suitable for elementary and high school students.

NAL Call No: Videocassette No. 145.

Carnivore Restraint and Handling. San Diego, CA: San Diego Zoological Society and Davis, CA: University of California; 1981; 112 slides, audiocassette, $25 \mathrm{~min}$.

Keyword: Tigers, foxes, wolves, bears, ferrets, raccoons, hyenas, mongooses, zoo animals, restraint, handling.

Note: This slide set demonstrates techniques for restraining and handling various species of wild carnivores representing the following family groups: Felidae, Canidae, Ursidae, Mustelidae, Procyonidae, and Viverridae. Proper techniques related to cleaning, feeding, chemical immobilization, and administering medicines are covered. A script accompanies the slide set.

NAL Call No: Slide No. 195.

Carnivores: Basic Needs, Handling and Care. Closter, NJ: Production Plus, Inc.; 1990; 1/2" VHS, 32 min.

Keyword: Animal welfare, laboratory animals, cats, dogs, ferrets, minks.

Note: Videotape of a presentation at the symposium Animal Welfare Compliance for Study Directors, presented at the Eleventh Annual Meeting of the American College of Toxicology in Orlando, FL, October 1990. The video focuses on the basic needs of dogs and cats, including air, food, water, environmental controls, and social interaction. Available guidelines, regulations, resource information, and training manuals are covered. Also discussed are methods of disease prevention, identification, housing, and exercise and the basic care and handling required for ferrets and mink.

NAL Call No: Videocassette No. 971.

Cat Care: A Video Guide to Successful Cat Care. New York, NY: United Media Productions; 1985; 
$1 / 2^{\prime \prime}$ VHS, $43 \mathrm{~min}$.

Keyword: Cats, cat care, veterinary care.

Note: This is one of a series of tapes on animals by Dr. Michael Fox. In this tape he shares the secrets to adopting, owning, and caring for your cat. Tips are given on eliminating fleas, vaccinations, illness, spaying/neutering, behavior, and massaging your cat. Proper care and understanding of your cat are addressed.

NAL Call No: Videocassette No. 908.

Catfish Farming in the South. Revised 1997. Mississippi State University, Cooperative Extension Service; Mississippi State University, Office of Agricultural Communications; Texas Agricultural Extension Service. [College Station, Tex.?] : Texas Agricultural Extension Service, [1997]. 1 VHS videocassette (22 min., $25 \mathrm{sec}$.).

Keywords: Catfishes, Southern states, fish culture, economics, ponds, construction, U.S.

Note: Provides an overall view of the catfish industry in the southern United States. Covers areas of production cost, pond and water management, pond site selection and construction, hatchery information, and transport of catfish.

NAL Call no: Videocassette no.2623.

Cats: Caressing the Tiger. Washington, D.C. :National Geographic Society; 1991; 1/2" VHS, 60 min. "No. 51478".

Keyword: Cats, behavior, domestic vs wild.

Note: A comparison of domestic cats to wild cats is used to explain the behavior of domestic cats.

NAL Call No.: Videocassette No. 1163.

Cattle Handling and Transportation. Madison, WI: Livestock Conservation Institute; 1988; 1/2" VHS, 16 min.

Keyword: Intensive livestock farming, behavior, loading equipment, cattle.

Note: This training video explains the basics of cattle behavior as it relates to moving and transporting livestock efficiently and humanely. Vision, reaction to noise, flight zone, natural circling, and following behavior are discussed. Other topics include overcrowding in pens, use of squeeze chutes, loading and unloading trucks, truckdriving techniques, and temperature stress during transportation.

NAL Call No: Videocassette No. 422.

Cattle Handling. Alberta Agriculture; Alberta Agriculture, Food, and Rural Development. Edmonton, Alta.: Alberta Agriculture, Food and Rural Development, c1993. 1 VHS videocassette (19 $\min$. .).

Keywords: Cattle, psychology, behavior, handling.

Note: Discusses cow psychology and cattle handling from the animal's point of view.

NAL Call No: Videocassette no.2607.

Cell Wars:The Life Revolution. Films for the Humanities (Firm). Films for the Humanities (Firm); Primedia Productions; Canoptic Productions; TVOntario; Telefilm Canada. Princeton, NJ: Films for the Humanities \& Sciences, Inc., c1990. 1 VHS videocassette (26 min).

Keywords: Humans, immune system, computer model, animal alternative.

Note: Computer animation demonstrates how the body's immune system works. Originally 
copyrighted in 1988. "FFH 2439."

NAL Call No: Videocassette no.1953.

Changing Relationship Between Humans and Animals. Minneapolis, MN: University of Minnesota; 1986; 1/2" VHS, $45 \mathrm{~min}$.

Keyword: Pets, intensive livestock farming, biological diversity, technology, future, ethics.

Note: Moderator Dr. David Garloff and panelists Drs. Joe Quigley and John Brantner, all of the University of Minnesota, consider changes in the human-animal relationship resulting from modern technology. The panelists address the following questions: What would a world without animals be like? Do we need animals anymore? Why do we have animals if we do not need them? One panelist concludes that as the world becomes more dependent on technology, animals will become less important. Agricultural animals and pets are emphasized in the discussion.

NAL Call No: Videocassette No. 321.

Channel Catfish Spawning \& Hatchery Management. Texas A \& M University. Dept. of Agricultural Communications; Texas Agricultural Extension Service. [College Station, Tex.?] : The Service, 1993. 1 VHS videocassette (16 min., $45 \mathrm{sec}$.).

Keywords: Channel catfish, spawning, production fish management.

Note: Explains the procedures used for fingerling culture--from the care of brood stock until the fingerlings are ready for stocking into grow out ponds.

NAL Call No: Videocassette no.1857.

Chicken for Dinner? (also called Sentenced for Life). Potomac, MD: Unitèd Poultry Concerns, Inc.; 1990; 1/2" VHS, 15 min.

Keyword: Battery systems, broilers, intensive housing, welfare.

Note: Produced by Chickens' Lib, this production documents the conditions of poultry in the broiler industry. Issues such as overcrowding, cannibalism, and conformation are addressed.

NAL Call No: Videocassette No.1288.

Cleveland City Club Forum Debate: Animals in Medical Research. Cleveland, OH: Cuyahaga Community College; 1989; 1/2" VHS, 60 min.

Key words: Animal rights, debate, medical research, PETA.

Note: Robert J. White, M.D., Ph.D., and Ingrid Newkirk of People for the Ethical Treatment of Animals (PETA) debate issues of the use of animals in medical research.

NAL Call No: Videocassette No. 907.

Commensal Rodents: Biology \& Behavior. National Pest Control Association (NCPA) rodent control series; 1. Dunn Loring, VA: NCPA; c1990; 1/2" VHS, 15 min. Includes 1 manual (17 leaves).

Keyword: Rats, (Rattus norvegicus), mice, behavior, physiology, controls, training.

Note: This National Pest Control Association Rodent Control Training Program (one of six videos) examines the biology and behavior of three commensal rodents, the Norway rat (sewer rat), the roof rat (wharf rat) and the house mouse. The purpose of this video training program is to increase the pest control service technician's knowledge of the habits of these pests, thereby enabling them to design effective control programs. The accompanying manual includes practical training tips, program presentation recommendations, a pretest and a post test (with answers), suggested reference materials, 
and a commensal rodent pictorial identification key.

NAL Call No.: Videocassette No. 1039.

Common Ground: Farming and Wildlife. Alexandria, VA: National Audubon Society, Turner Broadcasting System, and WETA; 1987; 1/2" VHS, 57 min.

Keyword: Organic farming, ecology, habitat, sustainable agriculture, pesticides, herbicides, crop rotation.

Note: In recent years farmers have realized what escalating use of pesticides and herbicides are doing to the land, wildlife, and human health. This video illustrates how farmers are joining with conservationists, as well as land and soil managers, to save soil, water, wildlife, and the farm. The program highlights methods of raising crops that can benefit farming and work with nature's abundance for generations to come. A teacher's guide accompanies the tape.

NAL Call No: Videocassette No. 1147.

Composting for Pork Producers. National Pork Producers Council (U.S.). National Pork Board (U.S.). Des Moines, IA: The Council, [1998?], c1997. 1 VHS videocassette (ca. 14 min.).

Keywords: Composting process, handling of swine carcasses, manure handling, recycling animal waste.

Note: Shows how composting can transform swine mortality and manure into a state where storage, handling, and land application can be achieved without adversely effecting the environment. Other title is Principles of mortality composting for pork producers.

NAL Call No: Videocassette no.2742.

Composting Poultry Mortality. College Park, MD: University of Maryland System, Cooperative Extension Service; c1992; 1/2" VHS, 17 min.

Keyword: Poultry, dead animals, disposal, composting, organic fertilizer.

Note: Demonstrates the applications of composting as a practical, economical, and environmentally safe alternative method of disposing of dead birds resulting from normal poultry farm mortality.

NAL Call No: Videocassette No. 1942.

Conformation. Lexington, KY: Blood-Horse Productions; c1985; 1/2" VHS, ca. 40 min.

Keyword: Horses, conformation, training, defects.

Note: Illustrates good horse conformation and examples of conformation defects, some of which may be acceptable to trainers and some not acceptable.

NAL Call No.: Videocassette No. 1894.

Connections: Animals, People and Biotechnology. St. Louis, MO: Monsanto Company; 1990; 1/2" VHS, 19 min.

Keyword: Animal welfare, genetic engineering, feed utilization efficiency, animal experimentation.

Note: This video introduces the audience to the use of animals and new biotechnological techniques to assist both man and animal.

NAL Call No: Videocassette No. 721.

Control of the Horse : "The Art of Restraint" in Horsemanship. Robert Miller. Lakeville, In : Video Horse World Productions, [199-?]. 1 VHS videocassette (60 min.). 
Keywords: Horses, training, behavior, restraint, methods

Note: Demonstrates the use of the twitch and hobbles, and describes many alternative methods of restraining horses.

NAL Call No: Videocassette no. 2643.

Control of Ventilation: Effects of Chemo and Mechano Receptors. Davis, CA: University of California; 1988; 1/2" VHS, 40 min.

Keyword: Dog, anesthesia, veterinary medicine, surgery.

Note: This program demonstrates the effects of chemical and mechanical receptors on ventilation in mammals. It examines the physiological responses of a dog after administration of various gases.

NAL Call No: Videocassette No. 409.

Controlling Grass Tetany. Mundelein, IL : IMC Fertilizer, Inc., with USDA. Agricultural Research Service. North Atlantic Area; 199-?; 1/2" VHS, 12 min.

Keyword: Cattle, grass tetany, causes, control, magnesium sulfate.

Note: Discusses various factors that can cause grass tetany in cattle and the different ways that it can be controlled such as by adding magnesium sulfate to drinking water or adding magnesium to silage.

NAL Call No.: NAL Videocassette No.1734.

Cow Handling. Davis, CA: University of California; 1980; U-Matic 3/4", 19 min. (Vol. 1), 40 min. (Vol. 2).

Keyword: Cows, restraint, handling, veterinary medicine, biomedical techniques.

Note: Volume 1 demonstrates techniques for manually restraining the cow. The tape illustrates the use of the halter, nose ring, nose lead, and hobbles, and demonstrates techniques for manipulating the tail and preventing kicks. Volume 2 demonstrates the following biomedical procedures: blood collection, vein location, bone marrow biopsy, injections, drenching, minor teat surgery, treatment of displaced abomasum and carcinoma of the eye, and use of the stomach tube, dose syringe, balling gun, and speculum.

NAL Call No: Videocassette No. 227.

Cryptosporidium and Cryptosporidiosis: The Parasite and the Disease. Ron Fayer, United States. Dept. of Agriculture. Video, Teleconference \& Radio Center. [Washington, D.C.?]: The Center, [1995?]. 1 VHS videocassette ( 25 min., $14 \mathrm{sec}$.).

Keywords: Cryptosporidium, life cycle, clinical signs, zoonotic disease.

Note: Dr. Ron Fayer presents the life cycle of Cryptosporidium. He also discusses the geographic distribution, groups at risk from cryptosporidiosis, the infective dose, and clinical signs of the disease itself.

NAL Call no: Videocassette no.2173.

Dairy Calf Management University of Idaho. Dept. of Agricultural Information. Moscow, Idaho: Ag Communications Center, University of Idaho, c 1980. 1 VHS videocassette (10 min., $45 \mathrm{sec}$.).

Keywords: Calves, dairy cattle, management.

Note: Shows various aspects of productions managment practices.

NAL Call No: Videocassette no.2598.

Dance of Death. Boston: World Society for the Protection of Animals; 1991; 1/2" VHS, 8 min. 
Keyword: Bulls, bullfights, animal welfare, pain.

Note: Shows the pain and suffering inflicted on a bull during a bullfight.

NAL Call No.: Videocassette No. 1709.

Dehorning Cattle. San Luis Obispo, CA: Da-Nel Productions; Vocational Education Productions; 1985; $1 / 2$ " VHS, $25 \mathrm{~min}$.

Keyword: Dehorning, cattle, techniques, horns, physiology, purpose, animal welfare.

Note: Discusses why and when cattle are dehorned. Provides information on horn growth and its physiology. Gives techniques used and at what age. Demonstrates several methods of dehorning. Discusses restraint and veterinary care needs.

NAL Call No: Videocassette No. 844.

Development and Reproduction of Mice in a Laboratory Setting. Seattle, WA: University of Washington; 1983; 39 slides, audiocassette, 15 min.

Keyword: Mice, laboratory animals, reproduction, husbandry.

Note: An interactive program in which the viewer is provided with facts about normal mouse development and reproduction, and is asked to apply these facts to animal care situations. Supervised practice with live animals at the time of presentation is recommended to reinforce the learning experience and to encourage skill-building and confidence.

NAL Call No: Slide No. 232.

Diseases of Laboratory Animals as Complications of Biomedical Research. Pullman, WA: Washington State University; 1975; 39 slides, audiocassette, $21 \mathrm{~min}$.

Keyword: Disease control, pathogenesis, public health, enzootic simian viruses, Pseudomonas aeruginosa.

Note: Presented is basic information concerning laboratory animal medicine and diseases intended for veterinary and other biomedical science students. The program examines causative agents and disease control. A script accompanies the slide set.

NAL Call No: Slide No. 225.

Diseases of Warmwater Fish. Robert M. Durborow and Clint Goins, Frankfort, KY: Kentucky State University. Cooperative Extension Program and Community Research Service. c1994. 1 VHS videocassette (ca. $30 \mathrm{~min}$.).

Keywords: Fish, pathogenic organisms, disease descriptions.

Note: Designed to aid fish culturists and students of fish health management in identifying warmwater fish pathogens.

NAL Call No: Videocassette no.2379.

Dissection \& Anatomy of the Crayfish. Linda Mruz. Omaha, Neb.: Nebraska Scientific, c1988. 1 VHS videocassette (14 min., 30sec.) and 1 student question sheet.

Keywords: Crayfish anatomy, dissection demonstration.

Note: Provides a close-up view of the anatomy of the crayfish as it is being dissected.

NAL Call No: Videocassette no.1124.

Dissection \& Anatomy of the Clam. Linda Mruz. Omaha, Neb.: Nebraska Scientific, c1988. 1 VHS videocassette (7 min., $41 \mathrm{sec}$.) and 1 student question sheet.

Keywords: Clam anatomy, dissection demonstration.

Note: Provides a close-up of the anatomical parts of a clam as it is being dissected. 
NAL Call No: Videocassette no. 1123.

Dissection and Anatomy of the Shark. Omaha, NE: Nebraska Scientific; 1988; 1/2" VHS, 26 min.

Keyword: Shark, dissection, anatomy.

Note: Gives a brief history and information on sharks. Uses a dogfish shark to demonstrate dissection of the internal and external anatomy. A worksheet accompanies the video.

NAL Call No: Videocassette No. 794.

Dissection and Anatomy of the Eye. Omaha, NE: Nebraska Scientific; 1989; 1/2" VHS, 16 min. Keyword: Eye, dissection, anatomy.

Note: Discusses the dissection and anatomy of the eye. Utilizes a bovine eye and plastic model. A worksheet accompanies the video.

NAL Call No: Videocassette No. 848.

Dissection and Anatomy of the Heart. Omaha, NE: Nebraska Scientific; 1989; 1/2" VHS, 15 min. Keyword: Heart, dissection, anatomy, mammal.

Note: Covers characteristics of the mammalian heart. Plastic model (human) and fetal pig used to demonstrate dissection. Anatomy, physiology, and function discussed. A worksheet accompanies the video.

NAL Call No: Videocassette No. 833.

Dissection and Anatomy of the Fetal Pig. Omaha, NE: Nebraska Scientific; 1988; 1/2" VHS, 26 min.

Keyword: Swine, embryo, training, alternative, veterinary.

Note: This film provides a view of the anatomy of the fetal pig as dissection takes place.

NAL Call No: Videocassette No. 795.

Dissection and Anatomy of the Brain. Omaha, NE: Nebraska Scientific; 1989; 1/2" VHS, 23 min. Keyword: Brain, dissection, anatomy, sheep.

Note: This video uses a sheep brain to show mammalian brain characteristics. Discusses brain development and function while demonstrating the dissection. A worksheet accompanies the video.

NAL Call No: Videocassette No. 834.

Dissection and Anatomy of the Rat. Omaha, NE: Nebraska Scientific; 1988; 1/2" VHS, 31 min.

Keyword: Veterinary, training, alternative.

Note: Taking you through step-by-step, this training video provides you with the complete dissection and anatomy of the rat.

NAL Call No: Videocassette No. 793.

Dissection and Anatomy of the Cat. Omaha, NE: Nebraska Scientific; 1988; 1/2" VHS, 46 min.

Keyword: Cat, dissection, anatomy.

Note: This video covers external and internal anatomy of the cat. Mammalian characterists are discussed. A worksheet accompanies the video.

NAL Call No: Videocassette No. 869.

Do Animals Reason?. Washington, DC: National Geographic Society; 1975; 16 mm, 14 min.

Keyword: Triggerfish, starlings, dolphins, chimpanzees, animal behavior, intelligence.

Note: Demonstrating classic and contemporary animal behavior experiments using fish, birds, 
and mammals, this film introduces students to the learning abilities of animals. A teacher's guide accompanies the film.

NAL Call No: Motion Picture No. 188.

Do Animals Think and Feel?. Minneapolis, MN: University of Minnesota; 1986; 1/2" VHS, 45 min.

Keyword: Animal behavior, intelligence, language, cognitive neuropsychology, splitbrain operations.

Note: University of Minnesota faculty members Gail Peterson (psychologist) and Joe Quigley (veterinarian) discuss animal behavior, consciousness, learning, intelligence, and emotions. Comparisons and contrasts are made between the mental and emotional processes of animals and humans. The panelists respond to audience questions.

NAL Call No: Videocassette No. 319.

Dog Lab: An Unnecessary Exercise. Washington, DC: People For the Ethical Treatment of Animals; 1987; 1/2" VHS, 16 min.

Keyword: Surgery, education, biomedical techniques, dogs.

Note: Taped segments obtained in 1987 from an East Carolina University surgical training class highlight questionable surgical techniques performed on a dog. The narrator asserts that the instructor was callous, unprofessional, and inept.

NAL Call No: Videocassette No. 555.

Dogsteps: A Study of Canine Structure and Movement. River Farm, NY: Racheal Page Elliot; 1988; 1/2" VHS, $67 \mathrm{~min}$.

Keyword: Anatomy, structure, conformation, physiology, gait.

Note: Illustrates some of the features that lend quality to a dog's overall conformation and to its performance. This video also examines some of the physical virtues and faults that can help or hinder groundcovering ability and serviceability. Also addressed are traits that help particular dog species meet particular requirements.

NAL Call No: Videocassette No. 1353.

Don't Kill the Animals. Washington, DC: People for the Ethical Treatment of Animals, Inc.; 1988; 1/2" VHS, $7 \mathrm{~min}$.

Key words: Animal experimentation, ethic, morals, animal liberation, animal rights.

Note: This video consists of "break-in" footage set to music. Vegetarianism is promoted, while research, farming, fur production, and hunting are criticized.

NAL Call No: Videocassette No. 846

Early Age Neutering of Puppies and Kittens. Massachusetts Society for the Prevention of Cruelty to Animals; American Humane Education Society. Boston: MSPCA : AHES, c1995. 1 VHS videocassette (ca. 30 min.).

Keywords: Kittens, puppies, surgical procedure.

Note: Shows safe and efficient methods of spaying and neutering puppies and kittens.

NAL Call No: Videocassette no.2381.

Early Learning: The Complete Training of the Newborn Foal During its Imprinting and Critical Learning Periods. Robert M. Miller. Virginia City, Nev.: Video Velocity, c1995. 1 VHS videocassette (120 min.).

Keywords: Foals, training, imprinting, psychology, behavior. 
Note: Demonstrates techniques for training newborn foals to accept grooming, hoof trimming, clipping, veterinary examinations, trailer loading and unexpected objects.

NAL Call No. Videocassette no.2593.

Early Spay/Neuter. Stuart, Fla.: Animal Rescue League of Martin County. [1994?]. 1 VHS videocassette (ca. $11 \mathrm{~min}$.).

Keywords: Puppies, surgical procedures, animal rescue society.

Note: Discusses the Animal Rescue League of Martin County's early spay/neuter program. Two surgical procedures, ovarian hysterectomy and castration, are demonstrated on dogs.

NAL Call No: Videocassette no.2092.

Educating your Foal. Educational Horse Videos. Linda Tellington-Jones Series. Linda Tellington-Jones. La Jolla, CA: Lawlor Productions, c1987, 1 VHS videocassette (54 min.).

Keywords: Foals, pre-training conditioning.

Note: T.E.A.M. (Tellington-Jones Equine Awareness Method) solutions are discussed for preparing a foal for future training by awakening its thinking, focus and hoof-eye coordination.

NAL Call No: Videocassette no.2140.

Elephant Care and Handling. San Diego, CA: San Diego Zoological Society and Davis, CA: University of California at Davis; 1981; 75 slides, audiocassette, 20 min.

Keyword: Asian elephants, African elephants, zoo animals, chaining, bull hooks, chemical immobilization, toenail trimming.

Note: This training film for zoo caretakers details topics related to the care and handling of captive Asian and African elephants. The following subjects are discussed and illustrated: taxonomy, anatomy, cleaning, feeding, and restraint.

NAL Call No: Slide No. 191.

Elephant. Washington, DC: National Geographic Society; 1989; 1/2" VHS, 60 min.

Keyword: Behavior, communication, endangered, poaching.

Note: From Sri Lanka to Kenya, this production takes an in-depth look at the elephant and its precarious future, as well as the behavior of elephants in the wild.

NAL Call No: Videocassette No. 1154.

Elephants in Need: Action Alert. Humane Society of the United States. Washington, DC: The Society, c1998. 1 VHS videocassette (6 min.).

Keywords: Elephants, handling, wildlife trade, welfare concerns.

Note: Focuses on a case showing the cruelty to wild baby elephants as they are being held and waiting to be sold for profit.

NAL Call No.: Videocassette no.2744.

Emergency Care. Lexington, KY: Blood-Horse Productions; c1984; 1/2" VHS, ca. 32 min.

Keyword: Horses, diseases, injuries, veterinary care, diagnosis, physical examination.

Note: A veterinarian demonstrates a routine physical examination which could be performed by a farm manager when faced with a sick or injured horse.

NAL Call No.: Videocassette No. 1898.

Emu Farming: A Guide to Hatching and Raising Emu. Author and publisher unkonwn [S.1. : s.n., 
1993?] 1 videocassette (ca. 30 min.).

Keywords: Emus, husbandry, egg handling for hatching.

Note: A guide to hatching, raising, handling, tattooing and sexing the Emu.

NAL Call No: Videocassette no.2668.

Environmental Assurance Program: America's Pork Producers--Dedicated to Conserving the Environment. National Pork Producers Council (U.S.); National Pork Board (U.S.). Des Moines, Iowa : The Council, [1995]. 1 VHS videocassette (ca. 10 min.).

Keywords: Pork industry, trade, environmental aspects, agricultural conservation.

Note: Shows ways for pork producers to create and implement environmentally sound practices in their operation's total management program.

NAL Call No: Videocassette no.2365

Environmental Enrichment: Advancing Animal Care. Potters Bar, Herts, England: Universities Federation for Animal Welfare; 1990; 1/2" VHS, 37 min.

Keyword: Housing, environmental engineering, zoo animals, animal welfare, design.

Note: Primarily aimed at individuals responsible for the care of animals in captivity, the video explores the physical and behavioral needs of zoo animals and gives practical suggestions for improving their lives. A straightforward guide to carrying out an enrichment program is provided.

NAL Call No: Videocassette No. 1327.

Equine Euthanasia: Peaceful Death in the Hospital or in the Home Pasture. Judy Marteniuk and Sally O. Walshaw. [East Lansing] : Michigan State University, Instructional Media Center [distributor], c1997. 1 VHS videocassette (13 min.). 1 guide (iv, 14 leaves ; 22 cm.) ("Developed by Judy Marteniuk and Sally Walshaw, MSU College of Veterinary Medicine"--Container label.)

Keywords: Humane methods, euthanasia.

Note: Focuses on the euthanasia of three horses to which the tape is dedicated: Daalda, B.T., and Echo. Considers both the medical/clinical and the personal aspects of euthanasia.

NAL Call No: Videocassette no.2692.

European Pork Production: Animal Welfare Concerns. Ames, Iowa: Iowa State University, University Extension, c1993. 1 VHS videocassette.

Keyword: Swine, pork industry and trade, Europe, animal welfare.

Note: $\quad$ "Sponsored by the Iowa Pork Producers, Pfizer Animal Health and Schering-Plough Animal Health" Consists of 4 parts. Why the concern? (30 min.); Pigs outside, pigs inside (30 min.); Fiber-based pigs (30 min.); Producers and consumers (30 min.).

NAL Call No: Videocassette no.2693.

Every Link in the Chain. U.S. Dept. of Agriculture, Video, Teleconference \& Radio Center; U. S. Dept. Of Agriculture, Agricultural Marketing Service, Transportation and Marketing Division. [Washington, D.C.?] : U.S. Dept. of Agriculture, Agricultural Marketing Service, Transportation and Marketing Division, 1997. 1 VHS videocassette (19 min., $42 \mathrm{sec}$.).

Keywords: Dairy cattle, US. livestocck marketing, transportation, handling, export sales, contracts.

Note: Each successful, humane livestock exporting experience is a team effort, and each link in the exporting chain--breeder, veterinarian, trucker, freight forwarder, and animal handler is essential. This video follows a shipment of dairy cattle from a farm in Maine to the 
port of embarkation at JKF International Airport.

NAL Call No:Videocassette no.2606.

Exodus at Yellowstone: The Second Catastrophe. Sacramento, CA: Animal Protection Institute of America; 1989; 1/2" VHS, 30 min.

Keyword: Hunting, bison, ecology, wildlife.

Note: In the winter of 1989 , following a severe drought and fire that destroyed food supplies within the park, large numbers of bison were shot after straying beyond Yellowstone National Park boundaries. Various animal protection advocates voice their protests over bison hunting, which is sanctioned by the Montana State Department of Wildlife.

NAL Call No: Videocassette No. 547.

External Parasites of Dogs and Cats. [United States]: Ciba Animal Health Division; 1993; 1/2/" VHS. Includes a manual.

Keyword: Dogs, fleas, ticks, external parasites.

Note: This set of 2 video cassettes pertains to external parasites such as fleas and ticks. Part 1 addresses diagnosis and control of external parasites on dogs and cats. Part 2 describes ways to control these pests.

NAL Call No.: Videocassette No. 2037.

External Physical Exam of the Dog. Davis, CA: University of California, Davis; 1981; U-Matic 3/4", 12 $\min$.

Keyword: Dogs, palpation, pupillary response, occlusion, veterinary-medicine.

Note: A veterinarian describes and demonstrates techniques necessary for conducting a general physical examination of a dog. Examination of the ears, eyes, nose, mouth, muscle and bone structure, feet, rectum, gonads, and internal organs is demonstrated.

NAL Call No: Videocassette No. 225.

Facing the Animal Rights Challenge. Animal Health Institute: Alexandria, VA; 1985; 49 slides, audiocassette, $7 \mathrm{~min}$.

Keyword: Farm animals, animal welfare, legislation.

Note: Directed at livestock producers, this slide presentation answers these questions: Who are animal rights groups? What are their origins? What do they want to accomplish? What can producers do? The audience is given tips on how to best deal with animal rights demonstrators and how to influence legislation affecting livestock production.

NAL Call No: Slide No. 289.

Fancy Footwork. Horseowner's Guide to Sound Shoeing Practices. Publisher Equalign; c1992; 1/2" VHS, $60 \mathrm{~min}$.

Keyword: Horseshoeing.

Note: Meredith Clarke explains the intricate relationship between the structure and function of the foot, and correct shoeing procedures.

NAL Call No.: Videocassette No. 1903.

Farm Animal Behavior Research. Beltsville, MD: National Program Staff, Agricultural Research Service, USDA; June 8, 1990; 1/2" VHS, 100 min.

Keyword: Animal behavior, swine behavior, animal welfare, behavioral research.

Note: A videotaping of a seminar given by Dr. Stanley Curtis. Discusses current research in 
farm animal behavior, with emphasis on swine behavioral research. Addresses issues such as farm animal welfare, psychological well-being, and animal awareness.

NAL Call No. Videocassette No. 906.

Farm Animal Welfare. London? Ministry of Agriculture Fisheries and Food, 199-? 1/2" VHS, 17 min., $11 \mathrm{sec}$.

Keyword: Animal welfare, Great Britain.

Note: Discusses various issues of animal welfare for farm animals in Great Britain.

NAL Call No.: Videocassette No. 2044.

Farm Animals with Care. England: Datascope Communications (produced for Glaxo Group Research in association with the Institute of Animal Technology); 1991; 1/2" VHS, 2 videocassettes, 65 min.

Keyword: Animal welfare, animal health, livestock, housing.

Note: A two volume series that illustrates regimes for housing and care of sheep, goats, pigs, cattle, and poultry, and provides breeding information and demonstrations of routine health care procedures and blood sampling techniques.

NAL Call No: Videocassette No. 1359.

Farming a New Fish: Hybrid Striped Bass. North Carolina State University. Agricultural

Communications Video Productions. North Carolina Cooperative Extension Service. University of North Carolina Sea Grant Program. Raleigh, N.C.: Agricultural Communications Video Productions, NCSU, c1995. 1VHS videocassette (22 min., $30 \mathrm{sec}$.).

Keywords: Aquaculture, striped bass, building ponds, marketing.

Note: Describes how to build fish ponds and the harvesting and marketing of hybrid striped bass.

NAL Call No: Videocassette no.2648.

Feeding Broodmares - Horse Nutrition and Feeding Video Series, 1. Pete George Gibbs, Texas Agricultural Extension Service, Creative Educational Video, Inc. [College Station, Tex.] : The Service; Lubbock, TX : Distributed by CEV Multimedia, [1996?]. 1VHS videocassette (25 min.). Includes 1 support publication.

Keywords: Horses feeding, feeds, mares.

Note: Texas Agricultural Extension Service horse specialist Pete Gibbs discusses nutritional well-being as an important part of a broodmare operation. Focuses on the broodmare from pregnancy through foaling and until weaning occurs. Uses the body condition scoring system to show how to tell if broodmares are in optimum condition as breeding season approaches. Covers roughage selection and use of various feedstuff in meeting nutritional requirments. "Funding for scripting provided by the Animal Nutrition Division of Cargill, Incorporated, Minneapolis, Minnesota." Support publication: Nutritional management of pregnant and lactating mares / Pete G. Gibbs and Karen E. Davison. "Tape \#TAM37001."

NAL Call No: Videocassette no.2728.

Feeding Management of Horses. Horse Nutrition and Feeding Video Series, 4. Don Douglas Householder, Texas Agricultural Extension Service, Creative Educational Video, Inc. [College Station, Tex.]: The Service; Lubbock, Tex.: Distributed by Creative Educational Video, [1997?]. 1 VHS videocassette (55 min.). Includes 2 support publications.

Keywords: Horses, basic feeding, condition scoring, eating behaviors, feed storage. 
Note: Texas Agricultural Extension Service horse specialist Dr. Doug Householder hosts a program that tries to provide an understanding of horse nutrition, the composition of feeds, and horse behavior. Covers classes of horses and basic feeding programs, determining body weights and condition scoring, storing hays and concentrates, feeding hays, feeding concentrates, and managing eating behaviors. Funding for scripting provided by the Animal Nutrition division of Cargill, Incorporated, Minneapolis, Minnesota." Support publications: The digestive system of the horse / D. Douglas Householder, Gary D. Potter, and Pete G. Gibbs (4 p.) ; Feeding management points for Texas horse owners by D. Douglas Householder... [et al.] (7 p.)."Tape \#TAM37005." NAL Call No: Videocassette-no.2731

Feeding Performance Horses. Horse nutrition and feeding video series 5. Don Douglas Householder, Texas Agricultural Extension Service, Creative Educational Video, Inc. [College Station, Tex.]: The Service; Lubbock, Tex.: Distributed by Creative Educational Video, [1997?] 1 VHS videocassette ( $35 \mathrm{~min}$.). Includes 3 support publications.

Keywords: Horses, feeding and feeds, horses nutrition. Horse shows, performance classes.

Note: Texas Agricultural Extension Service horse specialist Dr. Doug Householder reviews some biological concepts, discusses some horse nutrition studies, and ties them together into some practical recommendations to incorporate into a feeding program for performance horses. Covers how much total feed to feed a horse, how to know if nutritional needs are being met, and what feeding management practices need to be employed. "Funding for scripting provided by the Animal Nutrition Division of Cargill, Incorporated, Minneapolis, Minnesota." Support publications: "Feeding the performance horse" / G.D. Potter and P.G. Gibbs. ; Texas Performance Horse Excellence Program: basic nutrition and feeding of performance horses-- teacher supplement; horseowner self-study booklet. "Tape \#TAM37004."

NAL Call No: Videocassete no. 2732.

Feeding Young Horses for Sound Growth and Development. Horse Nutrition and Feeding Video Series 2. Pete G. Gibbs, Texas Agricultural Extension Service, Video Horse World Productions. [Lakeville, Ind.]: Distributed by Video Horse World Productions, [1996?]. 1 VHS videocassette (35 min.). Includes 1 support publication.

Keywords: Young horses, growth, feeding, diets.

Note: Texas Agricultural Extension Service horse specialist Pete Gibbs discusses young horses from birth to two years of age, addressing growth potential and developmental problems in young horses being fed for either moderate or rapid growth. Covers creep feeding practices, ration design and use, and special considerations. Script based on a publication written by Pete Gibbs, Gary D. Potter. "Funding for scripting provided by the Animal Nutrition Division of cargill, Incorporated, Minneapolis, Minnesota." "Video production and support provided by the Houston Livestock Show and Rodeo." Support publication: "Feeding young horses for sound development" / Pete G. Gibbs and Gary D. Potter.

NAL Call No: Videocassette no.2729.

Feeds for Horses. Horse Nutrition and Feeding Video Series 3. Don Douglas Householder, Texas Agricultural Extension Service, Creative Educational Video, Inc. [College Station, Tex.]: The Service; Lubbock, Tex.: Distributed by Creative Educational Video, [1996?]. 1 VHS videocassette (50 min.). Includes lsupport publication.

Keywords: Horses, feed mixtures, nutrition. 
Note: Tells how to put together the most nutritious, safest, simplest, and most economical feed for horses. Covers: roughages; energy concentrates; protein, vitamin, and mineral supplements; physical characteristics of these feedstuffs; nutrient content of these feedstuffs; and cautions concerning some of the feedstuffs that are sometimes given to horses. Support publication: Selection and use of roughage in horse feeding / Pete G. Gibbs and Karen E. Davison. "Funding for scripting provided by the Animal Nutrition Division of cargill, Incorporated, Minneapolis, Minnesota." "Tape \#TAM37003."

NAL Call No: Videocassette no.2730.

Feedyard. [New ed.]. Beef Production Video Series. Tape \#213. Lubbock, Tex.: Creative Educational Video, c1994. 1VHS videocassette $(27 \mathrm{~min}$.).

Keywords: Feedlots, livestock housing, animal nutrition, meat industry, trade.

Note: Visit to the Hill Feedyard in Hart, Tex., where 6 million cattle are fed annually. Discusses housing, handling, feeding and processing cattle.

NAL Call No: Videocassette no. 2576.

Ferret Keeping. James McKay. Ipswich, U.K. : Farming Press Videos ; New York : Distributed in N. America by Diamond Farm Enterprises, c1995. 1 VHS videocassette (60 min.). ISBN: 0852363095.

Keywords: Pet ferret, care, housing, behavior.

Note: Covers the basics of ferret management and breeding, includes advice on choosing feeding, housing, and handling.

NAL Call No: Videocassette no.2491.

Fish Tales. Innovation \#724 (Television program). WNET (Television station : New York, N.Y.). Washington, DC : Interface Video Systems, Inc. [distributor], c1989. 1 VHS videocassette (ca. 30 min.).

Keywords Aquaculture industry, technological innovations.

Note: Discusses technological advances in aquaculture that are being applied commercially. Originally produced as an episode of the television program Innovation.

NAL Call No: Videocassette no.2495.

Fleas: Biology and Control. Dunn Loring, VA: National Pest Control Association Education Committee and Purdue University of West Lafayette, IN; c1989; 1/2/" VHS, 29 min. Includes a training manual (1983).

Keyword: Fleas, identification, behavior, control, biology, training program.

Note: The biology, identification, and behavior of fleas and the techniques used to control fleas are discussed in this National Pest Control Association (NPCA) audio-visual training program for pest control service technicians. The four steps involved in eliminating a flea infestation are covered: 1) inspection, 2) sanitation, 3) pet treatment, and 4) treatment of the premises. Flea bites and diseases transmitted by fleas are described. This training package includes a video, practical training tips, program presentation recommendations, a pretest and a post test (with answers), and a program script.

NAL Call No.: Videocassette No. 1113.

Foal Management. Lexington, KY: Blood-Horse Productions; c1984; 1/2" VHS, ca. 30 min.

Keyword: Visits to several horse breeding farms afford an insight into the importance of early handling, vaccination and feeding programs, illnesses common to the young horse, and proper hoof care.

NAL Call No.: Videocassette No. 1892. 
Foaling Fundamentals: A Video Handbook for Healthy Foaling. Virginia City, NV: VideoVelocity; c1989; 1/2" VHS, 52 min. Includes a guide book.

Keyword: Foals, birth, postnatal care, mares, reproduction.

Note: Covers care of pregnant mare, foaling equipment and facilities, and all aspects of postnatal care.

NAL Call No.: Videocassette No. 2011.

Foaling Your Mare. Cuba, NY: Hemlock Brook Farm; c1988. 1/2" VHS, 50 min.

Keyword: $\quad$ Mares, foals, reproductive cycle, birth process, normal and abnormal delivery.

Note: The video illustrates the reproductive cycle in the mare from conception to foaling to weaning. See the birth of several foals, including hard deliveries, and learn what to look for in case of trouble and how to help your mare deliver a healthy live foal.

NAL Call No.: Videocassette No. 1939.

Foaling. Lexington, KY: Blood-Horse Productions; c1984, 1/2" VHS, ca. 28 min.

Keyword: Horses, mares, birth management, foaling.

Note: Discusses the preparations for producing a healthy foal and the proper procedures for handling the birth.

NAL Call No.. Videocassette No. 1893

Food Safety and Animal Drugs: Testing, Testing, Testing. Alexandria, VA: Animal Health Institute; c1992; 1/2" VHS, 11 min., $42 \mathrm{sec}$; Includes 1 brochure.

Keyword: Veterinary drugs, United States, veterinary drug residuẹs, food animal products, testing, drug approval process.

Note: Shows the procedures for testing and approving new animal drugs to ensure they will not negatively effect the safety of animal food products.

NAL Call No.: Videocassette No. 1530.

Footcare in Cattle: Hoof Structure and Trimming. R. W. (Roger William) Blowey. Ipswich, U.K.: Farming Press Videos ; Alexandria Bay, N.Y. : Distributed in N. America by Diamond Farm Enterprises, c1992. 1 VHS videocassette (55 min.). ISBN: 0852362471.

Keywords: Dairy cattle, foot care, hoof anatomy.

Note: An explanation of the internal \& external structure of the hoof of cattle and the importance of proper foot care for their health and well-being. Lamness caused by improper hoof care.

NAL Call No: Videocassette no.2493.

Foundation for Biomedical Research PSA: Use of Animals in Medical Research. Foundation for Biomedical Research (Washington, D.C.). C.Everett Koop.Washington, D.C.: Foundation for Biomedical Research, c1990. 1 VHS videocassette (1 min.).

Keywords: Reseach animal issues. Public service announcement.

Note: Former U.S. Surgeon General speaks in behalf of animal use in medical research. Two public service announcements-- 1. "RIIPPP" (30 sec.) -- 2. When I was born $(30 \mathrm{sec}$.).

NAL Call No: Videocassette no.2114.

Fundamentals of Blood Gas Analysis: Collection, Measurement and Interpretation. Davis, CA: University of California at Davis; 1987; 1/2" VHS, 33 min.

Keyword: Veterinary hematology, pulmonary function tests, anesthesia, blood gas analyzer.

Note: This program examines three components of blood gas analysis: sample collection, 
measurement of samples, and interpretation of results. It explains how blood gas analysis can be used to gain information about gas exchange, acid/base balance, and ventilatory status during anesthesia. The film also examines the function and applications of an automatic blood gas analyzer.

NAL Call No: Videocassette No. 408.

Gait...Observing Dogs in Motion. New York, NY: The American Kennel Club; 1986; 1/2" VHS, 37 min.

Keyword: Walking, movement, structure, conformation.

Note: This AKC production analyzes the way in which dogs move, so as to better understand this key element in breeding for the ideal dog of specific species. All dogs don't move alike but their movement is linked to the job for which the species was bred. This was designed as a learning tool for dog trial and show judges.

NAL Call No: Videocassette No. 1352.

Gnotobiotic Pig Production. West Lafayette, IN: Purdue Research Foundation; 1985; 1/2" VHS, 22 min.

Keyword: Germ-free, pigs, disinfection, isolation bubbles, laboratory animal facilities, Cesarean section.

Note: Gnotobiotic pigs are important as research models and disease-free seed stock for commercial producers. This video details the equipment and methods of surgery, transfer, and rearing required for the production of piglets in a germ-free environment.

NAL Call No: Videocassette No. 474.

Gnotobiotics in Production of Experimental Animals. Seattle, WA: University of Washington; 1975; 47 slides, audiocassette, $22 \mathrm{~min}$.

Keyword: Laboratory animals, germ-free animals, instruction.

Note: The development, maintenance, and use of the isolator for production of experimental animals, sterilization of isolators and supplies, and microbiologic monitoring techniques are discussed.

NAL Call No: Slide No. 219.

Goat Breeding and Kid Rearing. Hilary Matthews, Farming Press Videos (Firm). Diamond Farm Enterprises. Ipswich, [England]: Farming Press Videos; Alexandria Bay, N.Y.: Distributed in N. America by Diamond Farm Enterprises, c1995. 1 VHS videocassette (63 min.).ISBN: 0852362862.

Keywords: Goats, reproduction management, breeding.

Note: This video focuses on the management of breeding for the domestic goatkeeper. It covers mating, pregnancy, kidding, and care of young stock. Hilary Matthews demonstrates the techniques that she has successfully used for many years to control the breeding cycle, detect pregnancy accurately, and keep a healthy breeding goat herd.

NAL Call No: Videocassette no.2665.

Gorilla. Washington, DC: National Geographic Society and WQED of

Pittsburgh. Distributed by Vestron Video of Stanford, CT; [1986], c1981; 1/2" VHS, 59 min. ISBN: 0805100040. The cassette is closed captioned for the hearing impaired. Previously issued as motion picture and videorecording in 1981 by National Geographic Society of Washington, DC.

Keyword: Mountain gorillas, endangered species, behavior, interactions with humans.

Note: This program was produced by the Society, WQED/Pittsburgh and Vestron. It was broadcast April 8, 1981 by PBS. The authors are Thomas Skinner, Dennis Kane, Barbara Jampel. It calls attention to the plight of the gorilla, which is on the verge of extinction. 
Profiles a zookeeper, a research scientist, a research psychologist, a writer-photographer, and a husband and wife team working on the mountain gorilla project. Film footage demonstrates the animals' intelligence, humanlike qualities, and the effects of their exploitation by humans.

NAL Call No.: Videocassette No. 1105.

Granby's Primates. New York, NY: Film Makers Library, Inc.; 1983; 1/2" VHS, 28 min.

Keyword: Gorillas, orangutans, chimpanzees, gibbons, zoo animals, behavior, environmental enrichment.

Note: An experiment conducted at the Granby Zoo in Quebec shows how the behavior of captive primates is modified by changes in their environment. Climbing structures are introduced to relieve boredom and to stimulate more naturalistic behaviors.

NAL Call No: Videocassette No. 402.

Ground Handling Horses Safely. University of Nevada, Reno; University of Idaho; Washington State University; University of Idaho, Agricultural Communications Center. Moscow, ID: Ag Communications Center, University of Idaho, c1995. 1 VHS videocassette (18 min.).

Keywords: Handling horses, horse behavior, safety concerns, restraint.

Note: Demonstrates safe and proper methods for approaching, haltering, leading, and tying a horse.

NAL Call No. Videocassette no.2599.

Haltering a Foal without Trauma with T.E.A.M. Educational Horse Videos. Linda Tellington-Jones series Linda Tellington-Jones and Robyn Hood. La Jolla, CA : Lawlor Productions, c1987. 1 videocassette (42 min.).

Keywords: Foals, training, behavior.

Note: T.E.A.M. (Tellington-Jones Equine Awareness Method) solutions are discussed for teaching your foal to halter and lead without the fear and emotional shock of traditional methods.

NAL Call No: Videocassette no.2138.

Handling and Restraining Laboratory Rodents. Seattle, WA: Northwest Committee for Training in Laboratory Animal Care and Health Sciences Center for Educational Resources; 1983; 40 slides, audiocassette, $10 \mathrm{~min}$.

Keyword: Mice, rats, gerbils, hamsters, guinea pigs, restraint, handling, laboratory animals.

Note: Identification, taxonomy, and procedures for safe and effective restraint and handling of common laboratory rodents are presented in this slide set. Both mechanical and hand restraint methods are demonstrated, as are appropriate techniques for transferring animals between cages and from a cage to a restraining device. A manual accompanies the slide set.

NAL Call No: Slide No. 239.

Handling and Restraints of the Canine Patient. Manhattan, KS: Kansas State University, College of Veterinary Medicine; 1986; 1/2" VHS, 42 min.

Keyword: Immobilization, physical restraint, dogs, treatments.

Note: Approach, capture, and restraint techniques are demonstrated. Techniques include proper use of leashes and neck chains, and methods of holding dogs for examination and treatment. 
NAL Call No: Videocassette No. 1317.

Handling and Sexing Some Common Laboratory Animal Species. (Manipulation Et Sexage De Quelques Especes De Laboratoires Communes;) 1996 Canadian Association of Laboratory Animals Science. Winnipeg, Canada. 1997. VHS video cassette (32 Min).

Keyword: handling and sexing, novice technologists barrier vs. conventional housing units.

Note: An introductory video to guide a novice technologist, or a new member to the animal care and use committee, through an animal facility designed to house a variety of research animals. Safe handling and sexing is demonstrated for each species shown, The concept of microbial status is introduced as the technologist enters barrier vs. conventional housing units. This video is especially valuable to those new to the field of laboratory animal care. For more information go to: http://www.calas-acsal.org

NAL Call No: Videocassette No. in process

Handling Hoofed Stock. San Diego, CA: San Diego Zoological Society and Davis, CA: University of California at Davis; 1981; 165 slides, audiocassette, $50 \mathrm{~min}$.

Keyword: Zoo animals, giraffes, deer, rhinoceros, okapis, peccaries, audads, antelopes, handling, restraint, husbandry.

Note: This slide presentation addresses general principles concerning safe the handling of large exotic hoofed stock as well as cleaning, feeding, transporting, and chemical and mechanical restraint are addressed.

NAL Call No: Slide No. 198.

Handling Livestock Naturally. Kansas City, Mo.?: AgriBase, c1989; 1/2" VHS, 15 min.

Keyword: Livestock handling, animal welfare, behavior, transport, feeding and watering in markets, moving animals.

Note: Discusses viewing the world through the animal's eyes when handling them on the farm, for transport and at markets. Covers how to transport with gentleness, understanding of the animal's field of vision, point of balance, flight zone, and blind spot, how to feed and water animals at markets, how to move animals without hitting, yelling, or electric shock, how to deal with medical problems, and caring of facilities to reduce injuries. The program was produced in conjunction with the Livestock Marketing Association.

NAL Call No.. Videocassette No. 1334.

Hands-on Horse Care : An Owners' Guide for Relieving Colic, Illness \& Performance Stress. Diana Thompson. Santa Rosa, CA : Hands-on Animal Care (Firm), c1992. 1 VHS videocassette (51 min.).

Keywords: Horses, health, training, first aid for animals, emergencies.

Note:. This beautifully illustrated video has easy-to-learn accupressure and other touch techniques. Whether you are seven years old or seventy, a first time horse owner or an experienced trainer, the methods demonstrated in this video will work for you and prepare you for horse emergencies.

NAL Call No: Videocassette no.2622.

Hidden Crimes: A Film on Animal Experimentation. Students United Protesting Research on Sentient Subjects. Pasadena, Calif.: Javier Burgos/Supress, c1986. 1 VHS videocassette (78 min.).

Keywords: Animal experimentation, animal welfare, vivisection.

Note: Depicts the hidden world of animal experimentation by showing the mistreatment of research animals. Also included in this documentary is secret footage taken at animal 
research facilities in California and Pennsylvania.

NAL Call No: Videocassette no.1423.

Hope: A Story that Highlights the Critical Importance of Animal Research in Medical Progress through the Eyes of Three Families. Washington, DC: The Foundation for Biomedical Research; 1990;

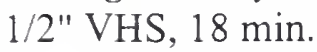

Keyword: Laboratory animals, experimentation, ethics, animal models.

Note: Hope tells the story of three families: one whose child has been saved through modern medical advances; one for whom treatment arrived too late; and one whose life hangs in the balance waiting and hoping for a treatment or cure. This program shows what is at stake in the debate about animal research.

NAL Call No: Videocassette No. 1093.

Horse Training (Intermediate). Edmonton, Albta. : Alberta Agriculture, Food and Rural Development, c1984. 1 VHS videocassette (15 min.).

Keywords: Horses, training methods, intermediate level.

Note: Information from Bill Collins on Intermediate horse training, psychology of the horse and equipment used to improve the performance of a horse.

NAL Call No. Videocassette no.2679.

Horses, Kids and Ethics. Jeff Goodwin, Goodwin Educational Video (Firm). Colorado State University: Instructional Materials Service. College Station, Tex.: Instructional Materials Service, c1997. 1 VHS videocassette (13 min., $56 \mathrm{sec}$.). Includes 1 video facilitator guide.

Keywords: Horses, horse shows, $4 \mathrm{H}$ clubs, moral and ethical issues.

Note: Dr. Jeff Goodwin discusses issues related to $4 \mathrm{H}$ and other youth horse program ethics.

NAL Call No: Videocassette no.2671.

Hot Branding. San Antonio, TX: The International Brangus Breeders Association, c1988. 1 VHS videocassette.

Keywords: Cattle marking, hot and freeze methods.

Note: Deals with both hot iron and freeze branding techniques. Hot branding ( $7 \mathrm{~min} ., 25 \mathrm{sec}$ ); Freeze branding (11 min., $20 \mathrm{sec}$.).

NAL Call No: Videocassette no.2683.

How to Housebreak Your Puppy. Also called: T.N.T.'s Dynamite how to Housebreak Your Puppy (or Dog) Aleithia Bower Artemis. Houston, TX: Top Notch Training, c1994. 1 VHS videocassette (ca. 30 min.).

Keywords: Dogs, obedience training, dog behavior.

Note: Describes the five most common mistakes made in housebreaking a puppy and how to avoid making them.

NAL Call No: Videocassette no.2243.

Human/Pig Behavior. Owatonna, MN : PigWorld, Inc., [199-?]. 1VHS videocassette [Human behavior (4 min., $50 \mathrm{sec}$.); Pig handling facilities \& practices (8 min.)].

Keywords: Human-animal relationships, swine handling, swine behavior.

Note: The characteristcs of pigs should be considered for facilities and handling; Humananimal relationships, swine handling and behavior are discussed. 
NAL Call No: Videocassette no.2601.

Humane Care and Use of Laboratory Animals. Raleigh, NC: Laboratory Animal Training Association; 1988; 1/2" VHS, $32 \mathrm{~min}$.

Keyword: Laboratory animal workers, animal welfare, Public Health Service.

Note: This video examines issues related to humane laboratory animal care and use, including the Animal Welfare Act and other legislation, government guidelines for humane laboratory animal care, ethical viewpoints of animal use, roles and responsibilities of research staff and institutional animal care and use committee members, humane experimentation, alternatives, and information resources. A manual that includes a script, test, and answer key accompanies the videocassette.

NAL Call No: Videocassette No. 338, Vol. 1.

Humane Care and Use of Laboratory Animals for Technicians (Cuidado y Uso Humanitario de Animales de Laboratorio para Tecnicos). Raleigh, NC: Laboratory Animal Training Association; 1991; $1 / 2$ " VHS, 36 min.

Keyword: Animal welfare, training, humane care.

Note: The program is designed to provide Spanish-speaking technicians with information on humane care and use of laboratory animals, in accordance with the regulations of the U.S. Department of Agriculture (USDA) and recommendations of the Public Health Service Guide. Services and information available through NAL's Animal Welfare Information Center is also discussed. An English language written narrative is also provided.

NAL Call No: Videocassette No. 1129.

Humane Educator/Obedience Trainer. Mahwah, NJ: Troll Associates; 1975; 35 mm, audiocassette, 7 $\min$.

Keyword: Pet industry, vocational guidance, juvenile films.

Note: Made for the Humane Society of the United States, this film focuses on careers related to the care and training of animals. Intended for elementary grades.

NAL Call No: Filmstrip No. 200.

Humane Principles and Procedures in Animal Research. Lubbock, TX: Texas Tech University Health Science Center; 1989, U-Matic 3/4" and 1/2" VHS, $30 \mathrm{~min}$.

Keyword: Animal experimentation, Animal Care and Use Committee, pain, animal welfare, legislation, law, humane treatment.

Note: Discusses the new legal requirements affecting the use of animals in research and describes the role of the Animal Care and Use Committee (ACUC) in implementing institutional responsibilities in humane animal treatment. The video addresses the practical aspects of animal use by providing information on animal pain assessment, selection and use of analgesics and anesthetics, pre- and post-operative care, aseptic surgical technique and health protection for individuals working with experimental animals.

NAL Call No: Videocassette No. 804 - U-Matic.

Videocassette No. 805 - 1/2" VHS.

Hunter's TiterMax. Norcoss, GA: CytRx Corporation. 1994?; 1/2" VHS. 7 min., 12 sec.

Keyword: Immunological adjuvants, research adjuvant. 
Note: Shows a new vaccine adjuvant developed by the CyRx Corporation that features maximum antibody production and avoidance of harmful side effects in the host animal.

NAL Call No.: Videocassette No. 2039.

IBBA "How To" Segment: Tattooing; Showtime. San Antonio, Tex. : The International Brangus Breeders Association, [1986?]. 1 VHS videocassette.

Keywords: Cattle showing, tatooing for identification, preparing an animal for the show ring.

Note: Recommended procedures for tattooing an animal (3 min., $45 \mathrm{sec}$.); Preparing an animal for show ( 9 min., $10 \mathrm{sec}$.).

NAL Call No: Videocassette no.2682.

Imprint Training the Foal "Palomine's Blue Ribbon Series". Thousand Oaks, CA: Palomine Productions. Distributed by Miller's of East Rutherford, NJ; c1985, 1/2" VHS, 60 min.

Keyword: Foals, training, imprinting, horse behavior.

Note: Robert Miller covers the training of foals from the time of birth through first months to gentle them, prepare them for future schooling, and to minimize injury to handlers.

NAL Call No.: Videocassette No. 1902.

In Defense of Animals: A Portrait of Peter Singer. Oley, PA: Bullfrog Films; 1989, 1/2" VHS, 28 min. Keyword: Philosophy, biography, animal rights.

Note: An introduction to Peter Singer, his philosophy on animal rights, and his life's work. $\mathrm{He}$ describes the movement and how he got involved.

NAL Call No: Videocassette No. 1080.

In Vitro Research: An Introduction. Elmira, NY: Educational Images; 1989; 20 slides.

Keyword: Rats, brain, tissue culture, biometry.

Note: These slides offer an introduction into in vitro biomedical research. Tissue culture techniques are discussed in the accompanying script, while slides demonstrate their uses.

NAL Call No: Slide No. 397.

Injection Techniques for Swine: Your 4-H Market Hog Project. Pork Quality Assurance Video Series. video \#1. National Pork Producers Council (U.S.); National Pork Board (U.S.). Des Moines, Iowa : The Council, c1996. 1 VHS videocassette (ca. 17 min.) and. 1 booklet $(33$ p. $)+1$ guide $(8$ p.) +1 quiz.

Keywords: Swine, drug delivery, drugs, needles,

Note: Demonstrates proper medicating techniques for swine. Topics covered include needle size, reading and understanding label instructions, and administering different types of medications.

NAL Call No: Videocassette no.2359.

Injection Vaccination of Fish. Biomed, Inc.; Hoylandet Film \& TV Produksjon. Bellevue, WA : Biomed, Inc., [1995?]. 1 VHS videocassette (ca. 24 min.).

Keywords: Fish, disease prevention, vaccines, injection techniques.

Note: Shows fish farmers how injection vaccination can protect fish from infectious diseases. Procedures for injecting fish are demonstrated

NAL Call No: Videocassette no.2164.

Inspection and Labeling Aspects of Genetically Engineered Food Animals. Washington, DC: USDA 
Food Safety and Inspection Service; 1985; 1/2" VHS, 53 min.

Keyword: Farm animals, biotechnology, meat inspection.

Note: Dr. Daniel Jones, USDA Office of Biotechnology, examines some of the legal and regulatory questions of labeling genetically engineered animals that may one day be produced and raised for food.

NAL Call No: Videocassette No. 274.

Inspection for Commensal Rodents. "National Pest Control Association"

(NPCA) rodent control series; 3 rodent control training programs. Dunn Loring, VA: NCPA; 1/2" VHS 15 min. Includes a manual.

Keyword: Rats, mice, rodent control, building inspections, rodent behavior.

Note: This National Pest Control Association Rodent Control Training Program (one of six videos) reviews the steps involved in conducting an inspection for commensal rodents (rats and mice). This video training program is designed to increase the pest control service technician's understanding of inspections, an essential planning process for all pest control programs. The accompanying manual includes practical training tips, program presentation recommendations, a pretest and a post test (with answers), suggested reference materials, and a commensal rodent pictoral identification key.

NAL Call No.: Videocassette No. 1041.

Integrated Pest Management. Chicago, IL: Lincoln Park Zoo; 1990; 1/2" VHS, 20 min.

Keyword: Pest control, zoos, disease, management.

Note: Describes how the Lincoln Park Zoo developed and manages its pest management program. The goa! of this program is to control the pests, because irradiation is an unrealistic goal. Communication, cooperation, and vigilance makes this program successful.

NAL Call No: Videocassette No. 1560.

Intercultural Views of Animals. Minneapolis, MN: University of Minnesota; 1986; 1/2" VHS, 45 min.

Keyword: Cultural values, animals, religion, ethics.

Note: Four guests from different socio-religious cultures (Hindu, Moslem, East African, and Buddhist) discuss various aspects of the human-animal relationship relative to their cultural habits, beliefs, and social conventions. There views are compared with American views on the subject.

NAL Call No: Videocassette No. 322.

Introduction of Foreign Genes into Livestock. Washington, DC: USDA Food Safety and Inspection Service; 1986; 1/2" VHS, $53 \mathrm{~min}$.

Keyword: Biotechnology, farm animals, sheep, pigs, nutrition.

Note: Dr. Robert Wall, USDA-ARS Reproduction Physiology Laboratory, discusses the introduction of foreign genes into sheep and pigs to increase feed efficiency.

NAL Call No: Videocassette No. 265.

Introduction to Chimpanzee Behavior. Washington, DC: National Geographic Society; 1977; 1/2" VHS, $23 \mathrm{~min}$.

Keyword: Feeding behavior, toolmaking, daily activities, communication, group and family behavior.

Note: The National Geographic Society presents an overview of Dr. Jane Goodall's long-term 
research on the wild chimpanzee's behavior in Tanzania's Gombe National Park. Following the daily routines of a number of chimpanzees, the viewer will be able to observe the animals feeding, making tools, playing, grooming, courting, and communicating with each other.

NAL Call No: Videocassette No. 1158.

Introduction to Rotational Grazing. North Star Productions; Lafayette County Rotational Graziers; Lafayette County AG Extension. [S.1. : North Star Productions?, 199-?] 1 VHS videocassette (26 min).

Keywords: Dairy farming, grass dairying, Wisconsin.

Note: Shows Wisconsin dairy farmers using a modernized version of an old age practice called intensive rotational grazing.

NAL Call No: Videocassette no.1449.

Investigational New Animal Drug. Thomas A. Bell, Hugh Mitchell with the INAD Workshop (1993: Boston, Mass.); Center for Veterinary Medicine (U.S.); Northeastern Regional Aquaculture Center (U.S.); National Aquaculture Association. [North Dartmouth, Mass.]: Northeastern Regional Aquaculture Center, [1993?] 1 VHS videocassette (4 hr., 42 min.).

Keywords: Veterinary drugs testing, U S, aquatic animals, diseases, chemotherapy, congresses.

Note: Thomas Bell of the Food and Drug Administration discusses procedures that must be followed when an exemption is given by the FDA to allow use of a drug on aquatic animals prior to the normal pre-approval requirement. Hugh Mitchell follows with a discussion of the exemption from the drug industry perspective. Workshop jointly sponsored by the Food and Drug Admnistration, National Aquaculture Association and the Northeast Regional Aquaculture Center.

NAL Call No: Videocassette no.2109.

Jane Goodall: A Life in the Wild. Burlington, NC: Cabisco Teleproductions, Carolina Biological Supply Company; 1990; 1/2" VHS, 30 min.

Keyword: Biography, chimpanzees, Tanzania, wildlife.

Note: A documentary on the life and work of Jane Goodall. Dr. Goodall explains how and why she moved to Africa and undertook the study of chimpanzee behavior. She recalls dayto-day events in Gombe National Park and discusses some of her discoveries about chimpanzee behavior. She also emphasizes her efforts to save the chimpanzee from exploitation.

NAL Call No: Videocassette No. 1305.

Joint Manufacturing for Iinvestigational and Licensed Biologics. BioEast'91 ; 9112 . Potomac, MD: BioConferences International, c1991. 1VHS videocassette (135 min.).

Keywords: United States Food and Drug Administration, licenses, biotechnology congresses, biologicals, contracting out licenses.

Note: Panel discussion on FDA and industry perspectives of how FDA will regulate contractual relationships between research biotechnoloyg companies and manufacturers. The biotechnology company may be liable for the final product, even if it does not manufacture it. Also discusses how FDA intends to develop a manufacturing of biologicals regulatory policy document. This is a Videorecording of session at BioEast'91 held in Washington, DC, Jan 6-9, 1991, sponsored by BioConferences International, Inc., Genetic Engineering News, IBE X; co-sponsored by the Pennsylvania State University Biotechnology and Bioprocessing Resource Center. 
NAL Call No: Videocassette no. 1142.

Keeping Ducks: Beautiful Comical Things. Tom Bartlett. Ipswich, U.K. : Farming Press Videos ; Alexandria Bay, N.Y.: Distributed in America by Diamond Farm Enterprises, c1996. 1 VHS videocassette (ca. 48 min.).

Keywords: Ducks, husbandry, breeding, rearing, livestock shows.

Note: Tom Bartlett explains his own methods of feeding, housing, breeding, and generally caring for ducks on the farm and at show.

NAL Call No: Videocassette no.2520.

Keeping Nature in Balance. Jay Novacek. National Cattlemen's Association (U.S.); Non-Stop Productions. Engelwood, CO: National Cattlemen's Association, c1994. 1 VHS videocassette (28 min.). Keywords: Conservation, natural resources, rangeland, beef cattle.

Note: This documentary features seven award-winning cattlemen and the steps their families are taking to ensure the land is productive for this and future generations.

NAL Call No: Videocassette no.2319.

Killing the Crisis, not the Animals. Vacavill, CA: Association of Veterinarians for Animal Rights and the International Society for Animal Rights; 1991?; 1/2" VHS Keyword: Conference on animal welfare, animal cruelty, pet overpopulation.

Note: Speakers discuss various aspects of animal welfare such as animal sterilization, animal overpopulation, and ways to combat cruelty to animals. There are 8 videocassette in the set.

NAL Call No.: Videocassette No. 1450.

Kiss the Animals Goodbye. Santa Monica, CA: Pyramid Film and Video; 1984; 1/2" VHS, 20 min. Keyword: Euthanasia, adoption, animal shelters, population control.

Note: A discussion of issues concerning animal population control, including euthanasia and adoption. The intended audience is junior high school students through adults.

NAL Call No: Videocassette No. 196.

Knowledge Now in Experimental Biology: The Model Organisms Series Sampler. [S.1.] Cogito Learning Media, c1996. 1 VHS videocassette (9 min.).

Keywords: Examples of animal models, mice, dorsophila, phage, yeast, Arabidopsis.

Note: Offers sample footage from each program in a six-videotape series: "The Mouse as a Model Organism;" "Drosophila as a Model Organism;" "Arabidopsis as a Model Organism;" "A Nematode as a Model Organism;" "Phage Lambda as a Model Organism;" "Yeast as a Model Organism."

NAL Call No: Videocassette no.2499.

Konrad Lorenz: Science of Animal Behavior "Animal behavior series." Washington, D.C.: National Geographic Society; 1986?; 1/2" VHS, 14 min. Includes 2 identical teacher's guides.

Keyword: Konrad Lorenz, animal behavior, animal intelligence, imprinting, social order.

Note: Examines the work of behaviorist, Konrad Lorenz, who holds that behavior is determined by a basic genetic blueprint that is modified by experience and innate knowledge.

Imprinting and a study of rank and social order are also examined by various observations of various types of animal. 
NAL Call No.: Videocassette No. 1162.

Laboratory Animal Medicine: What It is and How It Relates to Veterinary Medicine. Seattle, WA: University of Washington; 1975; 61 slides, audiocassette, $25 \mathrm{~min}$.

Keyword: Laboratory animals, veterinary medicine.

Note: This program is designed to stimulate interest in laboratory animal medicine and science. It provides the basis for further study and training for those students who choose to pursue a career in experimental animal medicine.

NAL Call No: Slide No. 217.

\section{Laboratory Animal Technician Training Course: Part 16, Veterinary Pharmacology,} Anesthesiology and Euthanasia. Cordoba, TN: American Association for Laboratory Animal Science; 1980, 1/2" VHS, 3 videocassettes, $180 \mathrm{~min}$.

Keyword: Animal welfare, laboratory animals, study, teaching, veterinary techniques.

Note: This program provides laboratory animal technicians with basic training in the areas of pharmacology, anesthesia, and euthanasia. Techniques and procedures are discussed.

NAL Call No: Videocassette No. 797, Parts 1-3.

Laboratory Animals: Toxicology and the Public. Closter, NJ: Production Plus, Inc., 1990?; 1/2" VHS, 46 min. Videotaped at the Symposium: "Animal Welfare Compliance for Study Directors;" presented at the Eleventh Annual Meeting of the American College of Toxicology, Orlando, Fla., Oct. 1990.

Keyword: Animal models, research, congresses, laboratory animals, product testing,

Note: The factual information regarding numbers of animals used, repetitive testing, source of animals and predictability of animal testing are presented to assist scientists who must respond to criticism of animal testing. A history of toxicology testing and a review of public opinion on animal research and testing is provided. The author is Shayne C. Gad.

NAL Call No.: Videocassette No. 974.

Laboratory Dogs. New York, NY: Animal Welfare Institute of New York; 1966; 1/2" VHS, 16 min.

Keyword: Biomedical research, veterinary medicine, handling, laboratory facilities.

Note: "Laboratory Dogs" is a videorecorded copy of a circa 1950 black and white film outlining laboratory dog management techniques. Methods of maintaining a canine research facility and ensuring healthy, manageable dogs are presented.

NAL Call No: Videocassette No. 543.

Lamb Evaluation: Ewe Evaluation. Ames, IA, CA: Iowa State University. Cooperative Extension Service. Distributed by : RMI Media Productions of Shawnee Mission, KS; 198-?; 1/2" VHS, 27 min.

Keyword: Sheep, lambs, ewes, visual and tactile evaluation, marketing.

Note: How to evaluate market lambs using hands and eyes. How to judge breeding ewes.

NAL Call No.: Videocassette No. 1350.

Lamb Survival. Ipswich; Farming Press Videos; Alexandria Bay, NY.

Distributed in N. America by Diamond Farm Enterprises; c1993, 1/2" VHS, 84 min.

Keyword: Lambs, post natal care.

Note: David Henderson presents techniques to help lambs survive their first few days of life.

NAL Call No.: Videocassette No. 1937.

Leakey. Washington, DC: National Geographic Society; 1983; 1/2" VHS, 22 min. 
Keyword: Anthropologist, biography, origin of man, discovery.

Note: The film documents Louis Seymour Leakey's important discoveries about human origins, and shows how paleoanthropologists work. This video comes with a teacher's guide.

NAL Call No: Videocassette No. 1153.

Licensing Veterinary Biologics: Traditional \& Recombinant Vaccines. Bethesda, MD: BioConferences International; c1992; 1/2" VHS, 60 min.

Keyword: Veterinary biologicals, licenses, regulatory policies, USDA, Animal and Plant Health Inspection Service, conference session.

Note: Two speakers from the Animal and Plant Health Inspection Service of the U.S. Dept. of Agriculture discuss federal regulatory policies for field trials and licensing requirements for veterinary biologics. This is a videorecording of a session at BioEast ' 92 held in Washington, DC. The session was sponsored by Genetic Engineering News, IBEX, and BioConferences International, Inc.

NAL Call No.: Videocassette No. 1975.

Licensing Veterinary in vitro Diagnostic Kits]. Potomac, MD: BioConferences International; c1992;

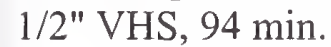

Keyword: Veterinary biologicals, licenses, diagnostic reagents, test kits, policies.

Note: Licensing requirements for veterinary in vitro diagnostic test kits are discussed. The videorecording is of a session of the BioEast ' 92 held in Washington, D.C. The program was sponsored by Genetic Engineering News, IBEX, and BioConferences International, Inc.

NAL Call No.: Videocassette No. 1976.

Life Force: Animal Welfare. Ames, IA: Iowa State University Extension Service; 1982; 3/4" U-Matic, $27 \mathrm{~min}$.

Keyword: Ethics, animal welfare, veterinarians.

Note: Through filmed interviews, Dr. John Herrick of the Iowa State Extension Service, Dr. Michael Fox of the Humane Society of the United States, and two practicing veterinarians express their views on the animal welfare movement and professional ethics.

NAL Call No: Videocassette No. 345.

Line in the Sand. Jeff Goodwin. College Station, Tex. : Instructional Materials Service, c1996. 1 VHS videocassette (16 min.). Includes 1 video/activity guide (14 p.). "Catalog \#9640" is printed on the container.

Keywords: Livestock showing, moral and ethical aspects.

Note: Addresses the ethical aspects of parctices involved in showing of livestock at agricultural fairs.

NAL Call No. Videocassette no.2669.

Livestock in Transit - Handle with Care. Potters Bar, Herts, England: Humane Slaughter Association; 1989; 1/2" VHS, 27 min.

Keyword: Transportation, humane slaughter, animal welfare.

Note: This production discusses and demonstrates humane and safe methods for loading, transporting, and unloading livestock.

NAL Call No: Videocassette No. 1306. 
Llama Training with Bobra Goldsmith: What Every Llama Should Know. Ashland, OR: Juniper Ridge Press; 1986; 1/2" VHS, 114 min.

Keyword: Animal training, care, maintenance, handling.

Note: Bobra Goldsmith narrates and demonstrates techniques for the training of llamas. These techniques are taught in order to allow proper and stress-free handling, care, and management of your llama.

NAL Call No: Videocassette No. 1358.

Man's Best Friends. New York, NY: Cinema Guild; 1985; 1/2" VHS, 60 min.

Keyword: Medical research, product safety, alternatives, regulation, PETA, NIH, USDA, FDA, ASPCA, animal welfare, ethics, laboratory animals.

Note: This taped PBS television program provides comprehensive, balanced coverage of the controversy surrounding the use of animals for research and testing. Dr. Edward Taub (NIH/IBR), Alex Pacheco (PETA), Dr. Michael Fox (HSUS), Dr. Lester Crawford (FDA), DR. A.K. Ommaya (George Washington University) and others comment on the ethical questions that are involved in medical, scientific, commercial and military animal experimentation. Topics include benefits of animal research, Draize and LD50 tests, the laboratory animal industry, use of pound animals for research, animal dealers, animal auctions, and legislation.

NAL Call No: Videocassette No. 182.

Management Practices for Beef cattle. II. Beef Production Video Series. Tape \#209. Lubbock, Tex.: Creative Educational Video Inc., c1985. 1 VHS videocassette (46 min.).

Keywords: Beef cattle, castration, parasites, insemination, palpation.

Note: Covers surgical and nonsurgical castration procedures, methods, restraining and benefits plus internal and external parasites, artificial insemination and palpation.

NAL Call No: Videocassette no.2583.

Management Practices for Beef Cattle. I. Tape \#208 Lubbock, Tex.: Creative Educational Video, [1985?] 1 VHS videocassette ( $25 \mathrm{~min}$.).

Keywords: Beef cattle, production methods.

Note: Covers handling, restraint facilities, identification, injection techniques, growth stimulant implants and dehorning.

NAL Call No: Videocassette no.2582.

Managing Giants. Chicago, IL: Lincoln Park Zoo; 1988; 1/2" VHS, 30 min.

Keyword: Elephants, care, handling, safety.

Note: Keeper and animal safety are emphasized in the Lincoln Park Zoo's "Elephant Management Program." Training required for both animals and keepers is described.

NAL Call No: Videocassette No.1561.

Manipulation of Mouse Embryos. Tokyo, Japan: Central Institute for Experimental Animals; 1989; 1/2" VHS, 12 min.

Keyword: Rats, mice, biotechnology, animal models, genetics, fertilization, DNA, chimeras.

Note: This film surveys various techniques for genetically manipulating laboratory rodents. Enucleation, DNA injection into ova, in vitro fertilization, embryo implantation, and the development of aggregation chimeras are among the procedures demonstrated. Invasion of sperm into an ovum, cell development in vitro, and the effects of rat growth hormone 
on mice are also described and illustrated. The narrator suggests that these techniques will one day lead to the development of new animal models for human diseases.

NAL Call No: Videocassette No. 438.

Marine Mammals Handling and Restraint. San Diego, CA: San Diego Zoological Society and Davis, CA: University of California at Davis; 1981; 73 slides, audiocassette, 17 min.

Keyword: Whales, dolphins, seals, sea lions, restraint, biomedical techniques.

Note: This program demonstrates techniques for the safe handling and restraint of cetaceans, pinnipeds, and sirens in order to perform common veterinary procedures. Surgery, physiological monitoring, blood collection, free feeding, and techniques for administering medicines are covered. A manual accompanies the slide set.

NAL Call No: Slide No. 193.

Marsupial Care and Handling. San Diego, CA: San Diego Zoological Society and Davis, CA: University of California at Davis; 1981; 54 slides, audiocassette, $12 \mathrm{~min}$.

Keyword: Kangaroos, koalas, opossums, wallabies, zoo animals, restraint, handling.

Note: This training program illustrates principles of handling and restraining various species of marsupials.

NAL Call No: Slide No. 192.

Mechanical Control. "National Pest Control Association (NPCA) rodent control Series;" 4. Dunn Loring, VA: NPCA, c1990; 1/2" VHS, 12 min. Includes 1 manual (16 leaves).

Keyword: Rodents, control, animal traps, pest control, training.

Note: This National Pest Control Association Rodent Control Training Program (one of six videos) discusses mechanical control (trapping methods to help eliminate rodent infestations) and the types of traps available: glue traps or glueboards, repeating or automatic traps and snap traps. The accompanying manual includes practical training tips, program presentation recommendations, a pretest and a post test (with answers), suggested reference materials, and a commensal rodent pictorial identification key.

NAL Call No.: Videocassette No. 1042.

Medication Handling and Storage. Pork Quality Assurance Video Series. Video \#2. Dick Juhl. National Pork Producers Council (U.S.). National Pork Board (U.S.). Des Moines, Iowa : The Council, c1996. IVHS videocassette (ca. 15 min.) and 1 manual (5 p.) +1 quiz.

Keywords: Veterinary drugs, storage, safe handling measures.

Note: Dick Juhl discusses the proper storage and handling of medications. Topics covered include recording methods, managing medications, usage, and transporting medications.

NAL Call No: Videocassette no.2331.

Metro Washington Park Zoo: Environmental Enrichment Program. Portland, OR: Metro Washington Park Zoo; 1992; 1/2" VHS, 15 min., $30 \mathrm{sec}$.

Keyword: Metro Washington Park Zoo, captive animals, animal behavior, environmental enrichment.

Note: The goal of environmental enrichment programs is to enhance the well being of zoo animals. This video shows how the Metro Washington Park Zoo introduces experiences to the animals that are functionally similar to those they would encounter in their natural habitat.

NAL Call No.: Videocassette No. 1532. 
Milking Methods. IV-123. Dept. of Agricultural Information. Moscow, Idaho: Ag Communications Center, University of Idaho, c1981. 1 VHS videocassette (8 min., $25 \mathrm{sec}$.).

Keywords: Milking, dairy cattle, production methods, handling.

Note: Discusses proper milking methods, hazards of poor milking methods, handling and treatment of cows, equipment care and sanitation, cow preparation for milking, physiology of milking and after care of teats.

NAL Call No: Videocassette no.2597.

Miss Goodall and the Wild Chimpanzees. Washington, DC: National Geographic Society; [198-?]; 1/2" VHS, $52 \mathrm{~min}$. First released as $16 \mathrm{~mm}$ films, c1965.

Keyword: Jane Goodall, chimpanzees, zoologists, Tanzania.

Note: Documents the experiences of British zoologist Jane Goodall, who spent five years studying chimpanzees in Tanzania's Gombe Stream Preserve. Discusses her belief that thorough understanding of chimpanzee behavior will lead man toward clearer understanding of himself.

NAL Call No.: Videocassette No. 1156.

Modern Veal Production: A Mixture of Technology and the Family Farm. American Veal Association: Freemont, WI; 1987; 1/2" VHS, 9 min.

Keyword: Farm animals, housing, transportation, nutrition, anemia, husbandry, cattle.

Note: This video is part of a marketing effort to educate laymen about how farmers utilize modern technology and proper management practices to raise veal calves. Special fed veal calves are shown in individual pens that reduce stress, decrease health risks, and increase feed efficiency. The video examines nutrition and health maintenance programs and addresses concerns over anemia in calves.

NAL Call No: Videocassette No. 481.

Molecular Modeling for Biological Systems]. Washington, D.C: The American Chemical Society; c.1990. Presented by San Diego Supercomputer Center, San Diego State University and American Chemical Society; 1/2 " VHS, 240 min. (Includes a reference manual.)

Keyword: Molecular biology, molecular structure, mathematical models, data processing.

Note: This is a set of four cassettes pertaining to molecular modeling for biological systems. Part 1 shows mathematical models in molecular biology. Part 2 addresses data processing in molecular biology. Part 3 addresses mathematical models in molecular structure. Part 4 illustrates mata processing in molecular structure. It is not intended for a non-technical audience. The program was filmed at an ACS Satellite Television Seminar held January 24, 1990.

NAL Call No.: Videocassette No. 1592.

Monkey Island. New York: WNET: Distributed by Time-Life Video of Alexandria, VA; c1991; 1/2" VHS, $60 \mathrm{~min}$. Closed-captioned for the hearing impaired.

Keyword: Rhesus monkeys, primate behavior, Cayo Santiago, Puerto Rico.

Note: Shows the behavioral repertoire of a community of rhesus monkeys on the island of Cayo Santiago in Puerto Rico. Originally broadcast on the PBS television program entitled Nature. George Page is the narrator.

NAL Call No..: Videocassette No. 1970.

Monkeys, Apes, and Man. Washington, DC: National Geographic Society with Wolper Productions; 
1971?; 1/2" VHS, 52 min. ("A National Geographic Society special." "No. 51149")

Keyword: Primates, humans, evolution.

Note: Points out that man is learning that the similarity between monkeys and himself is not superficial. Explains that man is a primate, bound in evolution to monkeys and apes.

NAL Call No.: Videocassette No. 1161.

MoorComfort Gestation System. Quincy, IL: MoorMan's Livestock Equipment Division; [1990]; 1/2" VHS.

Keyword: Housing, production systems, evaluation, gestation, sows.

Note: Discusses a new system of gestation housing that preserves the advantages of individual living places while permitting the sow much more freedom of movement than traditional gestation stall systems.

NAL Call No.: Videocassette No. 2041.

Mustang: Managing a Misfit. San Francisco? US Forest Service. Forest Service Range Management. Pacific Southwest Region. National Audiovisual Center; Distributed by National Audiovisual Center Capitol Heights; c1980; 1/2" VHS, $27 \mathrm{~min} .22 \mathrm{sec}$. (Originally issued as a motion picture in the 1970's by the U.S. Dept. of Agriculture, Dept. of Range Management, Pacific Southwest Region. "A18899.VNB1.")

Keyword: US Bureau of Land Management, Adopt A Horse or Burro program, wild horses, control, mustangs, laws, Modoc Nat'l Forest, California.

Note: Discusses the problems of wild horse overpopulation in the Modoc National Forest and describes the Bureau of Land Management's Adopt-a-Horse program, set up to deal with this problem.

NAL Call No.: Videocassette No. 1738.

Mystery of Animal Behavior. Washington, DC: National Geographic Society and Metromedia Producers Corporation; 1969; 1/2" VHS, $52 \mathrm{~min}$.

Keyword: Early behavior, research, Sealman

Note: A documentary of Hintz Sealman's work in the field of animal behavior. The video explores the world of animal behavior, from fish and sea otters to bears and baboons, and provides an extensive overview of the early research into animal behavior.

NAL Call No: Videocassette No. 1160.

National Anti-Vivisection Society Public Service Announcements. Chicago, IL: National AntiVivisection Society; Video Production Associates is the distributor; 1989; 1/2" VHS, 14 min. $33 \mathrm{sec}$.

Keyword: Animal welfare, personal care, cosmetics, public service announcements.

Note: Presents a series of public service announcements asking the consumer to only buy cosmetics from companies that don't perform laboratory animal testing or use animal ingredients.

NAL Call No.: Videocassette No. 2045.

Neuromuscular Blocking Agents. Davis, CA: University of California at Davis; 1980; U-Matic 3/4", 52 $\min$.

Keyword: Birds, cats, muscle relaxants, drugs, curare, suxamethonium, veterinary training. Note: This film examines the mode of action of various neuromuscular blocking agents by demonstrating their effects on the cat and chicken.

NAL Call No: Videocassette No. 221.

New Creation - Genetic Engineering Biotechnology: Ethical (Animal Welfare), Economic and 
Environmental Concerns. Humane Society of the United States; Video on Location (Firm) Rockville, Md. : Video on Location [distributor, 1993?]. 1 VHS videocassette (25 min.) and 1 article ([5] p.).

Keywords: Animals, genetic engineering, environmental concerns, moral and ethical issues.

Note: Discusses the ethical, environmental and animal welfare implications of genetic engineering.

NAL Call No: Videocassette no.2177.

New Rangeland Compact. Payson, Ariz.: Holistic Resource Mangement, [1994?]. 1 VHS videocassette (20 min.).

Keywords: Grasslands, grazing domestic livestock, rangelands, Western U.S.

Note: Promotes a holistic management plan of domestic livestock grazing on public lands. Shows how proper grazing procedures benefit grassland and riparian areas.

NAL Call No: Videocassette no.2197.

Non-human Primates: Basic Needs, Handling and Care. Jan Southers. American College of Toxicology. Meeting (11 th : 1990 : Orlando, Fla.). Symposium: Animal Welfare Compliance for Study Directors (1990 : Orlando, Fla.). Closter, N.J.: Production Plus, Inc., [1990?]. 1 VHS videocassette (34 min., $43 \mathrm{sec}$.).

Keywords: Conference, laboratory animals, primates, care, handling, disease control.

Note: The physical facilities, environment, caging, sanitization, watering, feeding vermin control, identification of non-human primates. Emphasis is given to preventive medicine, and safety. This is a videotape of a presentation at Symposium: Animal Welfare Compliance for Study Directors; presented at the Eleventh Annual Meeting of the American College of Toxicology, Orlando, Fla., Oct. 1990.

NAL Call No: Videocassette no.973.

Nonhuman Primates. Seattle, WA: University of Washington; 1975; 392 slides, 6 audiocassettes, 145 $\min$.

Keyword: Laboratory animals, primates, veterinary training.

Note: Prepared by laboratory animal specialists, this six-part program is intended to educate third year veterinary students on the characteristics, uses, and care of a variety of laboratory primates. Part 1: Introduction and Taxonomy (62 slides, 25 min.); Part 2: Biology and Use (66 slides, 30 min.); Part 3: Husbandry and Breeding (79 slides, 25 min.); Part 4: Viral Diseases (53 slides, 20 min); Part 5: Bacterial Diseases ( 72 slides, 25 min.); and Part 6: Parasitic and Noninfectious Diseases (62 slides, 20 min.). A study guide accompanies each of the slide sets.

NAL Call No: Slide No. 220.

Normal and Abnormal Behavior in Domestic Livestock Used for Research. Beltsville, MD: Animal Welfare Information Center, National Agricultural Library; West Lafayette, IN: Purdue University, 1993?; 1/2" VHS, 41 min., 41 sec. includes 1 script.

Keyword: Livestock behavior, laboratory animals, cattle, horses, pigs, stereotypic behaviors.

Note: Examines normal and abnormal behavior in livestock used for research, helping the viewer distinguish between apparently pointless behavior and the possibility of physiological reasons behind behavior such as parasites, injury, genetic problems, or nutritional deficiency."Funding for this video was provided through a US Department of Agriculture, National Agricultural Library, Animal Welfare Information Center cooperative grant with Purdue University." 
NAL Call No.: Videocassette No. 1542.

Northwest Sheep Growers: Benefitting Man and the World He Lives In. Allied Video; American Sheep Industry Association. Productions [Englewood, Colo.?] : American Sheep Industry Association, [1996?]. 1 VHS videocassette (10 min.).

Keywords: Sheep, forest conservation, wildlife habitat improvemen, range management.

Note: Discusses how sheep can improve forest and wildlife habitats. Benefits of grazing sheep include natural fertilization, removing brush from hillsides, and providing effective weed control.

NAL Call No: Videocassette no.2586.

Nuisance Wild life Trapping. Harrisburg, PA: Pest Wildlife Removal Services; c1990; 1/2" VHS, 43 $\min$.

Keyword: Wildlife pests, control, training.

Note: Demonstrates how a professional wildlife removal specialist checks for the presence of wildlife pests and how he removes them from customers' homes. The author is Joseph Uram.

NAL Call No.: Videocassette No. 1014.

Nutrition and Feeding Methods for Laboratory Animals. Seattle, WA: University of Washington; 1983; 58 slides, audiocassette, $25 \mathrm{~min}$.

Keyword: Guinea pigs, rabbits, dogs, cats, nutritional requirements, laboratory animals.

Note: This program examines the nutritional requirements of rodents, guinea pigs, rabbits, dogs, and cats. Feeding behaviors, typical feeding methods, and risks associated with improper feeding are discussed. A guide accompanies the slide set.

NAL Call No: Slide No. 216.

Ocean Ranching. Deborah Mercy. Cordova, Alaska : Prince William Sound Aquaculture Corp. ; Anchorage, Alaska : University of Alaska, Sea Grant Marine Advisory Program, c1990. 1VHS videocassette (29 min.).

Keywords: Fish hatcheries, Alaska, history, Pacific salmon.

Note: Portrays the history of Alaska's hatchery program and describes the year-round procedures of present-day operations.

NAL Call No. Videocassette no.1090.

Open Heart Valve Replacement in the Dog. East Lansing, MI: Instructional Media Center, Michigan State University; c1973; 1/2/" VHS; 18 min.

Keyword: Dogs, surgery, heart valve prosthesis, veterinary care.

Note: Demonstrates the surgical procedure for valve replacement in open heart surgery in the dog. This video is general in scope and detail.

NAL Call No.: Videocassette No. 1727.

Orangutans of the Rain Forest. Jackson Hole, WY: Wolfgang Bayer Productions, Inc.; c1989; 1/2 " VHS, 53 min..

Keyword: Orangutans, endangered species, behavior, Borneo.

Note: The video examines the problems facing orangutans, an endangered species. It does so in an entertaining, informative manner, showing you a view of the orangutan never seen 
before. The video is part of the Best of Nature Series and is narrated by Don Wescott.

NAL Call No.: Videocassette No. 1717.

Orientation to Small Animal ICU. Davis, CA: University of California at Davis; 1977; U-Matic 3/4", 2 min.

Keyword: Intensive care unit, veterinary equipment, veterinary training.

Note: This training film offers a brief introduction to the operation, maintenance, and trouble shooting of five pieces of veterinary ICU equipment: oxygen therapy unit, DC defibrillator, IVAC constant fluid infusion pump, ultrasonic nebulizer, and the wall mounted anesthetic machine and ventilator.

NAL Call No: Videocassette Nos. 213 and 224.

Ostrich Processing. American Ostrich Research Foundation; Texas A \& M University. [United States: s.n., 1996?]. 1 VHS videocassette (50 min.).

Keywords: Ostriches, slaughtering, slaughter houses.

Note: Shows commerical slaughter and meat fabrication techniques developed through researc at Texas A\&M University.

NAL Call No: Videocassette no.2532.

Ostriches and Emus: And on this Farm; \#7. Bobbie Floyd and Kenny Page. Athens, Ga. : Georgia Center for Continuing Education, University of Georgia. College of Veterinary Medicine. c1994. 1 VHS videocassette (30 min.).

Keywords: Ostriches, emus, ratites, farming, rearing techniques.

Note: Veterinarian Dr. Kenny Page describes ratites as flightless birds, explains reasons for increased interest in them, and answers questions and gives advice about raising ostriche and emus. Part of a series of programs showing various species of animals found on a farm and intended to give a sense of appreciation for livestock and how it affects and enriches our lives.

NAL Call No: Videocassette no.2684.

Our Side of the Fence. Englewood, CO: National Cattleman's Association; March 1989; 1/2" VHS, 9 min.

Keyword: Animal agriculture, Massachusetts referendum, animal activists, animal welfare, livestock, beef cattle industry.

Note: Discusses the Massachusetts Referendum of November 1988. Looks at the campaign strategies of animal activists. Promotes unification of agricultural groups to defeat the referendum. Discusses the importance of communicating with and educating the public on animal agriculture.

NAL Call No: Videocassette No. 791

Ovariohysterectomy of the Rabbit. Neutering of the Rabbit. College Station, TX: Biomedical Learning Resources Center; c1990; 1/2" VHS, 10 min.

Keyword: Rabbits, females, surgical procedure, neutering, veterinary procedure, techniques.

Note: Demonstrates the surgical procedure for an ovario-hysterectomy of the rabbit.

NAL Call No.. Videocassette No. 1793.

Parasites of the Horse. Texas Veterinary Medical Center. College Station, Tex.: Media Resources, 
[199-?] 1 VHS videocassette (38 min.).

Keywords: Horses, parasites, treatments.

Note: Describes the kinds of parasites that are often found on a hoses, symptoms, and standard trestments.

NAL Call No: Videocassette no.2672.

Partners in Progress: Growing \& Testing for Healthy Poultry. University of Delaware. University Media Service;.University of Maryland, College Park; University of Maryland Cooperative Extension Service; University of Delaware Cooperative Extension Service. [Maryland?] : Cooperative Extension Service, University of Maryland at College Park : Cooperative Extension Service, University of Maryland Eastern Shore : Cooperative Extension Service, University of Delaware ; College Park, Md. : Distance Education \& Outreach Communications, College of Agriculture, University of Maryland [distributor], c1995. 1 VHS videocassette (25 min., $21 \mathrm{sec}$.).

Keywords: Poultry, health, Delmarva Peninsula, salmonellosis, poultry industry.

Note: Demonstrates salmonella sampling and testing procedures utilized in a recent food quality improvement project on the Delmarva Peninsula.

NAL Call No: Videocassette no.2604.

Partners with Nature. Teddy Gentry. National Cattlemen's Association (U.S.). Englewood, CO: National Cattlemen's Association and Beef Board, [199-?]. 1 VHS videocassette (27 min.).

Keywords: Ranches, agricultural conservation, cattle trade.

Note: Features seven cattlemen who have incorporated sound conservation practices into their successful cattle businesses.

NAL Call No: Videocassette no.2318.

PAWS. Tucson, Ariz.: University of Arizona. Office of Public Information. Video Communications; c1990; 1/2" VHS, 14 min.

Keyword: Animal research, proper research, case study.

Note: Discusses reasons that animals are used in research, proper research procedures, and some of the objections to the use of animals in research. Shows a successful case study of continued life due to animal research.

NAL Call No.: Videocassette No. 1718.

Pfiesteria and the Factory Farm. Humane Society of the United States. Washington, DC: The Society, c1998. 1 VHS videocassette ( 7 min., $30 \mathrm{sec}$.).

Keywords: Poultry manure, environmental aspects, Chesapeake Bay, Maryland and Virginia, animal waste disposal, Pfiesteria, pollutants.

Note: Discusses how the disposal of animal wastes, particularly poultry manure, contributes to outbreaks of pfiesteria in the Chesapeake Bay.

NAL Call No: Videocassette no. 2739.

Pinniped Identification. San Diego, CA: San Diego Zoological Society and University of California at Davis; 1983; 32 slides, audiocassette, 20 min.

Keyword: Pinnipedia, seals, sea lions, identification, behavior, zoo animals.

Note: To assist in their identification, the physical and behavioral characteristics of various species of pinnipeds are described and illustrated. A guide accompanies the slides.

NAL Call No: Slide No. 199. 
Plan for Survival (Lincoln Park Zoo). [Chicago] : The Zoo, c1988. 1 VHS videocassette (ca. 11 min.).

Keywords: Spectacled bear, care in captivity.

Note: Discusses the Lincoln Park Zoo's management of spectacled bears in captivity.

NAL Call No: Videocassette no.2086.

Plum Island Animal Disease Center. Washington, DC: USDA, Food Safety and Inspection Service; 1985; 1/2" VHS, $53 \mathrm{~min}$.

Keyword: Animal research, infectious diseases, containment facilities, USDA, ARS.

Note: This is a videotaped record of a Technology Transfer and Assessment Staff seminar presented by Manuel Barbeito, Biological Safety Officer for the Agricultural Research Service (ARS). The speaker describes the biosafety containment facilities and practices at the Plum Island Animal Disease Center in New York, which is used by the USDA for the study of animal parasites and diseases. Four objectives of all containment laboratories are detailed: 1) serve research needs, 2) provide personnel protection, 3) prevent contamination, and 4) protect the environment.

NAL Call No: Videocassette No. 273.

Pork Quality Assurance: FDA and Your Farm. A Program of America's Pork Producers. National Pork Producers Council (U.S.); University of Nebraska, Lincoln. Cooperative Extension. Des Moines: National Pork Producers Council, c1994. 1 VHS videocassette, 2 booklets, 1 set of self-assessment materials, 1 calendar.

Keywords: Veterinary drugs, U.S., drug residues, laws and regulations, swine diseases, disease prevention, meat quality.

Note: A learning program designed to teach hog farmers the proper use of veterinary drugs. The two booklets contain the texts of the three learning modules. The videotape is used with lesson III. Issues discussed include: food safety, illegal drug residues, HACCP, drug regulators such as the FDA, EPA and FSIS, medicated feeds, mixing guidelines, and GMP (Good Management Practices). Videotape has segments: Pork quality assurance (37 min.); FDA and your farm : what you need to know (12 min.); Quiz (12 min.).

NAL Call No: Kit no. 278

Poultry at Home. Ipswich, UK; Farming Press Videos; Distributed in N.

America by Diamond Farm Enterprises of Alexandria Bay, NY; c1993; 1/2" VHS, 77 min. ISBN: 0852362595 .

Keyword: Raising chickens, basic management, health.

Note: A beginner's guide to poultry health and management. Victoria Roberts, and Julie Musk use over 50 pure breeds to illustrate the various points. Topics include: choosing your breed, housing, handling, predators, feed and digestion, diseases and parasites, breeding, sexing, candling eggs, and rearing chicks.

NAL Call No.: Videocassette No. 1914.

Practical Methodology: Endotracheal Intubation of the Rabbit. Davis, CA: University of California at Davis; 1985; U-Matic 3/4", 13 min.

Keyword: Rabbits, anesthesia, laboratory animals, veterinary training.

Note: This film demonstrates the proper techniques involved in performing endotracheal intubation for anesthetizing the rabbit.

NAL Call No: Videocassette No. 204. 
'ractical Methodology: Endotracheal Intubation of the Rat and Hamster. Davis, CA: University of Zalifornia at Davis; 1985; U-Matic 3/4", $10 \mathrm{~min} .30 \mathrm{sec}$.

Keyword: Rats, hamsters, anesthesia, laboratory animals, veterinary training.

Note: This film demonstrates the proper techniques involved in performing endotracheal intubation for anesthetizing the rat and hamster.

NAL Call No: Videocassette No. 204.

Practical Methodology: Endotracheal Intubation of the Guinea Pig. Davis, CA: University of California at Davis; 1985; U-Matic 3/4", 13 min.

Keyword: Guinea pigs, anesthesia, laboratory animals, veterinary training.

Note: This film demonstrates the proper techniques involved in performing endotracheal intubation for anesthetizing the guinea pig.

NAL Call No: Videocassette No. 204.

Practical Methodology: Humane Handling and Laboratory Techniques for the Hamster. Davis, CA: University of California at Davis; 1987; 1/2" VHS, 22 min.

Keyword: Hamsters, laboratory animals, biomedical techniques, restraint, veterinary training.

Note: This film on the use of the hamster in the laboratory, demonstrates proper restraint and handling techniques, endotracheal intubation, drug administration, blood collection, and sex determination. A script accompanies the videocassette.

NAL Call No: Videocassette No. 404.

Practical Methodology: Humane Handling and Laboratory Techniques for the Guinea Pig. Davis, CA: University of California at Davis; 1987; 1/2" VHS, U-Matic 3/4", 19 min. 24 sec.

Keyword: Guinea pigs, laboratory animals, restraint, veterinary training.

Note: This film provides instruction on the proper restraint and handling of guinea pigs and demonstrates common laboratory techniques, such as administering injections and oral dosages, and using guinea pigs.

NAL Call No: Videocassette Nos. 687 and 204.

Practical Methodology: Humane Handling and Laboratory Techniques for the Rabbit. Davis, CA; University of California at Davis; 1987; 1/2" VHS, U-Matic, 25 min. $30 \mathrm{sec}$.

Keyword: Rabbits, laboratory animals, biomedical techniques, restraint, veterinary training.

Note: Instruction for restraining and handling the laboratory rabbit is provided in this film. It demonstrates common laboratory techniques using the rabbit, including sexing, gavaging, injection techniques (intramuscular, intravenous, intradermal, and subcutaneous), ear vein and cardiac puncture blood collection, use of sedatives/vasodialators, and euthanasia.

NAL Call No: Videocassette Nos. 688 and 204.

Practical Methodology: Humane Handling and Laboratory Techniques for the Mouse. Davis, CA: University of California; 1987; U-Matic 3/4", $18 \mathrm{~min} .16 \mathrm{sec}$.

Keyword: Mice, laboratory animals, restraint, handling, veterinary training, biomedical techniques.

Note: This program instructs the viewer on methods of restraining and handling laboratory mice in order to perform common experimental procedures. Demonstrations of laboratory techniques using the mouse, including administering injections and oral dosages, are provided. 
NAL Call No: Videocassette No. 204.

Practical Methodology: Humane Handling and Laboratory Techniques for the Rat. Davis, CA: University of California at Davis; 1987; 1/2" VHS, 21 min.

Keyword: Rats, laboratory animals, biomedical techniques, restraint, veterinary training.

Note: This film demonstrates proper restraint and handling techniques, endotracheal intubation, drug administration, blood collection, and sex determination for the laboratory rat. A script accompanies the videocassette.

NAL Call No: Videocassette No. 405.

Practical Methodology: Nonhuman Primates Part II - Special Laboratory Techniques. Davis, CA: University of California at Davis; 1988; 1/2" VHS, 15 min.

Keyword: Macaques, technician training, biomedical techniques, intubation.

Note: The second part of a two part series, this program describes and demonstrates laboratory techniques involving primates, including gavaging, injections, and blood collection. A manual accompanies the videocassette.

NAL Call No: Videocassette No. 413, Part 2 of 2.

Practical Methodology: Nonhuman Primates Part I - Personnel Safety, Primate Handling and Restraint. Davis, CA: University of California at Davis; 1988; 1/2" VHS, 18 min. 40 sec.

Keyword: Squirrel monkeys, macaques, ketamine hydrochloride, Herpes B virus, restraint, technician training, occupational health and safety, laboratory animals.

Note: The first of a two-part series, this program discusses personnel safety for laboratory animal technicians working with primates. It covers Herpes B virus prevention, protective clothing, personal hygiene, and safe handling, practices with the goal of minimizing stress to the animals and maximizing safety for the handler. A manual accompanies the videocassette.

NAL Call No: Videocassette No. 413, Part 1 of 2.

Practical Methodology: Reptiles Part II - Special Laboratory Techniques. Davis, CA: University of California at Davis; 1988; 1/2" VHS, 17 min. $41 \mathrm{sec}$.

Keyword: Snakes, tortoises, terrapins, lizards, biomedical techniques, laboratory animals, succinyl choline, ketamine hydrochloride.

Note: The second of a two-part series, this program covers laboratory techniques such as sexing, blood sampling, catheter placement, injection sites, oral gavaging, intubation, restraint, anesthesia, and euthanasia for reptiles. A manual accompanies the videocassette.

NAL Call No: Videocassette No. 414 Part II.

Practical Methodology: Reptiles Part I - Humane Handling, Restraint and Husbandry. Davis, CA: University of California at Davis; 1988; 1/2" VHS, 17 min.

Keyword: Snakes, lizards, tortoises, terrapins, husbandry, restraint, handling.

Note: The first of a two-part series, this program discusses the basics of handling, restraint, and husbandry of snakes, lizards, tortoises, and terrapins. A manual accompanies the videocassette.

NAL Call No: Videocassette No. 414, Part I.

Practical Outdoor Pig Production [videorecording]. Ipswich; Farming Press Videos; Distributed in N. 
America by Diamond Farm Enterprises of Alexandria Bay, NY; c1993; 1/2 "VHS, ca 40 min.

Keyword: Swine breeding, housing, record keeping.

Note: Features examples of breeding units showing basic requirements, essential services, housing and equipment, records, and integration with other farming enterprises.

NAL Call No.: Videocassette No. 1912.

Preserving our Livestock Heritage. Pittsboro, NC : American Minor Breeds Conservancy, [199-?]. 1 VHS videocassette $(13 \mathrm{~min} ., 50 \mathrm{sec}$.).

Keywords: Conserving rare livestock, American Minor Breeds Conservancy orgnization.

Note: Discusses how many livestock breeds are facing extinction as breeders seek to meet farmer requirements for specialized animal traits. Concludes with a brief description of the work of the American Minor Breeds Conservancy.

NAL Call No: Videocassette no.2097.

Primates. San Diego, CA: San Diego Zoological Society and Davis, CA: University of California at Davis; 1981; 125 slides, audiocassette, 25 min.

Keyword: Chimpanzees, gibbons, orangutans, tarsiers, marmosets, gorillas, husbandry, restraint, handling, taxonomy, zoo animals, biomedical techniques.

Note: This slide set illustrates principles of handling and restraint of various species of primates. Topics related to handling include protective clothing, restraint devices, and capture methods. A number of laboratory techniques are also covered, including blood, urine, and fecal collection; tuberculin testing; injections; gavaging; and administering medicines. Primate nutrition is discussed briefly. A guide accompanies the slides.

NAL Call No: Slide No. 197.

Principles of Rodent Control. "National Pest Control Association (NPCA) rodent control series;" 2. Dunn Loring, VA: NPCA; c1990; 1/2" VHS, 12 min. Includes 1 manual (16 leaves).

Keyword: Rodent control, rodenticides, pesticide application.

Note: This"National Pest Control Association Rodent Control Training Program" (one of six videos) explains the three principles of rodent control: exclusion, sanitation and population reduction. An understanding of these principles enables the pest control service technician to utilize strategies and materials to effectively control or eliminate the rodent infestation. The accompanying manual includes practical training tips, program presentation recommendations, a pretest and a post test (with answers), suggested reference materials, and a commensal rodent pictorial identification key.

NAL Call No.: Videocassette No. 1040.

Proceptivity Patterns in Captive Lowland Gorillas, Orangutans, and Celebes Macaques. Shirley L. Davis. [Orono, Me.] : Onward Program, University of Maine, c1993. 1 VHS videocassette (21 min). Keywords: Courtship, sexual behavior, primate behavior, gorillas, orangutan, macaques.

Note: This film documents female courtship by primates, and shows individual variations of this behavior. The emphasis of this program is on young adult female gorillas at the zoo of the Jersey Wildlife Preservation Trust and the Woodland Park Zoo. These females perform an unusual estrous behavior dubbed "bottom bouncing". They are also seen presenting to males, and posturing for solicitation in a prolonged courtship period. Also shown are female courtship behaviors of Bornean and Sumatran orangutans (Pongo pygmaeus) and Celebes black (or Sulawesi crested) macaques (Macaca nigra). The female orangutans exhibit some unusual vocalizations. The macaques show examples of 
sex skin swelling, and a copulating pair is harassed by juveniles.

NAL Call No: Videocassette no.2368.

Professional Advice for Healthy, Happy Birds. New York, NY: Maier Group Communications; 1989; 1/2" VHS, 45 min.

Keyword: Pets, animal welfare, care.

Note: As part of Dr. Michael Fox's animal series, this video offers his professional advice on how to care for pet birds. He emphasizes techniques that will make your pet happier and healthier.

NAL Call No: Videocassette No. 692.

Professional Advice for the Care of Cage-dwelling Pets, Including Gerbils, Hamsters, Rabbits, Guinea Pigs, Rats, and Mice. New York, NY: Maier Group Communications; 1989; 1/2" VHS, 45 min.

Keyword: Animal welfare, rodents, small animals, lagomorphs, housing.

Note: Dr. Michael Fox provides professional advice for the care of cage-dwelling pets such as mice, gerbils, guinea pigs, and rabbits. Emphasis is given to providing the proper housing, care, and handling of these animals.

NAL Call No: Videocassette No. 691.

Progress Without Pain. London, England: The Lord Dowding Fund for Humane Research; 1984; 1/2" VHS, 55 min.

Keyword: Animal models, laboratory animals, pharmaceuticals, alternative medicine, alternative testing methods, medical research.

Note: Part I, A New Approach to Health, challenges the notion that modern medicine is responsible for the increased life span and better health care enjoyed by the Western world. Rather, it identifies better nutrition, sanitation, hygiene, and living and working conditions as the major factors for improvements in health in the West. Major alternative therapies practiced in Britain are briefly surveyed. Part II, New Approach to Testing, argues that animal models are unreliable indicators of the effects of disease and drugs in humans. Alternative techniques that eliminate the need for live animal models, including chromatography, chemical analysis, cell and organ culture, theoretical techniques, clinical observations, and research with patients, are presented. Finally, the program discusses obstacles to the development of a more holistic and humane approach to medical research and treatment. A manual accompanies the videocassette.

NAL Call No: Videocassette No. 424.

Proper Pig Handling for Markets \& Packers : Manejo Correcto de Cerdos para los Mercados y las Empresas Empaquetadoras. National Pork Producers Council (U.S.), National Pork Board (U.S.), Livestock Conservation Institute. Bowling Green, KY : Livestock Conservation Institute, c1997. 1 VHS videocassette (36 min.): 1 booklet.

Keywords: Swine, humane handling, pork, meat quality.

Note: Shows proper techniques and procedures for handling pigs to insure high quality meat. Narrative is in both English and Spanish.

NAL Call No: Videocassette no.2673.

Protecting Endangered Animals. Washington, DC : National Geographic Society; 1984; 15 min. 
Includes 2 identical teacher's guides.

Keyword: Endangered species, extinction, wildlife conservation.

Note: Explains why animals have become extinct in the past, describes the plight of presently endangered species, and examines success stories of animals that seem to have been snatched from the jaws of extinction.

NAL Call No.: Videocassette no. 1164.

\section{Quality Assurance: A Term Used by Animal Agriculture Which Refers to the Production of High}

Quality, Safe, and Wholesome Food!. Jeff Goodwin. College Station, Tex.: Instructional Materials Service, c1997. 1 VHS videocassette (16 min.).

Keywords: Meat quality, livestock handling.

Note: Shows in a humorous way the steps livestock producers can follow to ensure a quality product. Subtitle on container: "Strengthening the chain of wholesome food production."

NAL Call No: Videocassette no. 2747.

Quality Assurance for 4-H Swine Producers. Ames, Iowa : Iowa State University, Coperative Extension Service, [1992]. 1VHS videocassette (25 min.).

Keywords: Swine, meat quality pork industry, trade.

Note: This program uses interaction between a veterinarian and a 4-H group to introduce concepts of the Pork Quality Assurance program. Quality Assurance seeks to help 4-H pork producers be more aware of food safety and drug residue issues, be better livestock managers, and be more efficient through the safe use of feed and water medications.

NAL Call No: Videocassette no.2366.

Question of Ethics. Jeff Goodwin. College Station, TX: Instructional Materials Service, Texas A\&M University, c1994. 1 VHS videocassette (20 min., $30 \mathrm{sec}$.). Includes 1 facilitator guide.

Keywords: Ethics, 4-H-clubs, animal abuse, livestock showing.

Note: Addresses the rare cases of unethical practices associated with the Junior Livestock Program.

NAL Call No: Videocassette no.2637.

Questions \& Answers about BST and Milk . Washington, DC: Dairy Coalition, 199-?; 1/2" VHS, 6 $\min$.

Keyword: Bovine somatotropin, effects of bST on milk quality and composition.

Note: Former U.S. Surgeon General C. Everett Koop answers questions about BST and milk. Topics discussed include the composition of milk from cows treated with BST, the safety of milk from cows treated with BST, the effect of BST on cows' health, antibiotic residues, and labeling requirements for milk from cows treated with BST.

NAL Call No.: Videocassette no. 1885.

Rabbits: Bacterial and Mycotic Diseases. Seattle, WA: University of Washington, Health Sciences Center for Educational Resources; 1990; 60 slides, guide, audio cassette, 19 min.

Keyword: Signs, diagnosis, observation.

Note: Series 2 of the Laboratory Animal Medicine and Science slide series, which covers clinical signs of pasteurellosis, enterotoxemia, mucoid enteropathy, treponematosis, mastitis, Tyzzer's disease, and superficial mycoses.

NAL Call No: Slide No. 384. 
Rabbits: Biology. Seattle, WA: University of Washington, Health Sciences Center for Educational Resources; 1990; 36 slides, guide, audio cassette, 12 min.

Keyword: Laboratory animals, physiology, anatomy, animal care.

Note: This slide series, designed as a training tool, covers taxonomy, unique anatomical features, breeds of laboratory rabbits, normal vital signs and hematological values, injection sites, hair growth, gestation, and sex determination.

NAL Call No: Slide No. 382.

Rabbits: Care and Management in a Laboratory Setting. Seattle, WA: University of Washington, Health Sciences Center for Educational Resources; 1990; 47 slides, guide, audio cassette, 20 min.

Keyword: Laboratory animal, housing, animal welfare.

Note: As a training tool, these slides cover the importance of animal care as well as the procedures for care and management under the Animal Welfare Act and the Guide for the Care and Use of Laboratory Animals.

NAL Call No: Slide No. 381.

Rabbits: Introduction to Use in Research. Seattle, WA: University of Washington, Health Sciences Center for Educational Resources; 1990; 60 slides, guide, audio cassette, 19 min.

Keyword: Animal welfare, laboratory animal, testing.

Note: This training tool presents laws and guidelines, historical use in research and testing, development of alternatives, attributes as research animals, recognition of pain and disease, and signs and significance of common diseases.

NAL Call No: Slide No. 379.

Rabbits: Noninfectious Disease. Seattle, WA: University of Washington, Health Sciences Center for Educational Resources; 1990; 51 slides, guide, audio cassette, $18 \mathrm{~min}$.

Keyword: Laboratory animals, anatomical disorders, gastric disorders, skin diseases, nutrition.

Note: These slides cover clinical signs of neoplastic disease, splay leg, mandibular prognathism, pododermatitis, spinal fractures, gastric disorders, dermatitis, and nutritional deficiencies.

NAL Call No: Slide No. 383.

Rabbits: Parasitic, Protozoal, and Viral Diseases. Seattle, WA: University of Washington, Health Sciences Center for Educational Resources; 1990; 35 slides, guide, audio cassette, 12 min.

Keyword: Laboratory animal, clinical signs, diagnosis, treatment, and prevention.

Note: This presentation covers viral, protozoal, and parasitic diseases common to rabbits; clinical and pathologic signs; diagnostics; treatments; and preventive measures. This slide set is designed as a training tool.

NAL Call No: Slide No. 380.

Raising Emus \& Rheas. Ken Wilson. Kerrville, Tex.: Sportsmen on Film, c1993. 1VHS videocassette (60 min.)

Keywords: Ratites, emus, rheas, husbandry, production management.

Note: Ken Wilson shows how emus and rheas are raised on the Kerrville Ratite Ranch. Topics covered include egg collection, incubation, candling, hatching, housing, and feeding.

NAL Call no: Videocassette no.2584.

Recognition and Alleviation of Pain and Distress. Closter, NJ: Production Plus, Inc.; 1990; 1/2" VHS, 
$23 \mathrm{~min}$.

Keyword: Animal welfare, euthanasia, analgesia.

Note: Videotape of a presentation at the Symposium: Animal Welfare Compliance for Study Directors presented at the Eleventh Annual Meeting of the American College of Toxicology in Orlando, FL, October 1990. Relevant definitions and mechanisms for determining and alleviating pain are discussed. The responsibilities and interaction of the study director, attending veterinarian, and the animal care and use committee are outlined. Methods to determine the appropriate endpoint to studies are proposed.

NAL Call No: Videocassette No. 968.

Reducing Residues in the Main Causes of Violations: The Cull Dairy Cow and the Bob Veal Calf. Points to Dairy Quality. Benny Burge Norman; University of California, Davis; Agri-Education, Inc; Milk \& Dairy Beef Quality Assurance Program. Stratford, Iowa: Milk \& Dairy Beef Cattle Quality Assurance Center, c1993. 1 videocassette (VHS), 2 sound cassettes, 1 set of teaching materials

Keywords: Veterinary drugs, residues, product quality assurances, diseases chemotherapy, food safety concerns, production practices.

Note: Describes the ten-point program established by the National Milk Producers Federation and the American Veterinary Medicine Association to establish standards for the treatment of dairy and beef cattle with drugs and prevent residues from entering the food supply. Emphasizes the importance of the working relationship between the veterinarian and the producer.

Produced by the University of California, Davis in cooperation with Agri-Education, Inc. "USDA Extension Service \#91-EFSQ-1-4020." Instructional materials include script of video in English and Spanish, questions and answers, narratives to radio messages, $4-\mathrm{H}$ educational package, copies of slides and several articles. Slides originally issued with chapter 8 have been replaced by photos of the slides.

NAL Call No: Kit no. 246.

Reptiles: Bacterial Diseases of Captive Reptiles. Seattle, WA: University of Washington; 1975; 55 slides, audiocassette, $14 \mathrm{~min}$.

Keyword: Turtles, tortoises, terrapins, snakes, lizards, bacterial diseases, veterinary medicine.

Note: This slide set describes and illustrates the following aspects of bacterial diseases of reptiles: predisposing environmental factors, clinical symptoms, and disease treatment and prevention. Superficial cutaneous infections, septicemic cutaneous necerative disease, superficial abscesses, maxillary abscesses, infectious stomatitis, respiratory infections, and shell "fungus" are the disease conditions examined. A manual accompanies the slide set.

NAL Call No: Slide No. 222.

Research Animals: A Realistic View. Springfield, IL: Southern Illinois University; 1978; 1/2" VHS, 13 $\min .37 \mathrm{sec}$.

Keyword: Laboratory animal facility, veterinary medicine, husbandry.

Note: This program discusses the quality of animal care and equipment of a model animal research facility. A visual tour through an actual research facility serves to illustrate proper laboratory animal care.

NAL Call No: Videocassette No. 205.

Research Methods for Studying Animal Behavior in a Zoo Setting. Apple Valley, MN: Minnesota 
Zoological Garden and Portland, OR: Washington Park Zoo; 1983; U-Matic 3/4", (Part 1) 19 min., (Part 2) $60 \mathrm{~min}$.

Keyword: Musk oxen, macaques, flamingos, zoo animals, ethology, ethograms, statistics, sampling methods.

Note: This film introduces novice researchers to methods of studying animal behavior. Formulating a research question, reconnaissance observations, ethogram construction, sampling methods, data collection, statistical analysis, and interpretation of results are discussed. The program emphasizes five different sampling methods. The viewer can practice each method by watching and scoring the following samples of behavior: agonistic interactions of male musk oxen, social play in Japanese macaques, and feeding in flamingos. The accompanying manual includes examples of ethograms and data sheets for sampling.

NAL Call No: Videocassette No. 234.

Responsible Care and Use of Canine in Research. University of Wisconsin, Research Animal Resources Center; 1989; 1/2" VHS, 30 min.

Keyword: Dogs, laboratory animals, biomedical research, restraint, handling, veterinary techniques, teaching.

Note: This video discusses the uses of dogs in biomedical research. Physiological and psychological aspects are considered. Proper care, handling, and veterinary techniques are discussed and demonstrated. Regulations, guidelines, animal rights issues, and random source and purpose breeding are also discussed.

NAL Call No: Videocassette No. 736.

Restraining/Injecting. No. 204. Owatonna, MN: PigWorld, Inc., [199-?]. 1 VHS videocassette [Injecting pigs (11 min., $50 \mathrm{sec}$.$) , Snaring pigs (10 min.) ].$

Keywords: Veterinary injections, restraint techniques, swine handling.

Note: Covers injecting pigs, types of injection guns, needles, drugs, snaring methods and restraint of pigs.

NAL Call No: Videocassette no. 2600.

Restraint and Handling of the Bird. Davis, CA: School of Veterinary Medicine, University of California at Davis; c1978; 1/2" VHS, 12 min. (Tape no. \#3236.1"--Cassette label.)

Keyword: Birds, handling, restraint methods, birds.

Note: Discusses common anatomical characteristics of all birds. Common physical and chemical restraint techniques used on most birds are demonstrated.

NAL Call No.: Videocassette No. 1907.

Restraint and Handling of the Dog. Davis, CA: University of California at Davis; 1977; U-Matic 3/4", 19 min.

Keyword: Dogs, restraint, veterinary training, veterinary medicine.

Note: This program demonstrates proper methods of restraining and handling dogs in a veterinary hospital setting in order to perform various medical procedures.

NAL Call No: Videocassette No. 219.

Restraint and Handling of the Cat. Davis, CA: University of California at Davis; 1977; U-Matic 3/4", $15 \mathrm{~min}$.

Keyword: Cats, restraint, veterinary training, veterinary medicine. 
Note: This film demonstrates methods of restraining and handling cats in a veterinary hospital setting in order to perform various medical procedures.

NAL Call No: Videocassette No. 217.

Restraint and Handling of the Reptile--Snakes. Davis, CA: School of Veterinary Medicine, University of California at Davis; c1979; 1/2" VHS, 34 min. (Tape no. 3246-1--Cassette label.)

Keyword: Non-poison snakes, poisonous snakes, restraint, behavior, immobilization, handling.

Note: Restraint techniques and special handling procedures are demonstrated on a variety of poisonous and nonpoisonous snakes. Included is a protocol for snake bite emergencies and a demonstration of first aid procedures.

NAL Call No.: Videocassette no. 1909.

Restraint and Handling of the Reptile-- Crocodilians, Chelonians, and Lizards. Davis, CA: School of Veterinary Medicine, University of California; c1979; 1/2" VHS, 25 min. (Tape no. \#3246.2"--Cassette label).

Keyword: Reptiles, handling, restraint, immobilization, behavior, crocodiles, lizards, turtles.

Note: Describes the danger potential and physical characteristics and behavior as a basis for the demonstration of various types of restraint for reptiles. The proper handling as well as restraint or crocodilians, chelonians and lizards. is demonstrated.

NAL Call No.: Videocassette no. 1908.

Reverence for Life: Rights and Responsibilities. Minneapolis, MN: University of Minnesota; 1986; $1 / 2 "$ VHS, $45 \mathrm{~min}$.

Keyword: Ethics, values, rights, animal welfare.

Note: A panel discussion on how people value and treat animals is presented. The equality of different life forms, rights of animals, and human responsibility toward animals are discussed.

NAL Call No: Videocassette No. 325.

Rhea Intensive Farming: Reference Guide to the Exotic Bird Production from Egg to Breeder. Lea Hosman and Chris Ramsey. Utopia, Tex.: Hosman/Ramsey Rheas, c1993. 1 videocassette (ca. 45 min.).

Keywords: Rheas, ratities, husbandry, production practices, egg hatching.

Note: A guide to exotic bird production from egg to breeder. Rhea farming by Lea Hosman and Chris Ramsey.

NAL Call No: Videocassette no.2664.

Riding with Awareness. Educational Horse Videos. Linda Tellington-Jones Series. Linda Tellington-Jones and Robyn Hood and Pam Lawlor. La Jolla, CA: Lawlor Productions, c1987. 1 VHS videocassette (ca. $69 \mathrm{~min}$.).

Keywords: Horse training, riding, behavior.

Note: T.E.A.M. (Tellington-Jones Equine Awareness Method) solutions are discussed for correcting common problems, such as tail switching, ewe neck, tongue hanging and shying.

NAL Call No: Videocassette no.2137.

Rodents: Basic Needs, Handling and Care. Closter, NJ: Production Plus, Inc.; 1990; 1/2" VHS, 19 min. 
Keyword: Animal welfare, rodents, laboratory animals.

Note: Videotape of a presentation at the Symposium: Animal Welfare Compliance for Study Directors presented at the Eleventh Annual Meeting of the American College of Toxicology in Orlando, FL, October 1990. Training video for research personnel, which includes a discussion of animal shipping, identification, viral disease monitoring, confinement caging, water, bedding, and environment for rodents. Guidelines for determining when euthanasia is appropriate are provided.

NAL Call No: Videocassette No. 967.

Safely Handling Breeding Stallions \& Mares with T.E.A.M. Educational Horse Videos. Linda Tellington-Jones series. Linda Tellington-Jones and Robyn Hood. La Jolla, CA: Lawlor Productions, c1987. 1 VHS videocassette (71 min.).

Keywords: Stallions, mares, handling, training, restraint, behavior, breeding.

Note: T.E.A.M. (Tellington-Jones Equine Awareness Method) solutions are discussed for training horses without anxiety and overexcitation, to improve the breeding process and attitudes and performance.

NAL Call No: Videocassette no.2139.

Safety \& Regulatory Issues in Transgenic Production of Biopharmaceuticals. Bethesda, Md: BioConferences International, Inc; c1994; 1/2" VHS, 93 min.

Keyword: Transgenic animals, conference, biopharmaceuticals, safety.

Note: Three speakers discuss the role of transgenic animals in the production of biopharmaceuticals. Topics covered include transgenic animals for the production of biological products, production of medicinal products for human use in transgenic animals, and therapeutics from transgenic animals and the adventitious agent concerns. Recorded during a session at BioEast'94 held in Washington, DC, Jan 24-27, 1994.

NAL Call No.: Videocassette No. 1978.

Sales Preparation. Lexington, KY: Blood-Horse Productions; c1985; 1/2" VHS, ca. 35 min.

Keyword: Horses, grooming, yearlings, weanlings, broodmares, marketing.

Note: Production of The Blood-Horse, a weekly magazine devoted to improving thorough red breeding and racing. Techniques in presenting yearlings, weanlings, and broodmares to best advantage for prospective buyers are described.

NAL Call No.: Videocassette No. 1883.

Science in Agriculture. Career Opportunities: Biotechnology in the Animal Science Fargo, N.D.: North Dakota State University, College of Agriculture, c1987. 1 VHS videocassette (11 min.).

Keywords: Animal Science, careers, biotechnology, cell culture, genetic engineering.

Note: Discusses new areas of basic research in animal sciences. Topics covered include gene transfer, genetic engineering, animal cell culture, improved efficiency of feed usage, and growth control.

NAL Call No: Videocassette no.1796.

Search for the Great Apes. National Geographic video. Stanford, CT: Veston Video; c1989; 1/2" VHS, 60 min. ISBN: 0805106499. The video is closed captioned for the hearing impaired.

Keyword: Diane Fossey, Birute Galdikas-Brindamour, gorillas, orangutan, behavior, Africa, Borneo.

Note: This video was produced in cooperation with the National Geographic Society, Wolper 
Production and Vestron Video. It examines the efforts of Dian Fossey and Birute Galdikas-Brindamour to discover new facts about the life and behavior of gorillas and orangutans.

NAL Call No.: Videocassette No. 1101.

Searching the Literature for Alternatives. Closter, NJ: Production Plus, Inc.; 1990; 1/2" VHS, 26 min.

Keyword: Animal welfare, animal models, toxicology, resources, information.

Note: Videotape of a presentation at the Symposium: Animal Welfare Compliance for Study Directors presented at the Eleventh Annual Meeting of the American College of Toxicology in Orlando, FL, October 1990. This presentation provides scientists with information resources on alternatives. Alternatives are described using the $3 R^{\prime}$ 's of Russell and Birch. There is a detailed description of information services and products available from major organizations, information centers, and scientific databases. In addition, pointers are given on how to effectively define and locate alternative methods.

NAL Call No: Videocassette No. 970.

Sentenced for Life (Also called "Chicken for Dinner."). Potomac, MD: United Poultry Concerns, Inc.; 1990; 1/2" VHS, $34 \mathrm{~min}$.

Keyword: Battery systems, poultry production, intensive housing, welfare.

Note: Produced by Chickens' Lib in the U.K., this exposé documents the battery caging systems used for housing poultry in egg production in Great Britain. Welfare, housing, and behavior are addressed.

NAL Call No: Videocassette No. 1288.

Separating Fact from Myth: The Veal Industry Challenge. Chicago: Beef Industry Council(US).Veal Committee. American Veal Association; 1990; 1/2" VHS, 11 min.

Keyword: Veal industry, animal welfare issues, food safety.

Note: Describes the veal industry's viewpoint on the issues of animal welfare and food safety.

NAL Call No.: Videocassette no. 1537.

Share the Care: Humane Education. Minneapolis, MN: University of Minnesota; 1986; 1/2" VHS, 45 $\min$.

Keyword: Pets, ethics, children, education, animal welfare.

Note: Barbara Raye of the Minnesota Humane Society and Dr. Ashley Robinson of the University of Minnesota discuss Share the Care, a project designed to teach students K-12 humane treatment of animals. The panelists describe the curriculum and activities of the program. Raye states that the project aims at developing ideas and opinions about animals rather that just providing information, and that it has imparted to participants respect and fondness for animals.

NAL Call No: Videocassette No. 327.

Sheep Management Practices. I. Sheep Production Video Series. Tape \#214. Lubbock, Tex.: Creative Educational Video, Inc., c1987. 1 VHS videocassette (55 min.).

Keywords: Sheep, husbandry practices, restraint, basic care procedures.

Note: Covers characteristics of sheep, housing and facilities, handling and restraint, lambing, docking and castration; includes quizzes and answers.

NAL Call No: Videocassette no.2580. 
Sheep Management Practices. II. Tape \#215. Lubbock, Tex. : Creative Educational Video, Inc., c1987.

1 VHS videocassette (44 min.).

Keywords: Sheep, production practices, parasites, shearing.

Note: Discusses sheep management practices concerning identification, internal and external parasites, foot care, and shearing of sheep.

NAL Call No: Videocassette no.2581.

Shiverer Mouse. Tokyo: Central Institute for Experimental Animals; 1989; 1/2" VHS, 12 min.

Keyword: $\quad$ Mouse, neuron, myelin basic protein, biotechnology, DNA.

Note: This short film examines how biotechnology is used to study the cause and cure for the disease that afflicts shiverer mice. The cause, a deficiency in the myelin basic protein (MBP), is described and illustrated using micrographs of nerve cells. A MBP gene is injected into a zygote of a shiverer mouse to produce healthy offspring. The Chugai Pharmaceutical Company of Japan developed the video.

NAL Call No: Videocassette No. 439.

Shoeing the Horse. Equine Educational Video Series. Todd Parmenter. [Florida?] : Edmar Video Productions : Todd Parmenter's Show Horses, c1985. 1 VHS videocassette (40 min., $31 \mathrm{sec}$.).

Keywords: Horseshoeing, tools, horse restraint.

Note: Todd Parmenter demonstrates resetting the hooves on one front and one hind foot of a horse. Includes discussion of ferrier tools and their use, tips on choosing a shoe, and reshaping, fitting and tacking the horseshoe.

NAL Call No: Videocassette no.2609.

Signs of Enrichment. Ellensburg, WA: Friends of Washoe Foundation; 1986; 1/2" VHS, 41 min.

Keyword: Chimpanzees, environmental enrichment, laboratory animals, behavior.

Note: Roger and Deborah Fouts of the Friends of Washoe Foundation narrate this film, which demonstrates techniques for enriching the environment of captive chimpanzees. Providing a varied diet; "celebrating" birthdays and holidays; and supplying balloons, crayons, and other toys are among the suggestions aimed at alleviating the monotony of confinement in a laboratory animal facility.

NAL Call No: Videocassette No. 184.

Signs of the Apes, Songs of the Whales. Nova (Television program); Stanford, CT.:Vestron Video; 1988; c1983; 1/2" VHS, 58 min. Originally broadcast on the television program Nova.

Keyword: Human-animal communication, Washoe, apes, dolphins, sea lions, gorillas, whales.

Note: Revisits Washoe, a chimpanzee that communicates using American Sign Language, and examines some of the most recent language experiments being done with apes, dolphins, sea lions, gorillas, and whales.

NAL Call No.: Videocassette No. 1747.

\section{Silent World: Genetic Engineering-Ethical, Environmental and Animal Welfare Concerns.} Washington, DC: Center for Respect of Life and Environment; 1988; 1/2" VHS, 39 min.

Keyword: Animal welfare, genetics, biotechnology, chimeras, ecology, diseases, patenting, intensive livestock farming, ethics, medical research, pesticides.

Note: Dr. Michael W. Fox considers the environmental effects and ethical implications of genetic engineering. Fox warns that the production of genetically altered organisms could lead to environmental devastation, reduced biological diversity, and increased suffering of 
research animals. The video examines recent genetic manipulations: monoclonal antibody production from mice, insertion of avian leukosis virus into poultry and the AIDS virus into mice, genetically engineered bacteria for bacterial pesticides, and pigs endowed with the human growth gene. The program concludes with a plea for greater respect for the sanctity of life and possible alternatives to genetic engineering.

NAL Call No: Videocassette No. 417.

jilver Spring Monkeys. Washington, DC: People for the Ethical Treatment of Animals, Inc.; 1981; 1/2" $\checkmark \mathrm{HS}, 17 \mathrm{~min}$.

Keyword: Cynomologus monkeys, rhesus monkeys, PETA, NIH, deafferentation, neurology, animal abuse, animal welfare.

Note: This videorecording consists of a series of photographs taken by Alex Pacheco while working at the NIH's Institute of Behavioral Research in Silver Spring, MD. The photographs document the poor care and treatment of primates held at the laboratory of Dr. Edward Taub and were used by Pacheco to testify on animal abuse before the U.S. House Subcommittee on Science Research and Technology.

NAL Call No: Videocassette No. 301.

Small Animal Anesthetic Induction Technique. Ames, Iowa: Iowa State University; 1978; U-Matic 3/4", 19 min. $50 \mathrm{sec}$.

Keyword: Cats, dogs, anesthesia, veterinary training, sodium pentobarbital, sodium pentothal, ketamine hydrochloride, halothane, nitrous oxide.

Note: This film demonstrates techniques involved in administering common anesthetic agents to cats and dogs, and illustrates their effects. The program covers intramuscular, intravenous, and inhalation methods of anesthetic induction. Both the face mask and chamber methods of inhalation anesthetic induction are illustrated.

NAL Call No: Videocassette No. 344.

Small Mammals Restraint and Handling. San Diego, CA: San Diego Zoological Society and University of California at Davis, School of Veterinary Medicine; 1981; 109 slides, audiocassette, 21 min.

Keyword: Porcupines, chinchillas, muskrats, armadillos, bats, zoo animals, restraint, handling, veterinary medicine.

Note: Designed as a tutorial for zoo animal caretakers and veterinarians, this slide set illustrates techniques for the safe and humane restraint and handling of various wild small mammals. The program demonstrates the proper use of nets, snares, squeeze cages, and other equipment in order to perform veterinary exams, radiography, and tuberculin tests, provide routine health maintenance, and administer medicines. A guide accompanies the slide set.

NAL Call No: Slide No. 194.

Some Preferred Techniques for the Laboratory Rat. [Edmonton, Alta.?]: Canadian Association for Laboratory Animal Science, [1997] 1VHS videocassette (24 min.).

Keywords: Rats as laboratory animals, animal welfare, Animal experimentation.

Note: A presentation of certain techniques for using and handling the laboratory rat which are considered effective and humane.

NAL Call No: Videocassette no.2585.

Some Preferred Techniques for the Laboratory Guinea Pig. (Quelques Techniques Choisies Pour Le Cochon D'inde De Laboratoire) Canadian Association of Laboratory Animals Science. Winnipeg, 
Canada. 1997?. 1 VHS videocassette (15min).

Keywords: Guinea pigs, techniques, blood collection, teaching animals, restraint, anesthesia.

Note: The fourth video presentation in our species specific series is the guinea pig. This animal presents unique challenges for blood collection as it is one of the tail-less laboratory rodents. Safe restraint and anesthesia are demonstrated to reduce, replace and refine the ust of teaching animals. The target audience includes animal health technologists, graduate students, laboratory assistants and members of animal care and use committees. For more information go to: http://www.calas-acsal.org

NAL Call No: Videocassette No--in process

Some Preferred Techniques for the Laboratory Rabbit. (Quelques Techniques Choisies Pour Le Lapi: De Laboratoire.) Canadian Association of Laboratory Animals Science. Winnipeg, Canada. 1998. VHS video cassette (17 $\mathrm{min})$.

Keywords: Lab techniques, injections, rabbit, anesthesia with resuscitation

Note: This is the second video in our species specific series on laboratory techniques. Safe handling and restraint for injections, blood sampling and anesthesia with resuscitation methods are demonstrated. This training video id designed as a teaching aid to refine, replace and reduce the numbers of rabbits used for demonstration purposes. The target audience includes animal health technologists, graduate students, laboratory assistants and members of animal care and use committees. For more information go to: http://www.calas-acsal.org

NAL Call No: Videocassette No. in process

Some Preferred Techniques for the Laboratory Rat. (Quelques Techniques Choisies Pour Le Rat De Laboratoire.) Canadian Association of Laboratory Animals Science. Winnipeg, Canada. 1997. VHS video cassette (24 Min.).

Keyword: laboratory techniques, rats, handling and restraint, blood sampling and anesthesia

Note: This is the first video in our species specific series on laboratory techniques. Safe handling and restraint for injections, blood sampling and anesthesia methods are demonstrated. This training video is designed as a teaching aid to refine, replace and reduce the numbers of rats needed for demonstration purposes. The target audience includes animal health technologists, graduate students, laboratory assistants and members of animal care and use committees. For more information go to: http://www.calas-acsal.org

NAL Call No: Videocassette No. in process

Some Preferred Techniques for the Laboratory Mouse. Quelques Techniques Choisies Pour La Souris De Laboratoire. Canadian Association of Laboratory Animals Science. Winnipeg, Canada. 1998. VHS video cassette (13 min.).

Keyword: Mouse, laboratory techniques, numbers needed, demonstration

Note: This is the third video in our species specific series techniques. Safe handling and restraint for injections, blood sampling and anesthesia methods are demonstrated. This training video is designed as a teaching aid to refine, replace and reduce the numbers of mice needed for demonstration purposes. The target audience includes animal health technologists, graduate students, laboratory assistants and members of animal care and use committees. For more information go to: http://www.calas-acsal.org

NAL Call No: Videocassette No. in process 
jorry, Charlie. Phoenix, AZ: Arizona Humane Society; 1984; 1/2" VHS, 14 min.

Keyword: Animal control, pets, overpopulation, children.

Note: While searching for a home, an abandoned dog is picked up by an animal control worker and brought to a shelter. This dramatization is designed to educate children about the plight of stray animals and to foster more responsible pet ownership. A teaching guide accompanies the videocassette.

NAL Call No: Videocassette No. 339.

Sources of Information on Animal Research Legislation and Animal Welfare. Closter, NJ: Production Plus, Inc.; 1990; 1/2" VHS, 15 min.

Keyword: Resources legislation, databases, alternatives, organizations, compliance.

Note: Videotape of a presentation at the Symposium: Animal Welfare Compliance for Study Directors presented at the Eleventh Annual Meeting of the American College of Toxicology in Orlando, FL, October 1990. Information resources on animal welfare, educational materials, databases, alternatives, and animal research are described in this video. Descriptions, information, and addresses are provided for organizations such as AALAS, AAALAC, AWIC, ILAR, SCAW, CAAT, FRAME, NABR, FBR, iiFAR, and others.

NAL Call No: Videocassette No. 969.

Speaking of Harvey. Santa Monica, CA: Pyramid Film \& Video; 1982; 16 mm, 9 min.

Keyword: $\quad$ Ethics, medical research, surgery, laboratory animals, animal welfare.

Note: A film for junior high through college biology students, it introduces the concept of scientific ethics in relation to animal experimentation. It shows a young physiologist performing a surgical experiment on a rabbit while discussing the emotional difficulties he and other researchers experience when working with live animals. The narrator stresses the importance of sensitivity and a humane attitude, recommends restraint when euthanizing animals, and proposes using one animal for several research projects. A complete operation (dearterializing a rabbit's liver) is performed while the researcher shares his thoughts and feelings about his work.

NAL Call No: Motion Picture No. 169.

Spirits of the Forest. New York: Thirteen/WNET: Distributed by Time-Life Video of Alexandria, VA; c1989, 1/2", 60 min. Closed-captioned for the hearing impaired.

Keyword: Lemurs, Madagascar, habitats, behavior.

Note: Shows the various species of lemurs. Footage was taken in the wild on the island of Madagascar. It shows the lemurs in their species specific unique habitats exhibiting their unique behaviors. The video is narrated by George Page and was originally broadcast on the PBS program Nature.

NAL Call No..: Videocassette No. 1974.

Sportsmedicine Therapies and Treatments. Grand Prairie, TX: Equine Racing Systems, c1991; 1/2" VHS, ca. $90 \mathrm{~min}$.

Keyword: Race horses, lameness, veterinary physical therapies.

Note: The program was taped at the Houston 1990 Sportsmedicine Seminar. A sports therapist, Mimi Porter, discusses physical therapy for lameness in race horses.

NAL Call No.: Videocassette No. 2043. 
Stallion Management. Lexington, KY: Blood-Horse Productions; c1984; 1/2" VHS, ca. 30 min.

Keyword: Horse breeding, stallions, management.

Note: Discusses how to maintain stallions that have the best possible chance to get the mares in foal.

NAL Call No.: Videocassette No. 1897.

Starting a Young Horse. Omaha, NE: Farnam Companies, Inc.; c1986; 1/2" VHS, 90 min.

Keyword: Horses, training methods, training the horse for riding.

Note: The video will take you through the basic steps for preparing a horse for riding. TellingtonJones demonstrates the body work and ground exercises including using a whip as a "wand"; how to use driving reins; preparation for lunging; preparing the horse to accept a bit; the first steps of saddling; plus much more. All of these exercises and techniques will result in a smooth transition to the final goal of riding the horse.

NAL Call No.: Videocassette No. 1969.

Step Beyond: A Question of Ethics. Jeff Goodwin. College Station, Tex. : Instructional Materials Service, c1995. 1 VHS videocassette $(23$ min. $)+1$ video/activity guide $(37 \mathrm{p}$.$) .$

Keywords: 4-H-clubs, ethics, showing livestock, fairs.

Note: Raises the issue of the challenge of ethics in the Junior Livestock Program and attempts to give teachers, agents, and parents the tools to address the subject of unethical practices before situations arise at the local level.

NAL Call No: Videocassette no.2662.

Stimulus Response. Cambridge, UK: The Association for the Study of Animal Behavior, Department of Biological Sciences, Homerton College; 1996; 1/2" VHS, 33 min.

Keyword: $\quad$ Farm animals, five steps, stimulus response, preferences, motivation.

Note: Using a variety of farm animal species, the teaching video examines the five steps of stimulus response. Steps include stimulus perception, physiological receptors, coordination of the response, effectors, and the behavioral response. The video is geared towards high school and undergraduate college levels and is a collaborative effort between the Universities of Bristol and Cambridge.

NAL Call No: Videocassette No. 2350.

Suffer the Animals. London, England: British Films Ltd.; 1980; 16 mm, 25 min.

Keyword: Ames test, Draize test, alternative testing methods, pharmaceuticals, cosmetics.

Note: This film is a graphic depiction of experimental animals undergoing stressful and/or painful procedures. The film expresses the view that the use of animals for research and testing is unnecessary, and briefly discusses possible alternatives to animal experimentation. Suitable for high school students and older persons.

NAL Call No: Motion Picture No. 189.

Superanimals, Superhumans? The Life Revolution. Films for the Humanities (Firm); Primedia Productions. Canoptic Productions.; TVOntario; Telefilm Canada. Princeton, N.J: Films for the Humanities \& Sciences, Inc., c1990. 1 VHS videocassette (26 min.).

Keywords: Genetic engineering, animals, humans.

Note: Looks at the scientific goals and social controls of the genetic engineering of animals--and humans. The film is part of the series Films for the Humanities and Sciences; produced by Primedia Productions and Canoptic Productions, in association with Channel 4 and 
TVOntario, with the participation of Telefilm Canada.

NAL Call No: Videocassette no. 1963.

Surgery Preparation. Davis, CA: University of California; 1984; U-Matic 3/4", 22 min.

Keyword: Sterile techniques, surgery, veterinary training.

Note: This tutorial program details presurgical scrubbing, gowning, and gloving procedures to ensure a sterile surgical environment. It is intended for students of veterinary medicine.

NAL Call No: Videocassette No. 223.

Surgical Instruments and Their Use. Davis, CA: University of California at Davis; 1985; U-Matic 3/4", $33 \mathrm{~min}$.

Keyword: Surgical equipment, surgical techniques, veterinary medicine, veterinary training.

Note: The proper use of various veterinary surgical instruments, including scalpels, scissors, clamps, tissue forceps, retractors, needle holders, suture needles, groove directors, and other miscellaneous instruments is described and illustrated. Proper suturing techniques are also covered.

NAL Call No: Videocassette No. 207.

Surgical Procedures on Swime. Manchester, NH: Group Five Communications; 1989; 1/2" VHS, 36 min., $30 \mathrm{sec}$.

Keyword: Swine surgery, blood sampling, neck region and medial thigh.

Note: Topics covered include blood sampling, preanesthetic administration, and surgical approaches to the trachea, carotid sheath, external jugular vein, and the vessels of the medial thigh. This video was also produced by Charles River Laboratories.

NAL Call No.: Videocassette No. 1612.

Swine Handling and Transportation. Madison, WI: Livestock Conservation Institute; c1989?; 1/2" VHS, $21 \mathrm{~min}$.

Keyword: Swine, handling transport, behavior.

Note: Dr. Temple Grandin describes basic principles of pig behavior including vision, flight zone, reaction to noise, and following behavior. Shows various handling and transportation practices that reduce bruises, decrease injuries, and increase efficiency.

NAL Call No.: Videocassette No. 1593.

Swine Handling for Pork Producers. Pork Quality Assurance Video Series. Video \#3. National Pork Producers Council (U.S.); National Pork Board (U.S.). Des Moines, Iowa : The Council, c1996. 1 VHS videocassette (ca. 15 min.) and 1 manual ( 8 p.) +1 quiz.

Keywords: Swine, behavior, production system, humane restraint and handling methods.

Note: Discusses how pigs need to be handled on the farm and how the understanding of a pig's behavior makes it easier to handle them.

NAL Call No:. Videocassette no.2332.

Swine Handling for Transporters. Pork Quality Assurance Video Series. Video \#4. National Pork Producers Council (U.S.); National Pork Board (U.S.). Des Moines, Iowa : The Council, c1996. 1 videocassette (ca. 17 min.) and 1 manual $(10$ p. $)+1$ guide $(2$ p. $)+1$ quiz.

Keywords: Swine, transport, safe handling, behavior, techniques.

Note: Addresses transportation techniques to help assure the safe delivery of pigs to their destination. Pre-loading, loading, transporting, and delivery procedures are shown. 
NAL Call No: Videocassette no.2333.

Swine Health Care. San Luis Obispo, CA: Vocational Educational Productions; 1981; audio cassette, guide.

Keyword: Management, care, husbandry, diseases.

Note: This program discusses the importance of prevention in combating diseases and parasites of swine, and gives an overview of common diseases and parasites of swine.

Recommended practices for prevention and/or treatment are also covered.

NAL Call No: Filmstrip No. 209.

Swine Management Practices II. Swine Production video Series. Tape \#204 Lubbock, Tex.: Creative Educational Video, c1995. 1VHS videocassette (19 min.).

Keywords: Swine, reporduction mangement, production, housing.

Note: Shows advanced management procedures required for efficient swine production. Includes sow and farrowing management, litter management, environmental controls, waste management, and shipping procedures.

NAL Call No: Videocassette no.2579.

Swine Management Practices I. Swine Production Video Series. Tape \#203. Lubbock, Tex.: Creative Educational Video, c1995. 1 VHS videocassette (18 min.).

Keywords: Swine, production practices, reproduction, husbandry.

Note: Shows the fundamental management procedures required for successful swine production. Includes types of operations, housing facilities and breeding management.

NAL Call No: Videocassette no.2578.

Swine Respiratory Disease. Ames, IA: Iowa State University, Extension Service in cooperation with WOI-TV. Shawnee Mission, KS: Distributed by RMI Media Productions; 1986; 1/2 " VHS, 120 min.

Keyword: Swine diseases, pneumonia.

Note: This is a set of four videos on swine respiratory disease. It was originally broadcast on Iowa Public Television Network between February 3-24, 1986. Part 1 is an introduction to swine pneumonia. Part 2 addresses atrophic rhinitis. Part 3 is a description of various bacterial pneumonia. Part 4 discusses mycoplasma viruses.

NAL Call No.: Videocassette no. 1422.

Symposium: Animal Welfare Compliance for Study Directors. Closter, NJ: Production Plus, Inc.; 1990; 1/2" VHS, 2 videocassettes, $208 \mathrm{~min}$.

Keyword: Animal welfare, legislation, regulations, standards.

Note: Videotape of a presentation at the Symposium: Animal Welfare Compliance for Study Directors presented at the Eleventh Annual Meeting of the American College of Toxicology in Orlando, FL, October 1990. This program was specifically designed to provide information for study directors and principal investigators so that they can be in full compliance with USDA animal welfare regulations, but is also of value to those involved in animal care. Specific areas required for training under the Act are included in addition to information on the necessity for animal research.

NAL Call No: Videocassette No. 976.

Systemic Anatomy of the Cat. Columbia State College, Learning Resources Center; Denver, CO: Distributed by Micron BioSystems, 19--; 1/2" VHS, 155 min. 
Keyword: Comparative anatomy, dissection, domestic cats.

Note: This set of 8 videocassette guides students through cat anatomy dissection. V. 1. Muscular system, pt. 1: The hindlimb and hip -- v. 5. Urinary and reproductive systems.

NAL Call No.: Videocassette no. 2046.

T.E.A.M. Learning Exel'cises, part 2: Obstacles and Groundwork. Educational horse Linda Tellington-Jones and Robyn Hood. La Jolla, CA : Lawlor Productions, [1988?] 1 videocassette (62 min.).

Keywords: Horses, training, behavior problems, methods.

Note: Linda demonstrates how to apply her methods to such problems as nervousness, whirling, poor balance, lack of coordination, stubborness and shying.

NAL Call No: Videocassette no.2142.

T.E.A.M. Learning Exercises, Part 1: Awareness Movements. Educational horse videos. Linda Tellington-Jones series Linda Tellington-Jones and Robyn Hood. La Jolla, CA : Lawlor Productions, c 1988. 1VHS videocassette (68 min.).

Keywords: Horses, training, horsemanship, behavior.

Note: These balancing exercises for horse and rider can improve problems such as nervousness, lack of coordination, and lack of concentration by working from the ground instead of the saddle.

NAL Call No: Videocassette no.2141.

Take Time? Training Your Dog from Farm Work to Trailing. H. Glyn Jones. Ipswich, U.K. : Farming Press Videos ; Alexandria Bay, N.Y.: Distributed in N. America by Diamond Farm Enterprises, c1995. 1 VHS videocassette (ca. 56 min.). ISBN: 0852362927.

Keywords: Sheep herding dogs, training, farms, competition trials.

Note: Glyn Jones demonstrates how a working sheep dog can become a competent trials competitor.

NAL Call No: Videocassette no.2502.

Teaching the Touch. Linda Tellington-Jones.Virginia City, NV: Video Velocity, c1984. 1 VHS videocassette (120 min.).

Keywords: Horses, training, human-animal communication, veterinary physical therapy.

Note: A demonstration of the methods that have proven so successful in the relatively new frontier of physical therapy and communication with horses.

NAL Call No: Videocassette no.2306.

Teaching the Yearling. Powder Springs, GA: Betsy Beineke; c1992. 1/2" VHS, 45 min.

Keyword: Training horses, yearlings, positive interaction techniques.

Note: Useful for those handling their first yearling as well as for those breeders and trainers who have had difficult yearlings in the past, this program gives clear and useful information about how to use the yearling year to develop a positive interaction between horse and trainer.

NAL Call No.: Videocassette no. 1900.

Techniques with Guinea Pigs. Raleigh, NC: North Carolina State University; 1986; 1/2" VHS, 6 min. 30 sec.

Keyword: Guinea pigs, laboratory animals, biomedical techniques, cardiac puncture, restraint, handling. 
Note: This film provides concise coverage of techniques involved in the manipulation of guinea pigs for research. Handling, gender determination, administration of substances both orally and by injection, and blood collection techniques are demonstrated using a live guinea pig.

NAL Call No: Videocassette No. 423.

Tellington TTouch for Happier, Healthier Dogs. Linda Tellington-Jones. Olympia, WA : Hartworks Video, c1992. 1 VHS videocassette (60 min.).

Keywords: Dogs, training, health, human-animal communication, massage.

Note: Join Linda Tellington-Jones with ten dogs at a four-day clinic, where she demonstrates the Tellington TTouch, a method for healing and communicating with dogs and other animals.

NAL Call No: Videocassette no.2349.

Tellington TTouch for Happier, Healthier Cats. Linda Tellington-Jones. Ashland, Or.: Hartworks Video, c1992. 1 VHS videocassette (ca. $60 \mathrm{~min}$.).

Keywords: Cats, training, behavior, human-animal communication.

Note: Join Linda Tellington-Jones in a visit to a multi-cat household, where she demonstrates the Tellington TTouch, a method for healing and communicating with cats and other animals.

NAL Call No: Videocassette no.1967.

Terrorism in Dixon. Kansas City, MO: AgriBase; 1989; 1/2" VHS, 10 min.

Keyword: Arson, farm animals, agricultural marketing.

Note: On January 29, 1989, a fire gutted the Dixon livestock auction in Dixon, CA. The environmentalist group Earth First claimed responsibility for the blaze. This video examines the aftermath of the fire that destroyed an estimated $\$ 400,000$ worth of property.

NAL Call No: Videocassette No. 625.

The American Mule: Yesterday and Today. Beltsville, MD: National Agricultural Library; 1988; 1/2 " VHS, 174 min. Recorded Oct. 25, 1988 at the National Agricultural Library, Beltsville, MD.

Keyword: Mules, history, symposium, special exhibit. National Mule Day.

Note: Presents speakers discussing the heritage of the American mule and the Missouri mule at a symposium held to celebrate National Mule Day. Part 1 is the recorded Symposium proceedings. Part 2 is the recording of the exhibit dedication ceremony. The symposium was held in conjunction with a special exhibit at the National Agricultural Library that opened October 25, 1988.

NAL Call No: Videocassette no. 1540.

The Americas' View of Animals. Minneapolis, MN: University of Minnesota; 1986; 1/2" VHS, 45 min.

Keyword: Cultural values, history, religion.

Note: Representatives from the Jewish faith, South American Catholic faith, Fundamentalist Christian faith, and Native American culture discuss their views on human-animal relationships in the Americas. The discussion reveals how current attitudes toward animals have been influenced by religious beliefs and historical conventions.

NAL Call No: Videocassette No. 323.

The Animal Welfare Act: Philosophy and Intent. Closter, NJ: Production Plus, Inc.; 1990?; 1/2" VHS, $14 \mathrm{~min} ., 40 \mathrm{sec}$. Videotape of a presentation at Symposium: Animal Welfare Compliance for Study Directors; presented at the Eleventh Annual Meeting of the American College of Toxicology, Orlando, Fla., Oct. 1990.

Keyword: United States, Animal Welfare Act, IACUC's history, 
Animal Welfare Law and legislation.

Note: The history and intent of the Animal Welfare Act and the participatory development of regulations is presented. The specific responsibilities of the IACUC and the study director and principal investigator are outlined. The approaches of the USDA to refine skills and develop appropriate attitudes through education is described. The author is Bruce Evald.

NAL Call No: Videocassette no. 972.

The Animals Are Crying. New York, NY: Learning Corporation of America; 1973; 16 mm, 28 min. Keyword: $\quad$ Pets, dogs, cats, animal shelter, spaying, population control.

Note: Through a visit to an animal shelter and discussions with shelter personnel, a young family becomes aware of dog and cat overpopulation and the urgent need for animal birth control.

NAL Call No: Motion Picture No. 170.

The Animals Film. New York, NY: Cinema Guild; 1981; 1/2" VHS, 136 min.

Keyword: Population control, intensive livestock farming, hunting, animal products, laboratory animals, saboteurs, animal welfare.

Note: Interviews with activists and filming on location provide the vehicles for a thorough examination of the animal rights philosophy and activities. A number of issues are examined, including animal population control, intensive livestock farming, hunting, animal products, and animal experimentation and testing.

NAL Call No: Videocassette No. 183.

The Ascent of the Chimps. Santa Monica, CA: Greene and Dewar New Wilderness Productions; 1984; 1/2" VHS, $23 \mathrm{~min}$.

Keyword: Chimpanzees, zoo animals, behavior, dominance.

Note: Lome Greene narrates this segment of a popular television program that examines the behavior of over 50 captive chimpanzees held at the Arnhem Zoo in the Netherlands. It emphasizes the human-like "politics" and power struggles that occurred within the largest chimp colony of its kind from 1976 to 1983. Although footage from The Family of Chimps (Videocassette No. 434) has been incorporated into the program, this film is not as complete nor as entertaining as "The Family."

NAL Call No: Videocassette No. 433.

The Avian Physical Examination and the Handling of Various Avian Species. East Lansing, Mich: Michigan State University; c1979; 1/2" VHS, 31 min.

Keyword: $\quad$ Birds, handling, avian medicine, veterinary medicine.

Note: Demonstrates techniques involved in handling birds for physical examinations. Birds used for the demonstration include the parakeet, cockatiel, great horned owl, kestrel, blue jay, and Canada goose. Discusses handling, physical diagnosis, treatments, and medicines.

NAL Call No: Videocassette No. 1858.

The Bear Necessities: Environmental Enrichment for Captive Polar Bears. Potters Bar, Herts [England]: Universities Federation for Animal Welfare; c1992; 1/2 VHS, 20 min.

Keyword: $\quad$ Polar bears, behavior, captive animals, zoos, environmental enrichment.

Note: Repetitious, invariant behaviors without apparent goal are typical of captive polar bears.

This video illustrates such behaviors and offers practical suggestions for reducing them and creating an environment which offers the bears greater opportunities for a variety of activities. 
NAL Call No.: Videocassette No. 1438.

The Challenge of Animals in Research. Lubbock, TX: Texas Tech University Health Sciences Center; $1989 ; 1 / 2$ " VHS, 30 min.

Keyword: Ethics, animal research, animal models, social attitudes, medical advances, animal welfare, regulations, guidelines, laws.

Note: Discusses different social attitudes and ethics toward the use of animals in research. Gives historical viewpoints and doctrines on the use of animals by man. Discusses medical advances. Gives historical background on animal rights and animal welfare, as well as the present animal rights situation, legislation and educational efforts. Covers current guidelines and regulations that govern animal research.

NAL Call No: Vidiocassette No. 807.

The Control of Feral Cat Colonies. Potters Bar, Herts, England: The Universities Federation for Animal Welfare; c1985; 1/2" VHS, 13 min.

Keyword: Feral cats, control, humane methods.

Note: This program, authored by Brian Redhead, describes effective and humane methods to control feral cats as developed by the Universities Federation for Animal Welfare at the request of the Cat Action Trust. The method is based on trapping, neutering, marking by ear-tipping and returning the cats to supervised sites where their long term care can be assured.

NAL Call No.: Videocassette No. 1372.

The Dog and Cat in Research. Seattle, WA: University of Washington; 1977; 72 slides, audiocassette, $25 \mathrm{~min}$.

Keyword: Dogs, cats, laboratory animals, biomedical techniques, husbandry.

Note: Research uses, acquisition, physical examination, conditioning, health maintenance, housing, and care of cats and dogs are presented.

NAL Call No: Slide No. 215.

The Dog and Cat. Raleigh, NC: Laboratory Animal Training Association; 1988; 1/2" VHS, 35 min.

Keyword: Dogs, cats, laboratory animals, husbandry, experimental techniques.

Note: This program provides information on the humane care and use of laboratory dogs and cats for scientists, laboratory technicians, and students. The recommendations are consistent with the Public Health Services' Guide for the Care and Use of Laboratory Animals and regulations set by the USDA. Topics include housing, nutrition, environment, recordkeeping, animal health care, occupational safety, handling and restraint, experimental techniques, and euthanasia. A script, test, and answer key accompany the videocassette.

NAL Call No: Videocassette No. 338, Vol. 4.

The Dog Owner's Manual. New York, NY: Maier Group Communications; 1984; 1/2" VHS, 51 min. Keyword: Doctor Fox, pets, dog care.

Note: As part of Dr. Michael Fox's animal series, this video provides professional advice for healthier, happier, loving dogs. The tape serves as a guide to dog selection, care, and handling, including massaging techniques for dogs.

NAL Call No: Videocassette No. 690. 
The Down Side of Livestock Marketing. Watkins Glen, NY: Farm Sanctuary; 1991; 1/2" VHS, 19 min. Keyword: Cattle, pigs, marketing, animal welfare, stockyards, transport, downed animals.

Note: Frank talk and explicit videotaping of weak, sick, and dying animals at stockyards and auctions comprise this tape. Farmers, livestock handlers, livestock transporters, profit margins, and low livestock prices combine to create pressures to overcrowd animals for transport and to ship sick or downed animals to market.

NAL Call No: Videocassette No. 1285.

The Family of Chimps. New York, NY: Filmakers Library; 1980; U-Matic 3/4" (No. 421), 1/2" VHS (No. 434), 55 min.

Keyword: Chimpanzees, behavior, zoo animals.

Note: In 1971 the largest colony of chimpanzees ever assembled together in a zoo environment was established at the Burgers Zoo in Arnhem, Holland. This film illustrates how ethologists use the 2.5 acre wooded exhibit to study chimpanzee behavior. Social play, aggression, mating behavior, the development of social hierarchies, and other interactions are examined in this informal, and often amusing, film. (See also The Ascent of the Chimps, Videocassette No. 433).

NAL Call No: Videocassette Nos. 421 and 434.

The Frog Inside-Out. Livingston, NJ: Instructivision, Inc.; 1988; 1/2" VHS, 67 min.

Keyword: Frogs, laboratory animals, experimental techniques, dissection, anatomy, physiology.

Note: A clear, comprehensive instructional film appropriate for high school or college biology students. Part I, External Examination of the Frog's Anatomy, investigates how the frog's anatomy allows it to adapt to life on land and in water. It discusses the anatomy and physiology of vision, reproduction, locomotion, respiration, vocalization, hibernation, and skin pigmentation. Part II, Internal Examination and Dissection, outlines proper and humane dissection techniques, and uses footage of dissected frogs to examine the following body systems: skeletal, muscular, digestive, circulatory, urogenital, and nervous. Parts I \& II use live animals, animations, diagrams, and micrographs of tissue cells to illustrate important points. The narrator states that this video is intended to reduce the number of frogs used for experimental purposes.

NAL Call No: Videocassette No. 426 Part I and 426 Part II.

The Future of Human-Animal Relations. Minneapolis, MN: University of Minnesota; 1986; 1/2" VHS, $45 \mathrm{~min}$.

Keyword: Pets, veterinary medicine, farm animals.

Note: This panel discussion addresses such topics as what pets will be like in the future, how preparation of veterinarians will change, the future of food animals, and our changing expectations from pets.

NAL Call No: Videocassette No. 328.

The Guinea Pig and Rabbit. Raleigh, NC: Laboratory Animal Training Association; 1988; 1/2" VHS, $28 \mathrm{~min}$.

Keyword: Guinea pigs, rabbits, laboratory animals, husbandry, experimental techniques.

Note: This video presents information on the humane care and use of laboratory guinea pigs and rabbits for scientists, laboratory technicians, and students. The recommendations are consistent with the Public Health Services' Guide for the Care and Use of Laboratory Animals, and regulations set by the USDA. Topics covered include housing, nutrition, 
environment, recordkeeping, animal health care, occupational safety, handling and restraint, experimental techniques, and euthanasia. A manual that includes a script, test, and answer key accompanies the videocassette.

NAL Call No: Videocassette No. 338, Vol. 3.

The Guinea Pig: Biology. Seattle, WA: University of Washington; 1975; 51 slides, audiocassette, 20 min.

Keyword: Guinea pigs, diseases, anatomy, physiology, antibiotics, anesthesia, veterinary medicine.

Note: Aspects of guinea pig anatomy, physiology, reproduction, nutrition, and pharmacology are presented. Special attention is given to vital signs, growth, and hematological uniqueness, as well as to reactions to antibiotics and anesthesia.

NAL Call No: Slide No. 218.

The Guinea Pig: Diseases. Seattle, WA: University of Washington; 1975; 53 slides, audiocassette, 18 min.

Keyword: Guinea pigs, parasites, tumors, nutrition, infections, veterinary medicine.

Note: Common or important diseases of guinea pigs in five major categories are examined: bacterial infections, viral and chlamydial infections, parasitic diseases, neoplastic diseases, and nutritional and metabolic diseases.

NAL Call No: Slide No. 218.

The Guinea Pig: Introduction and Husbandry. Seattle, WA: University of Washington; 1975; 55 slides, audiocassette, $25 \mathrm{~min}$.

Keyword: Guinea pigs, laboratory animals, husbandry.

Note: Guinea pig taxonomy, history, uses, husbandry, behavior, and reproduction are covered.

Topics related to husbandry include environment, nutritional requirements, costs, sexing, and handling.

NAL Call No: Slide No. 218.

The Guns of Autumn. New York, NY: Carousel Films, Inc.; 1975; U-Matic 3/4", 78 min.

Keyword: Hunting, wildlife, conservation, regulations.

Note: Produced by CBS News and narrated by Dan Rather, this program documents hunting across America. The film crew records the thoughts and actions of hunters as they stalk bear, deer, bison, and waterfowl. The portrayal of hunting in this video was not favorable.

NAL Call No: Videocassette No. 179.

The Hamster: Biology and Diseases, Part 2. Seattle, WA: University of Washington; 1975; 62 slides, audiocassette, $24 \mathrm{~min}$.

Keyword: Hamsters, anatomy, physiology, husbandry.

Note: This program examines the anatomy, physiology, and pharmacology of hamsters, as well as the following disorders: enteritis, bacterial and viral diseases, parasites, neoplasms, and amyloidosis.

NAL Call No: Slide No. 223.

The Hamster: Introduction and Husbandry, Part 1. Seattle, WA: University of Washington; 1975; 59 slides, audiocassette, $25 \mathrm{~min}$.

Keyword: Reproduction, behavior, instruction. 
Note: Hamster taxonomy, history, uses, husbandry, behavior, and reproduction are presented. The discussion of husbandry includes environmental and nutritional requirements, costs, sexing, and handling.

NAL Call No: Slide No. 223.

The Heart of the Matter. College Station, TX: Instructional Materials Service, Texas A\&M University; c1993; 1/2" VHS, 21 min. Includes a facilitator guide.

Keyword: Animal rights, Moral and ethical aspects, utilitarian philosophy.

Note: The discussion targets basic philosophical concepts related to the subject of animal rights/welfare (rights-based philosophy vs. utilitarian philosophy). The narrator is Josie Peacher.

NAL Call No.: Videocassette no. 1996.

The Image of Animals Today. Minneapolis, MN: University of Minnesota; 1986; 1/2" VHS, 45 min. Keyword: Cultural values, mass media, literature.

Note: University of Minnesota faculty members Dr. David Garloff, Dr. Tom Scanlan, and Dr. Arthur Geffen discuss the portrayal of animals in contemporary American mass media. The panelists review depictions of animals in cartoons, books, poems, and on television, and formulate a general conception of America's image of animals.

NAL Call No: Videocassette No. 320.

The Laboratory Rat: Biology, Husbandry, and Research Methodology. Seattle, WA: University of Washington; 1977; 59 slides, audiocassette, 15 min.

Keyword: Rats, biomedical techniques, laboratory animals, husbandry, veterinary training, veterinary medicine.

Note: This slide set describes and illustrates basic anatomy and physiology of laboratory rats, discusses standard procedures for housing rats in the laboratory, and familiarizes the viewer with basic methodology employed for manipulating rats in research. Research methodology includes handling, restraint, blood collection, anesthesia, and euthanasia. Biological values, nutrient requirements, and environmental considerations are listed in the accompanying guide.

NAL Call No: Slide No. 221.

The Laboratory Rat: Diseases. Seattle, WA: University of Washington; 1977; 48 slides, audiocassette, $16 \mathrm{~min}$.

Keyword: Rats, murine respiratory mycoplasmosis, haemobartonellosis, laboratory animals, veterinary medicine, veterinary training.

Note: This autotutorial program will familiarize veterinary and other biomedical science students with the principal diseases of laboratory rats, giving emphasis to two spontaneous infections occurring in laboratory rats. Etiology, pathogenesis, diagnosis, prevention, and treatment of the infections are detailed. A manual accompanies the slide set.

NAL Call No: Slide No. 221.

The Laboratory Rat: Introduction. Seattle, WA: University of Washington; 1977; 46 slides, audiocassette, $15 \mathrm{~min}$.

Keyword: Rats, history, veterinary training, medical research, laboratory animals.

Note: This program provides basic information to veterinary and other biomedical students concerning the role of the rat in research. The presentation covers the history of the rat 
with respect to its domestication and use in research, and specific attributes that make this species particularly valuable as an experimental subject. Specific uses of rats in research are also examined, including its use in physiological, dental, and nutritional research; behavioral studies; drug evaluation; and oncology. A manual accompanies the slide set.

NAL Call No: Slide No. 221.

The Mongolian Gerbil, Meriones Unguiculatus. Manhattan, KS: Kansas State University. College of Veterinary Medicine; 1990; 1/2" VHS, 26 min.

Keyword: Meriones unguiculatus, gerbils, animal model, care, breeding.

Note: Presents an overview of gerbil taxonomy, behavior, adaptations, and history as a model in laboratory research. The topics of husbandry, general care, breeding, and preventive medicine through a careful physical examination are also covered.

NAL Call No.: Videocassette no. 1662.

The Mongolian Gerbil. Seattle, WA: University of Washington; 1979; 60 slides, audiocassette, 20 min. Keyword: Gerbils, husbandry, laboratory animals, biomedical techniques.

Note: This program discusses the husbandry, reproduction, diseases, and research uses of gerbils. A manual accompanies the slide set.

NAL Call No: Slide No. 224.

The Mouse: Bacterial and Parasitic Diseases. Seattle, WA: University of Washington; 1975; 67 slides, audiocassette, 20 min.

Keyword: Mice, laboratory animals, diseases, parasites, veterinary medicine.

Note: This slide program serves as a guide to the principal bacterial and parasitic diseases of mice including gram positive cocci, enteric gram negatives, small gram negative bacilli, miscellaneous bacteria, and mycoplasma. The program also describes and illustrates the history, significance, etiology, pathogenesis, clinical signs, diagnosis, pathology, and control of Tyzzer's disease and ectoparasites. A manual accompanies the slide set.

NAL Call No: Slide No. 227, Part 5.

The Mouse: Biology and Use in Research. Seattle, WA: University of Washington; 1975; 77 slides, audiocassette, $25 \mathrm{~min}$.

Keyword: Mice, laboratory animals, medical research.

Note: This slide set covers basic biology and research uses of mice. The program describes and illustrates the following: history, taxonomy, nomenclature, sources and costs, anatomy, reproduction, physiological parameters, genetics, nutrition, behavior, growth, and life span. A manual accompanies the slide set.

NAL Call No: Slide No. 227, Part 1.

The Mouse: Handling, Restraint, and Other Techniques. Seattle, WA: University of Washington; 1975; 48 slides, audiocassette, $12 \mathrm{~min}$.

Keyword: Mice, laboratory animals, experimental techniques.

Note: This program demonstrates basic technical skills required for the proper care of mice and for their use in biomedical research. It includes handling and restraint, injections and oral administration of medicine, blood and urine collection, sexing, identification, anesthesia, and euthanasia. A manual accompanies the slide set.

NAL Call No: Slide No. 227, Part 2. 
The Mouse: Husbandry. Seattle, WA: University of Washington; 1975; 74 slides, audiocassette, 15 min. Keyword: Mice, laboratory animals, husbandry, housing.

Note: This slide set examines environmental requirements, caging, bedding, feeding and watering, sanitation, breeding, transportation, and quarantine procedures involving laboratory mice. A manual accompanies the slide set.

NAL Call No: Slide No. 227, Part 3.

The Mouse: Neoplastic, Non-Infectious and Miscellaneous Diseases. Seattle, WA: University of Washington; 1975; 44 slides, audiocassette, 14 min.

Keyword: $\quad$ Mice, laboratory animals, cancer, tumors, veterinary medicine.

Note: This slide program illustrates the role of mice in cancer research. The presentation provides some insight into neoplastic diseases (leukemia, mammary tumors), noninfectious diseases (hormone contamination, chloroform and ethylene oxide poisoning), and miscellaneous causes of disease (hexamitiasis, encephalito-zoonosis, eperythrozoonosis, dermatomycosis) in mice. A manual accompanies the slide set.

NAL Call No: Slide No. 227, Part 6.

The Mouse, Rat and Hamster. Raleigh, NC: Laboratory Animal Training Association; 1988; 1/2" VHS, $34 \mathrm{~min}$.

Keyword: Mice, rats, hamsters, laboratory animals, restraint, husbandry, biomedical techniques.

Note: This training film provides information on the humane care and use of laboratory rodents for scientists, laboratory technicians, and students. The recommendations are consistent with the Public Health Services' Guide for the Care and Use of Laboratory Animals and regulations set by the USDA. Topics include housing, nutrition, environment, recordkeeping, animal health care, occupational safety, handling and restraint, experimental techniques, and euthanasia. A manual that includes a script, test, and answer key accompanies the videocassette.

NAL Call No: Videocassette No. 338, Vol. 2.

The Mouse: Viral Diseases. Seattle, WA: University of Washington; 1975; 45 slides, audiocassette, 18 $\min$.

Keyword: Mice, laboratory animals, mouse pox, diarrhea.

Note: This slide set discusses ectromelia (mouse pox) and viral diarrhea of infant mice, and illustrates their effects on mice. The etiology, pathogenesis, clinical signs, pathology, and diagnosis of the diseases are described. A manual accompanies the slide set.

NAL Call No: Slide No. 227, Part 4.

The Nature of Change. St. Louis, MO: The Monsanto Company; 1984; 1/2" VHS, 3/4" U-Matic, 17 min. Keyword: Biotechnology, bovine somatotropin, farm animals.

Note: This film discusses the limitations of traditional animal and plant breeding, and the possibilities of overcoming these limitations using recombinant DNA technology. The program examines the uses of bovine growth hormone to increase milk production in cows and Agrobacterium tumefaciens for crop improvement.

NAL Call No: Videocassette Nos. 202 and 407.

The New Research Enviromment. Washington, DC: Foundation for Biomedical Research; 1987; 1/2" VHS, 14 min. (Tape 1), 30 min. (Tape 2). 
Keyword: Rats, rabbits, laboratory animals, regulations, animal welfare, public opinion, surgery, biomedical techniques, animal care and use committees.

Note: Tape 1: The Animal Rights Movement: The Threat to Research explains how media coverage of a few instances of research animal abuse has significantly disrupted biomedical research. The history of the anti-animal research movement is briefly reviewed, and the results of a public opinion survey concerning the animal research community are presented. Tape 2: This program is divided into three parts: 1) An examination of the role of Animal Care and Use Committees (ACUC's) for ensuring humane laboratory animal treatment. It includes a dramatization of an ACUC conducting a protocol review; 2) A demonstration of techniques for manipulating laboratory animals for research. It covers handling, identification, injections, gavaging, anesthesia, blood collection, and euthanasia, using rats and rabbits as subjects; and 3) A demonstration of recommended procedures involved in survival surgery. Presurgical scrubbing, instrument sterilization, and postsurgical care are discussed.

NAL Call No: Videocassette No. 194.

The Nonhuman Primates. Raleigh, NC: Laboratory Animal Training Association; 1988; 1/2" VHS, 29 min.

Keyword: $\quad$ Primates, laboratory animals, veterinary medicine, husbandry, restraint, veterinary training.

Note: This program provides information on the humane care and use of laboratory primates for scientists, laboratory technicians, and students. The recommendations are consistent with the Public Health Services' Guide for the Care and Use of Laboratory Animals and regulations set by the USDA. Topics include housing, nutrition, environment, recordkeeping, animal health care, occupational safety, handling and restraint, experimental techniques, and euthanasia. A manual that includes a script, test, and answer key accompanies the videocassette.

NAL Call No: Videocassette No. 338, Vol. 5.

The Other Side of the Fence. Camden, ME: American Society for the Prevention of Cruelty to Animals and Varied Directions, Inc.; 1988; 1/2" VHS, 10 min. $37 \mathrm{sec}$.

Keyword: Veal calves, intensive livestock farming, animal welfare.

Note: The narrator questions whether veal calves raised under modern intensive farming systems are supplied their fundamental needs of adequate shelter, nutrition, and companionship. Although the script denigrates this production system, the still pictures and footage of actual veal calf operations provide the viewer with a realistic depiction of modern veal production.

NAL Call No: Videocassette No. 432.

The Physical Exam. Merritt Island, FL: K-F Equine Video Production, Inc.; c1987; 1/2" VHS, 70 min. Keyword: Horses, buying stock, basic anatomy, common diseases, scoring condition.

Note: Dr. Floyd D. Kirby teaches the prospective buyer how to examine a horse with a view toward what conditions might be present and how serious that condition is. Problem areas covered include: eyes, mouth, ears, skin, lameness, locomotion and internal problems.

NAL Call No.: Videocassette No. 1935

The Principles of Horseshoeing: The Sound Horse. LaPorte, CO: Butler Publishing and Tools; c1987; $1 / 2^{\prime \prime}$ VHS, $55 \mathrm{~min}$. 
Keyword: Horseshoeing, normal conditions.

Note: Describes machine-made shaping and cold shoeing, handmade shoeing and hot shoeing for the sound horse.

NAL Call No.: Videocassette No. 1938.

The Rhino War: A Desperate Fight to Save an Endangered Species. Stanford, CT: Vestron Video "A National Geographic Explorer production"; 1987; 1/2" VHS, 60 min.

Keyword: Black rhino, conservation, poaching, smuggling, conservation.

Note: This video presents efforts to save the black rhino from poachers in East Africa. Greed, corruption, and ignorance are the main factors for their destruction. The conservation and life of the rhino depends solely on humans.

NAL Call No: Videocassette No. 1104.

The Soviet Circus. Washington, DC: National Geographic Society. Distributed by Vestron Video of Stanford, CT; c1989,1988; 1/2" VHS, 60 min. ISBN: 0805107126. Videocassette release of the 1988 film. Closed captioned for the hearing impaired.

Keyword: Circus, Moscow Circus School, animal trainers.

Note: Go behind the scenes at the Moscow Circus School and observe the wonders of performances that have delighted millions. Shows the work of lion tamers, trapeze artists and the famous clowns among others. The author is Theodore Bikel.

NAL Call No.: Videocassette no. 1099.

The T Touch That Teaches, Part I: Head and Neck. La Jolla, CA: Lawlor Productions; 1988; 1/2" VHS, 60 min.

Keyword: Horses, training, pain, injury, nervous system, behavior.

Note: Linda Tellington-Jones explains and demonstrates how sore muscles and tender spots and behavioral problems of horses can be overcome by the use of touches and body awareness, described as the Tellington-Jones Equine Method. These techniques can be easily learned and used by the novice or professional.

NAL Call No: Videocassette No. 1319.

The T Touch That Teaches, Part III: Body, Legs, and Tail. La Jolla, CA: Lawlor Productions; 1988; $1 / 2^{\prime \prime}$ VHS, $70 \mathrm{~min}$.

Keyword: Horses, training, pain, injury, nervous system, behavior.

Note: Part II of this series further demonstrates the use of the Tellington Touch to locate and relieve areas of pain, tension, and discomfort. Through T.E.A.M. (Tellington-Jones Equine Method) the horse becomes more aware of its body and movement, thus improving performance.

NAL Call No: Videocassette No. 1320.

The Tellington TTouch for Happier, Healthier Cats. Ashland, OR: Hartworks Video; c1992; 1/2" VHS, ca $60 \mathrm{~min}$.

Keyword: Cats, massage, healing touch techniques, Linda Tellington Jones techniques, human-animal bond communication.

Note: Join Linda Tellington-Jones in a visit to a multi-cat household, where she demonstrates the Tellington Ttouch. The Tellington Ttouch is a method for healing and communicating with cats and other animals.

NAL Call No.: Videocassette No. 1967. 
The Ultimate Test Animal. New York, NY: Cinema Guild; 1985; 1/2" VHS, 41 min.

Keyword: Animal models, product safety, Depo Provera, contraceptives, pharmaceuticals, cancer, depression.

Note: This film examines the controversy surrounding the widespread use of Depo Provera, a contraceptive drug produced by Upjohn Company. The drug is currently available in the United States and in some Third World countries. Representatives of the Upjohn Company and FDA, as well as drug recipients comment on its safety and side effects. The validity of data from animal studies are called into question.

NAL Call No: Videocassette No. 425.

The Value of Animal Research in the Betterment of Health. Gainesville, FL: University of Florida; 1984; 1/2" VHS, 16 min. 50 sec.

Keyword: Laboratory animals, medical research, animal welfare, ethics.

Note: An overview of animal use in research, this program emphasizes the role of animal experimentation in the advancement of human health care.

NAL Call No: Videocassette No. 203.

Think Like a Horse. Mary Ann Simonds. Richmond, CA : COMMARTS [Communication Arts (Firm)], c1992. 1 VHS videocassette (ca. $37 \mathrm{~min}$.).

Keywords: Horses, behavior, human-animal communication.

Note: Learning to understand horse behaviors and interpret them.

NAL Call No: Videocassette no.2636.

Thoracotomy and Lung Lobectomy in the Dog. Columbus, OH: Biomedical Media; c1986; 1/2" VHS, 26 min.

Keyword: Dogs, surgical procedure, veterináry medicine, lungs, chest.

Note: Acquaints the viewer with anatomy of the thoracic cavity through a demonstration of an open thorax procedure and a lung lobectomy in a dog.

NAL Call No: Videocassette no. 1719.

Tips for Safe Horse Handling. Belleview, FL: Dillon Video Productions;

c1990; 1/2" VHS, 24 min.

Keyword: Horses, foals, handling, restraint.

Note: Illustrates the safe handling methods/practices for horses and foals.

NAL Call No.: Videocassette no. 1946.

TiterMax: An Adjuvant Update. Eugene Davidson and Ernest Prentice. Norcoss, GA Vaxcel, [1994?]. 1 VHS videocassette (18 min.).

Keywords: Monoclonal anitibody production, adjuvants, alternative method.

Note: TiterMax provides a less toxic experimental formulation for the production of antibodies. This program documents superiority of this product as a preferred alternative in inducing reliable antibody titers to diverse antigens, while reducing the risk to animals used in experimentation. The program is in 2 parts. Part 1. (10 min.) features Dr. Ernest Prentice, Dean of Research, Univ. of Nebraska Medical Center; and Dr. Eugene Davidson, Professor and Chairman of the Dept. of Biochemistry and Molecular Biology at Georgetown Univ. -- Part 2. (8 min.) features four recommended methods for TiterMax emulsification depicting each method in a step-by-step visual preparation.

NAL Call No: Videocassette no.2038. 
To be a Gorilla: The Management of Lowland Gorillas in Captivity.Chicago, IL: Lincoln Park Zoological Society; 1990; 1/2" VHS, 22 min.

Keyword: Lincoln Park Zoo, primates, gorillas, zoos, care, environmental enrichment, veterinary care, history, management.

Note: This program looks at the care that the 22 (in 3 family groups) gorillas receive from the zoo staff. The gorillas' environment is designed to provide stimulation and exercise and imitate natural habitat with ropes and steel climbing trees to promote social development and interaction between gorillas. The gorillas receive a nutritious diet and are encouraged to forage for their food. Living areas are cleaned daily, and new straw is provided regularly. The zoo hospital staff provide vaccinations and deal with many medical situations, including surgery. Infants born at the zoo receive special attention for their first 72 hours of life.

NAL Call No.: Videocassette no. 1559.

To Hunt or Not to Hunt. Minneapolis, MN: University of Minnesota; 1986; 1/2" VHS, 45 min. Keyword: Hunting, wild animals, animal welfare.

Note: Dr. Barbara O'Connel, Professor of Anthropology at Hamline University, Dov Cohn, an animal protection advocate, and Dr. James Cooper, Associate Professor of Fisheries and Wildlife of the University of Minnesota discuss why people hunt and whether hunting should be permitted.

NAL Call No: Videocassette No. 370.

Tools for Research: Questions About Animal Rights. Oley, PA: Bullfrog Films; 1983; 1/2" VHS, 37 $\min$.

Keyword: LD 50, Draize test, animal welfare, pound animals, animal models, medical research, ethics.

Note: This film questions basic assumptions about animal research: Do existing laws actually protect laboratory animals? Is all animal research of value to humans? Is most current research repetitive and wasteful? Can experimental results from animals be accurately extrapolated to humans? Do lab animals suffer? Comments from psychologist Don Barnes and philosophers Peter Singer and Bernard Rollin suggest that much of animal research is unnecessary. The film includes old footage from Department of Defense animal experiments, and cosmetic and pharmaceutical laboratory animal testing.

NAL Call No: Videocassette No. 499.

Touch for Dogs. La Quinta, CA: Thane Marketing International; c1994; 1/2" VHS, 84 min. Originally copyrighted in 1993.

Keyword: Dogs, behavior, training, health, Ttouch, Linda Tellington-Jones, human-animal communication.

Note: Linda Tellington-Jones demonstrates how various types of touches can be used to change a dog's behavior. There are also types of touch that can ease pain and stress associated with old age, injuries, or surgery.

NAL Call No.: Videocassette no. 2040.

Training Corral-Living Rhesus Monkeys for Fecal and Blood Sample Collection. Covington, LA: Falkenstein Productions and the Delta Regional Primate Research Center; 1990; 1/2" VHS, 27 min. Includes 1 article reprint of $3 p$. 
Keyword: Rhesus monkeys, Macaca mulatta, blood, feces, collection and preservation, behavior, animal welfare, Laboratory animals.

Note: This videotape, authored by Margaret R. Clarke, shows acclimation techniques to reduce stress for corral-living rhesus monkeys (Macaca mulatta) when collecting fecal and blood samples. The monkeys are given food rewards in return for defecation in single holding cages. They also are trained to extend their leg through a modified squeeze cage for unanesthetized bleeding from the saphenous vein. Once the acclimation is completed, the animals are shown to be relaxed during the procedure. One adult female continued to nurse her neonate infant through the venipuncture. This behavior modification is intended to reduce stress and increase safety for the animals and the technicians. This tape also provides a look at the corral facility at the Delta Regional Primate Research Center at Tulane University.

NAL Call No.: Videocassette no. 1315.

Training Game. Behind-the-Scenes Look at Animal Care at Brookfield Zoo. Chicago Zoological Society (IIl.). Chicago: Brookfield Zoo, c1997. 1 VHS videocassette (ca. 16 min.).

Keywords: Zoo animals, training strategies, natural behaviors, Brookfield Zoo.

Note: Shows Brookfield Zoo staff as they work to provide animals with opportunities to express natural behaviors.

NAL Call No: Videocassette no. 2719.

Additional support for this video was provided by the U.S. Department of Energy through the Science Explorers Program and Argonne National Laboratory.

Training Medical Behaviors in Orangutans at Brookfield Zoo. Chicago, IḶ: The Chicago Zoological Society and The Brookfield Zoo; 1989; 1/2" VHS, 10 min.

Keyword: Training, behavior modification, veterinary treatment

Note: This video demonstrates the long, progressive process of positive reinforcement training needed to administer insulin injections and oral medications to two diabetic orangutans.

May serve as a case study for training other animals with chronic diseases to receive injections.

NAL Call No: Videocassette no. 1841.

Transgenic Animals: Food Sources--FDA, FSIS, Industry and Future Perspectives. BioConferences International, Inc.; BioEast (Washington, D.C). Bethesda, MD: BioConferences International, c1993. 1 VHS videocassette (ca. $90 \mathrm{~min}$.).

Keywords: Transgenic animals, congresses, f.ood biotechnology, regulations, technology.

Note: Three speakers discuss transgenic animals as food sources. Topics covered include the Food Safety and Inspection Service's proposal on the regulation of transgenic food animals to ensure the safety and wholesomeness of products resulting from transgenic livestock and poultry, why use transgenic animals for food products, what is transgenic animal technology, and how scientific societies can help the public understand how transgenic animals are achieved.

NAL Call No: Videocassette no.2195.

Transgenic Animals in the Production of Biopharmaceuticals. Bethesda, MD: BioConferences International, Inc; 1993; 1/2" VHS, 104 min.

Keyword: Swine, transgenic animals, conference, biopharmaceuticals, swine.

Note: Four speakers discuss the role of transgenic animals in the production of 
biopharmaceuticals. Topics covered include the technological strategy of making transgenic animals for different purposes, production of proteins in the milk of transgenic animals, production of recombinant human hemoglobin in transgenic swine, and transgenic production of the human cystic fibrosis protein in livestock. The video is of a session of the conference BioEast'93 held in Washington, DC, January 24-27, 1993.

NAL Call No.: Videocassette no. 1977.

Transgenic Farm Animals. Washington, DC: USDA Food Safety and Inspection Service; 1986; 1/2" VHS, $53 \mathrm{~min}$.

Keyword: Biotechnology, pigs, USDA.

Note: This is a videotaped seminar given by Dr. Douglas Bolt, USDA-ARS Reproduction Physiology Laboratory, describing the methodology and results of a research project in which a foreign growth gene was transferred by microinjection into the pronuclei of a pig's ovum.

NAL Call No: Videocassette No. 264.

Transgenic Technologies. Potomac, MD: BioConferences International; 1991; 1/2" VHS, 113 min.

Keyword: Biotechnology congresses, transgenic animals transgenic plants.

Note: Panel discussion on transgenics and how they can be applied to biotechnology, development studies on mice using transgenics; immunological developments using transgenics; transgenic pigs; and transgenics and fish. This is a videorecording of session at BioEast'91 held in Washington, DC, Jan 6-9, 1991, sponsored by BioConferences International, Inc., Genetic Engineering News, IBEX; co-sponsored by the Pennsylvania State University Biotechnology and Bioprocessing Resource Center.

NAL Call No.: Videocassette no. 1143.

Triploid Oyster Production. Hatchery Manual for Producing Triploid Oysters. Sandra L. Downing and Richard Strickland. [Seattle, Wash.?] : Washington Sea Grant Program, c1989. 1 VHS videocassette (38 min.).

Keywords: Oyster culture, polyploidy, techniques for breeding.

Note: Discusses the background of polyploidy research, explains the 10 steps of producing triploid oysters using cytochalasin B and how to recognize the difference between triploid and diploid oysters and the commercial importance of the type of oyster. Related to "Hatchery manual for producing triploid oysters" by Standish K. Allen, Jr.; Sandra L. Downing, and Kenneth K. Chew. "T60-892; 396999; 06/27/89"--Spine label of cassette.

NAL Call No: Videocassette no.1047.

Trout Diseases. Kentucky State University. Cooperative Extension Program and Community Research Service; United States. National Oceanic and Atmospheric Administration. Frankfort, KY : KSU Cooperative Extension, 1995. I VHS videocassette (ca. 30 min.).

Keywords: Trout diseases, diagnosis, treatment.

Note: Describes conditions which cause diseases associated with trout. Discusses these various diseases including viral, bacterial, etc. Methods for correcting the problems are listed. Using drugs should not be used accept as the last resort.

NAL Call No: Videocassette no.2535.

Ttouch for Horses. Linda Tellington-Jones. La Quinta, CA : Thane Marketing International, c1994. 1 VHS videocassette (47 min.). 
Keywords: Horses, behavior, t.raining, health, massage, touch, human-animal communication.

Note: Linda Tellington-Jones demonstrates how touches can be used to change a horse's behavior and also to ease pain and stress associated with old age, injuries, or surgery. Originally copyrighted in 1993.

NAL Call No: Videocassette no.2355.

Tuberculin Testing Exotic Animals. San Diego, CA: San Diego Zoological Society and University of California at Davis; 1981; 84 slides, audiocassette, 18 min.

Keyword: Tuberculin, serological diagnosis, zoo animals, diseases.

Note: This program demonstrates use and methodology of tuberculin testing in exotic animals.

NAL Call No: Slide No. 196.

Understanding Dairy Cattle Behavior to Improve Handling \& Production. Madison, WS: Livestock Conservation Institute; c1992; 1/2", 24 min.

Keyword: Dairy farming, dairy cows, behavior, handling, milk production..

Note: Provides insight into dairy cattle behavior for handlers and herders. Gives suggestions to reduce handling stress which can result in improved milk production.

NAL Call No.: Videocassette no. 2036.

Understanding Farm Animal Behavior. Minneapolis, MN: University of Minnesota; 1986; 1/2" VHS, $45 \mathrm{~min}$.

Keyword: Cattle, pigs, farm animals, behavior, animal welfare.

Note: Dr. William Hall, Professor of Veterinary Medicine at the University of Illinois, and Dr. William Rempel, Professor of Animal Science at the University of Minnesota, discuss and explain aspects of farm animal behavior. The panelists field questions from the moderator and the audience. The discussion touches on factory farming and animal rights.

NAL Call No: Videocassette No. 367.

Unlocking Nature's Secrets. Englewood, CO : National Cattlemen's Association ; [S.1.] : Beef Board, [199-?]. 1 VHS videocassette (27 min.).

Keywords: Agricultural conservation.

Note: Shows how seven cattlemen have unlocked some of nature's secrets by working daily to care for the natural resources that provide for their livelihoods.

NAL Call No: Videocassette no.2530.

Unnecessary Fuss. Washington, DC: People for the Ethical Treatment of Animals (PETA); 1984; 1/2" VHS, 29 min.

Keyword: Biomedical techniques, baboons.

Note: Ingrid Newkirk of PETA narrates segments of videotape removed from the University of Pennsylvania Head Injury Clinic by the Animal Liberation Front in June 1984. The segments highlight neurological procedures on baboons and critique research methodologies by scientists.

NAL Call No: Videocassette No. 299.

USDA Slaughter. American Emu Association. [United States] : The Association, c1995. 1 VHS videocassette (ca. 23 min.).

Keywords: Emus, slaughtering, slaughter houses, US Department of Argriculture inspections. 
Note: Shows what the USDA inspector looks for in the slaughtering process of emus.

NAL Call No. Videocassette no.2647.

Using Animals in Research: Guidelines for Investigators. Beltsville, MD: USDA, Agricultural Research Service; 1986; U-Matic 3/4", 6 videotapes, 240 min.

Keyword: Animal welfare, legislation, animal research, regulations, euthanasia, PETA, APHIS, NIH, investigators.

Note: This film records in its entirety a course sponsored by the USDA/Agricultural Research Service and presented to investigators on March 25, 1986. Speakers from the Animal and Plant Health Inspection Service, National Institutes of Health, Public Health Service, and Agricultural Research Service present information on laws, policies, and practices that affect the use of research animals; discuss techniques that are commonly used in an animal laboratory; and provide references for those who want to learn more about specific procedures. Tape 1 - regulatory issues from an APHIS perspective. Tape 2 - film, "Unnecessary Fuss," assembled by PETA from the University of Pennsylvania research documentation. Tape 3 - principles and policies for animal use in NIH extramural programs. Tape 4 - principles and policies for animal use in the Beltsville area. Tape 5 technical information and training opportunities for animal users. Tape 6 - panel discussion of audience questions.

NAL Call No: Videocassette No. 186.

Veal Farming Is Special. Park Ridge, IL: American Farm Bureau Federation; 1983; 1/2" VHS, 12 min.

Keyword: Veal calves, intensive livestock farming, animal welfare, husbandry.

Note: Promoting the merits of the veal industry, this film begins with a tour of a family-operated veal farm. Family members comment on aspects of animal management including iron supplementation, ventilation, and sanitation. Dr. Don Lawson of the Provimi Veal Company discusses research on alternate housing systems, including the loose housing and modified stall systems.

NAL Call No: Videocassette No. 436.

Veterinary Medicine \& Human Health. [United States] : American Veterinary Medical Association : Association of American Veterinary Medical Colleges, c1994. 1 VHS videocassette (12 min.).

Keywords: Veterinary medicine, research, United States, relationships to human health.

Note: Shows how veterinary medicine directly impacts the health of human beings. Areas covered include biomedical research, food safety and public health.

NAL Call No: Videocassette no.2681.

Video Guide to Recording Marine Mammal Stranding Data. Orlando, Fla: Southeastern United States Marine Mammal Stranding Network, c1992. 1 VHS videocassette (13 min.).

Keywords: U.S., South East, instructional video, basic data and measurements, stranded maring mammals.

Note: Shows Stranding Network participants how to collect the basic data needed on stranded marine mammals in the southeastern United States and how to fill out the individual categories found on the marine mammal data record form used by the Southeastern United States Marine Mammal Stranding Network.

NAL Call No: Videocassette no.2105.

Vitamin E for Beef Cattle. L. R. McDowell. [Kenilworth, NJ]: Schering-Plough Animal Health, c1992. 1 VHS videocassette (ca. $20 \mathrm{~min}$.) and 1 guide. 
Keywords: Vitamin E, structure and function, cattle requirements, deficiency.

Note: Also called "Vitamin E, a Crucial Link to Peak Performance." Topics explored in video and in guide include: structure and function of vitamin $\mathrm{E}$, vitamin $\mathrm{E}$ requirements of cattle, vitamin $\mathrm{E}$ deficiency in cattle, assessment of vitamin $\mathrm{E}$ status, vitamin $\mathrm{E}$ sources and need for supplementation.

NAL Call No: Videocassette no.2076.

Voices I Have Heard. Raleigh, NC: Culture and Animals Foundation; 1988; 1/2" VHS, 60 min.

Keyword: Animal welfare, activists, laboratory animals, pets, wildlife.

Note: Older activists tell how they are improving the welfare of animals. Among the activities undertaken by these individuals are caring for injured wildlife, protesting animal research, maintaining a private wildlife refuge, preventing carriage horse abuse, promoting alternatives to the use of live animals for experimentation, protecting Canadian seal pups, and rescuing burrows in the Grand Canyon.

NAL Call No: Videocassette No. 419.

Watching Animals. Washington, DC: National Geographic Society; c1978; 1/2" VHS, 12 min. Includes 2 identical teacher's guides.

Keyword: Animal behavior, wildlife watching.

Note: Explains that scientists learn about the behavior of animals by watching them closely and that any person with an interest in animals can do the same. Shows scientists in places all over the world conducting experiments with interesting animals that live in the wild.

NAL Call No.: Videocassette no. 1157.

We Are All Noah. New York: American Fund for Alternatives to Animal Research; 1986; 1/2" VHS, 25 min.

Keyword: Religion, ethics, alternatives, cats, dogs, cattle, chickens, pigs, medical research.

Note: Tom Regan narrates this discussion of religious values regarding the care and use of animals. Representatives from the Jewish and Christian faiths call for a more compassionate relationship between humans and animals. Painful research and testing procedures, fur trapping, intensive animal agriculture, and pound animal euthanasia are discussed. Alternatives to the use of live animals in research and education are briefly examined.

NAL Call No: Videocassette No. 505.

Weaning. Lexington, KY: Blood-Horse Productions; c1984, 1/2" VHS, ca. 32 min.

Keyword: Weaning, horses.

Note: Weaning programs at four horse farms are discussed.

NAL Call No.: Videocassette no. 1899.

Welfare Parameters in Veal Calf Production Facilities. Carolyn L. Stull, Duncan A. McMartin. Davis, Calif:: University of California, Davis. School of Veterinary Medicine.and Visual Media, [1992]. 1 VHS videocassette (17 min.).

Keywords: Cattle housing, veal industry, animal welfare.

Note: Describes and evaluates the welfare of special fed veal calves at commercial facilities.

NAL Call No: Videocassette no.2130.

What's The Beef?. Lubbock, TX: Creative Educational Video; 1991; 1/2" VHS, 15 min. 
Keyword: Production, livestock, animal welfare, animal rights.

Note: This video, along with the accompanying facilitor's guide, concentrates on the animal activists' concerns about animal production. Contrasting viewpoints are explored, with a factual and realistic look at animal agriculture and the animal rights movement.

NAL Call No: Videocassette No. 1284.

When Should I Call the Vet?. La Jolla, CA: Lawlor Productions; c1988; 1/2" VHS, 104 min.

Keyword: Horses, diseases, normal behavior, diagnosis, colic, injuries, hoof problems, veterinary care.

Note: This set of two video cassettes is part of the Equestrian Horse Video Series. Pam Lawlor discusses the various indicators and conditions that can affect a horse and when you should seek veterinary help. In part 1, Finding the norm for your horse, there is a discussion on what are normal behaviors and activities for a horse. Part 2. Colic, wounds and hoof ailments. addresses the symptoms and seriousness of those conditions that require veterinary care.

NAL Call No.: Videocassette no. 1910.

Whither Biogenetics? The Life Revolution. Films for the Humanities (Firm); Primedia Productions; Canoptic Productions; TVOntario; Telefilm Canada. Princeton, NJ: Films for the Humanities \& Sciences, Inc., c1990. 1 VHS videocassette (26 min.).

Keywords: Biotechnology, genetic engineering, benefits, risk factors.

Note: Discusses the possible future benefits from biotechnology in ending disease, malnutrition, and starvation; also notes the possible future negative aspects in dangerous and irreversible side-effects, political uses of genetic information, the development of bioweaponry, and the perversion of scientific breakthroughs to private gain. Originally copyrighted in 1988 . "FFH 2442."

NAL Call No: Videocassette no.1964.

Who Cares Anyway. Toronto, Canada: Lynx Film Production; 1979; 1/2" VHS, 30 min.

Keyword: Animal welfare, euthanasia, overpopulation, puppy mills, humane society, animal abuse.

Note: This video shows what happens when animals are no longer desired as pets. Emphasizes the abuses of puppy mill breeding. Discusses abandonment of pets and the need for controls, and what happens to animals in shelters.

NAL Call No. Videocassette No. 827.

Who Speaks for the Animals?. Hyattsville, MD: USDA/Animal and Plant Health Inspection Service; 1987; 80 slides, audiocassette, 15 min.

Keyword: Animal welfare, ethics, APHIS, legislation, regulations.

Note: This slide set presents an overview of animal welfare issues and discusses the role of the Animal and Plant Health Inspection Service (APHIS) in enforcing legislation designed to protect animals from abuse.

NAL Call No: Slide No. 208.

Why I Should Stay Awake in Science Class. Washington, DC: Foundation for Biomedical Research; $1 / 2$ " VHS, ca. $10 \mathrm{~min}$.

Keyword: Scientists, teaching, elementary school, laboratory research.

Note: Depicts scientists at work in laboratories, on land and sea, and in the air. Explains the value 
of scientific knowledge and research.

NAL Call No.: Videocassette no. 2008.

Will I Be Alright Doctor?. Washington, DC: Foundation for Biomedical Research; 1984 (No.146) and 1985 (No.147); 1/2" VHS, 14 min. 6 sec.

Keyword: Health care, laboratory animals, medical research, animal welfare, ethics.

Note: Surgeons and patients discuss the contribution of animal research to the advancement of human health care. Particular benefits discussed in this program include greater success with organ transplants and correcting congenital birth defects, extending operating time, and improving chemotherapy treatments for leukemia patients. A laboratory animal veterinarian comments on his role in ensuring humane care and use of experimental animals. Footage of humans and animals undergoing surgery is presented.

NAL Call No: Videocassette Nos. 146 and 147.

Within Striking Distance. [Chicago]: The Lincoln Park Zoo, c1987. 1 VHS videocassette (ca. 11 min.). Keywords: Captive animals, zoos, handling of animals.

Note: Discusses the dangers that zoo keepers face when they get too close to the animals and suggest ways to handle the animals.

NAL Call No: Videocassette no.2089.

World Congress Awards Luncheon. William Moy Stratton Russell. World Congress on Alternatives and Animal Use in the Life Sciences (1993 : Baltimore, Md.). 1993. 1 VHS videocassette (60 min.).

Keywords: Awards, congress on animal welfare, alternatives. Russell \& Burch.

Note: Program consists of a ceremony honoring the recipients of the Center for Alternative Animal Testing and the Russell \& Burch awards. Includes a speech by William Russell.

NAL Call No: Videocassette no.2083.

Youth and Dairy Cattle: A Safe Partnership. Bowling Green, Ky.: The Livestock Conservation Institute, [between 1988 and 1995]. IVHS videocassette (16 min.).

Keywords: Cattle, restraint, handling, safety precautions, animal behavior.

Note: Teaches youth how to understand cattle behaviors better so they can work with the animals in a safe way.

NAL Call No: Videocassette no. 2483.

Zoo careers: A Look Behind the Scenes at a Modern Zoo. Part of the series--"Zoo careers video curriculum."; Portland, OR: Metro Washington Park Zoo. Education Division; c1990; 1/2" VHS, 30 min.

Keyword: Metro Washington Park Zoo, careers, educational requirements.

Note: Using the Metro Washington Park Zoo as a model, describes the duties of and necessary skills and education for various jobs in a zoo. For grades 4 and above.

NAL Call No.: Videocassette No. 1595.

Zoos of the World. Washington, DC: National Geographic Society and Metromedia Producers Corporation; c1970; 1/2" VHS, 50 min.

Keyword: Zoos, worldwide, captive animal issues.

Note: Shows animals in zoos all over the world, presents the history of man's obsession with capturing and keeping animals, and discusses how the concerns of zoos have changed. The narrator is Joseph Campanella.

NAL Call No.: Videocassette No. 2035. 


\section{National Agricultural Library} Document Delivery Services Branch

\section{Services Available to Individuals}

The National Agricultural Library (NAL) supplies agricultural materials not found elsewhere to other libraries and information centers. Submit requests first to your local library resources. In the United States, possible sources are public libraries, state libraries, land-grant university or other large research libraries within a state. In other countries submit requests through major university, national, or provincial institutions.

If the publications are not available from your local library, have your library submit requests to NAL with a statement indicating their non-availability following the directions below.

\section{Library Must Include the Following Data Elements in Each Request:}

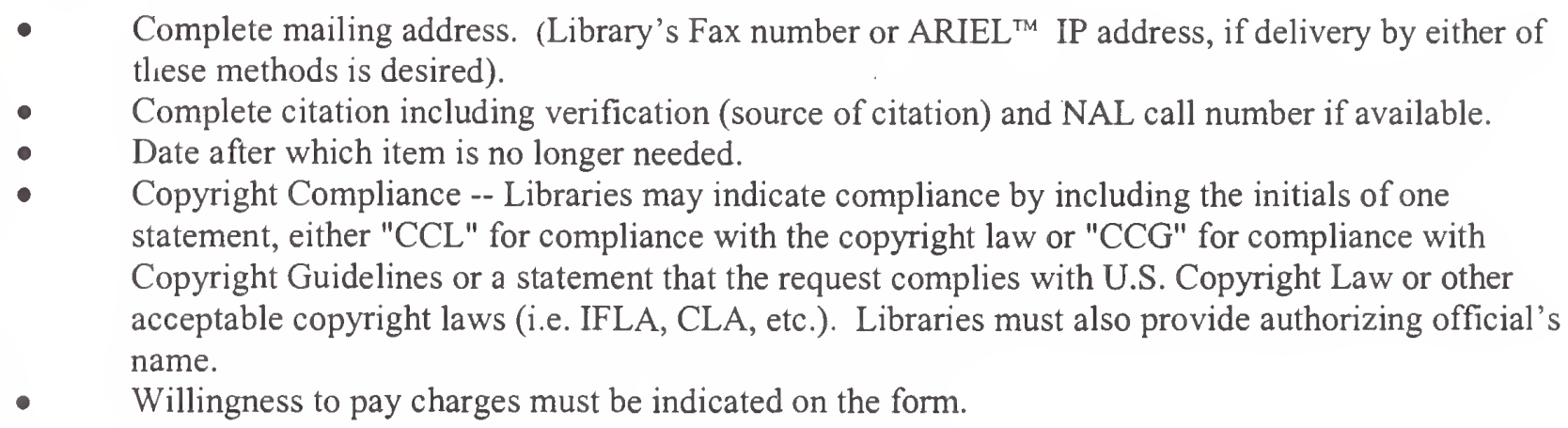

The library must submit a separate interlibrary loan form or request for each item. If the citation is from an NAL database (AGRICOLA, Bibliography of Agriculture, or the NAL Catalog) and the call number is given, please include it. Materials in NAL's collection are loaned only to other U.S. and Canadian libraries. The following materials are not loaned: serials, rare materials, reference and reserve books, microforms, and proceedings of conferences or symposia. Photocopy or microform of non-circulating publications may be requested for a fee provided that the request does not exceed 50 pages per item.

\section{Send Requests to:}

Postal Mail: $\quad$ USDA, National Agricultural Library

Document Delivery Services Branch, PhotoLab 10301 Baltimore Ave., NAL Bldg.

Beltsville, Maryland 20705-2351
FAX: 301-504-5675

Ariel IP Address: ariel.nal.usda.gov

E-mail: lending@nal.usda.gov OCLC: AGL

\section{Charges for delivery:}

- $\quad$ Photocopy, hard copy of microfilm and microfiche -- $\$ 5.00$ for the first 10 pages or fraction copied from a single article or publication. $\$ 3.00$ for each additional 10 pages or fraction.

Duplication of NAL-owned microfilm -- $\$ 10.00$ per reel.

Duplication of NAL-owned microfiche -- $\$ 5.00$ for the first fiche and $\$ .50$ for each additional fiche per title.

Billing -- Charges include postage and handling, and are subject to change. Invoices are issued quarterly by the National Technical Information Service (NTIS), 5285 Port Royal Road, Springfield, VA 22161.

Establishing a deposit account with NTIS is encouraged. DO NOT SEND PREPAYMENT.

Contact the Access Services Librarian at (301) 504-6503 or via email at access@nal.usda.gov with questions or comments about this policy. 


\section{Services Available to Libraries, Institutions and Organizations}

The National Agricultural Library (NAL) accepts requests from libraries and other organizations in accordance with the national and international interlibrary loan code and guidelines. In its national role, NAL supplies copies of agricultural materials not found elsewhere. Submit requests to major university libraries, national or provincial institutions or network sources prior to sending requests to NAL. If the needed publications are not available from these sources, submit requests to NAL with a statement indicating their non-availability.

Materials in NAL's collection are not loaned outside the United States; however, copies of materials may be provided. There is a limit of 50 pages per item to comply with copyright law.

AGLINET -- Requestors in countries with an AGLINET library are encouraged to make full use of that library and its networking capabilities. As an AGLINET participant, NAL provides free document delivery service for materials published in the United States to other AGLINET participants.

Requests -- Submit requests on the American Library Association (ALA) or the International Federation of Library Associations and Institutions (IFLA) interlibrary loan form, or via electronic mail, Ariel ${ }^{\mathrm{TM}}$, or facsimile. (See further details under For Electronic Access and Delivery below.)

\section{Charges:}
- Photocopy, hard copy of microfilm and microfiche-- $\$ 5.00$ for the first 10 pages or fraction copied from a single article or publication. $\$ 3.00$ for each additional 10 pages or fraction.
- Duplication of NAL-owned microfilm--\$10.00 per reel.
- Duplication of NAL-owned microfiche-- $\$ 5.00$ for the first fiche and $\$ .50$ for each additional fiche per title.

Billing -- Charges include postage and handling, and are subject to change. Invoices are issued quarterly by the National Technical Information Service (NTIS), 5285 Port Royal Road, Springfield, VA 22161.

Establishing deposit accounts with NTIS is encouraged. Annual billing is available on request by contacting NAL at the address below. DO NOT SEND PREPAYMENT.

\section{For postal service delivery send requests to:}

USDA National Agricultural Library Document Delivery Services Branch 4th Floor PhotoLab 10301 Baltimore Ave., NAL Bldg. Beltsville, Maryland 20705-2351

\section{For electronic access and delivery :}

The Document Delivery Services Branch accepts ILL requests from libraries via several electronic methods. All requests must comply with established routing and referral policies and procedures. A sample format for ILL requests follows.

INTERNET lending@nal.usda.gov

Start the subject line with one word format:

3 letter month abbreviation + day $+\mathrm{NAL}+\#$ of request placed that day,

For Example: jul25NAL4 (if this is the fourth request on July 25).

For Example: jul 25NAL1-4 (if this is four requests submitted at one time) 
Requests can be created on standard ILL forms and then faxed. NAL will fill via FAX at no additional cost if FAX number is included on request. NAL will send up to 30 pages per article. If request exceeds 30 pages, NAL will ship via postal service. There is no RUSH service.

ARIELTM

NAL will fill the request via ARIEL ${ }^{T M}$ if the ARIEL ${ }^{T M}$ address is included in the request. NAL treats ARIELTM as an alternative delivery mechanism--not an expedited service. NAL will send up to 30 pages per article via ARIEL ${ }^{\mathrm{TM}}$. If request exceeds 30 pages, NAL will ship via postal service.

\section{Required data elements for all requests:}

Complete mailing information for all requests regardless of method of delivery. (Borrower's Fax number or ARIEL ${ }^{\top M}$ IP address if delivery by either of these methods is desired.)

Complete citation including verification (source of citation) and NAL call number if available.

Date after which item is no longer needed.

Copyright Compliance -- Pre-printed forms must contain your signature to indicate copyright compliance. On e-mail requests include the complete Statement of Copyright Compliance. Libraries may indicate compliance by including the initials of one statement, either "CCL" for compliance with the copyright law or "CCG" for compliance with Copyright Guidelines or a statement that the request complies with U.S. Copyright Law or other acceptable copyright laws (i.e. IFLA, CLA, etc.). Libraries must also provide authorizing official's name. Requests will be rejected if this information is not included.

Maximum cost you are willing to pay for billing purposes.

\section{Sample Electronic Mail Request}

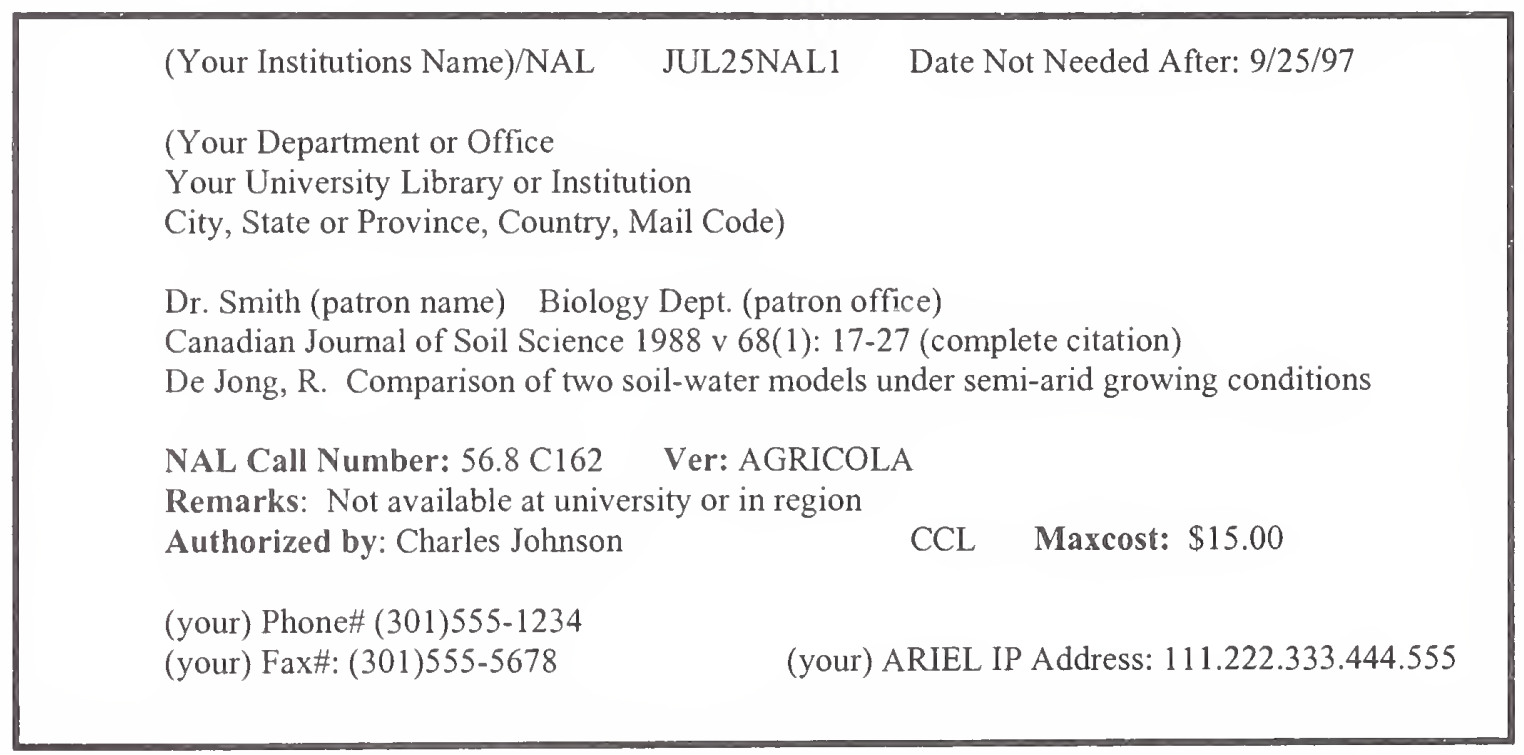

Contact the Access Services Librarian, Document Delivery Services Branch at (301) 504-6503 or via Internet at access@nal.usda.gov with questions or comments about this policy. 


\section{Index}

Abnormal Behavior ................ 64 Activists . . . . . . . . 23, 31, 66, $\underline{89}, \underline{104}$ Adjuvant ............... 53, $\underline{54}, \underline{98}$ Adopt a horse or burro program .......... Adoption .............................. Advantages of groups $\ldots \ldots \ldots \ldots \ldots \ldots \ldots$ Africa ............... $21, \underline{56}, \underline{78}, \underline{97}$ African elephants ............... Agricultural marketing ........... $43, \underline{88}$

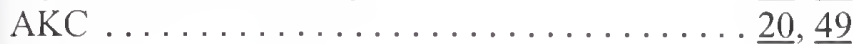

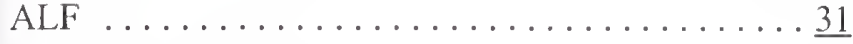
Alternative medicine $\ldots \ldots \ldots \ldots \ldots \ldots \ldots \ldots \ldots$ Alternative testing methods . . . . . . 20. $20, \underline{72}, \underline{84}$ Alternatives .... 20. $21, \underline{24}, \underline{35}, \underline{37}, \underline{38}, \underline{40}, \underline{53}, \underline{60}$, $\underline{72}, \underline{74}, \underline{79}, \underline{81}, \underline{83}, \underline{84}, \underline{98}, \underline{104}, \underline{106}$

Aluminum rod splints .27

AMDUCA Regulations ................

American indians ................ 25

AMES test .................

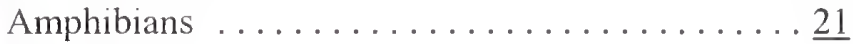

Analgesia ........................ . . . . .

Anatomical disorders .............. . . . . . Anatomy . . . . . 22 $, \underline{30}, \underline{39}, \underline{40}, \underline{41}, \underline{42}, \underline{48}, \underline{74}, \underline{86}$, $\underline{87}, \underline{91}, \underline{92}, \underline{93}, \underline{94}, \underline{96}, \underline{98}$

Anemia ......................62 Anesthesia . . . . 22 $, \underline{38}, \underline{48}, \underline{49}, \underline{58}, \underline{68}, \underline{69}, \underline{70}$, $\underline{81}, \underline{82}, \underline{92}, \underline{93}, \underline{94}, \underline{96}$

Anesthesia in Small Laboratory Animals ..... 22 Anesthesiology .................. $\underline{58}$ Anesthetic ...............66, $\underline{61}$ Animal abuse ............ $73, \underline{81}, \underline{96}, \underline{105}$ Animal activists ............... 66 Animal agriculture ........22, $\underline{66}, \underline{73}, \underline{104}, \underline{105}$ Animal and Plant Health Inspection Service (APHIS) $\underline{26}, \underline{59}, \underline{103}, \underline{105}$

Animal behavior .....22, 24, $\underline{30}, \underline{32}, \underline{40}, \underline{41}, \underline{44}, \underline{45}$, $\underline{57}, \underline{61}, \underline{63}, \underline{75}, \underline{76}, \underline{84}, \underline{102}, \underline{104}, \underline{106}$

Animal breeding ................. Animal care ........23 $, \underline{24}, \underline{39}, \underline{43}, \underline{50}, \underline{51}, \underline{53}$, $\underline{74}, \underline{75}, \underline{82}, \underline{86}, \underline{96}, \underline{100}$

Animal Care and Use .... 23, 24, 1, 포 $\underline{75}, \underline{82}, \underline{96}$ Animal Care and Use Committees ....... Animal control ................... . . . . . . Animal cruelty ................... Animal drug . . . . . . . . . . . . . $\underline{56}$ Animal experimentation $\underline{20}, \underline{23}, \underline{25}, \underline{37}, \underline{41}, \underline{51}, \underline{53}, \underline{60}$, $\underline{81}, \underline{83}, \underline{84}, \underline{89}, \underline{98}$

Animal health ..... 26, $\underline{32}, \underline{43}, \underline{44}, \underline{45}, \underline{48}, \underline{82}, \underline{90}$, $\underline{92}, \underline{95}, \underline{96}, \underline{103}$
Animal intelligence . . . . . . . . . . . . . 57 Animal models . . . 19 $19, \underline{20}, \underline{21}, \underline{23}, \underline{25}, \underline{52}, \underline{57}, \underline{58}, \underline{60}$, $\underline{61}, \underline{72}, \underline{79}, \underline{90}, \underline{94} \underline{98}, \underline{99}$

Animal products .............. Animal research . . 19 $19, \underline{21}, \underline{22}, \underline{23}, \underline{24}, \underline{25}, \underline{31}, \underline{52}, \underline{53}$, $\underline{58}, \underline{60}, \underline{67}, \underline{68}, \underline{75}, \underline{83}, \underline{86}, \underline{90}, \underline{96}, \underline{98}, \underline{99}, \underline{103}$, $\underline{104}, \underline{106}$

Animal rights .....21 $, \underline{23}, \underline{24}, \underline{36}, \underline{41}, \underline{44}, \underline{54}, \underline{57}$, $\underline{76}, \underline{89}, \underline{90}, \underline{93}, \underline{96}, \underline{99}, \underline{102}, \underline{105}$

Animal senses .................... . . . . . . . .

Animal shelter . . . . . . . . . . . . . . . . $\frac{89}{89}$

Animal shelters ..............5 57, $\underline{89}$

Animal societies .................... . . . . . . .

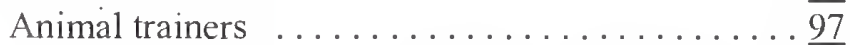

Animal training $\ldots \ldots \underline{24}, \underline{26}, \underline{53}, \underline{60}, \underline{90}, \underline{91}, \underline{95}, \underline{96}$

Animal traps ...................61

Animal welfare $\ldots \underline{19}, \underline{20}, \underline{21}, \underline{22}, \underline{23}, \underline{24}, \underline{25}, \underline{28}, \underline{34}$, $\underline{37}, \underline{39}, \underline{43}, \underline{44}, \underline{45}, \underline{51}, \underline{53}, \underline{57}, \underline{58}, \underline{59}, \underline{60}, \underline{63}$, $\underline{64}, \underline{66}, \underline{72}, \underline{74}, \underline{75}, \underline{77}, \underline{78}, \underline{79}, \underline{80}, \underline{81}, \underline{83}, \underline{86}$, $\underline{88}, \underline{89}, \underline{90}, \underline{91}, \underline{96}, \underline{98}, \underline{99}, \underline{100}, \underline{102}, \underline{103}, \underline{104}$, $\underline{105}, \underline{106}$

Animal Welfare Act ......... $\underline{53}, \underline{74}, \underline{88}, \underline{89}$

Animal Welfare Compliance . . $\underline{34}, \underline{58}, \underline{64}, \underline{75}, \underline{78}, \underline{79}$, $\underline{83}, \underline{86}, \underline{88}$

Animal Welfare Information Center .... 24, $\underline{53}, \underline{64}$

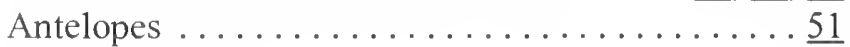

Anthropologist ................... $\frac{59}{59}$

Anti-Vivisection ................. $\frac{\underline{63}}{9 .}$

Antibiotics ............... 26, 92

Apes ............... $\underline{62}, \underline{63}, \underline{78}, \underline{80}$

Aquaculture industry $\ldots \ldots \ldots \ldots \ldots \ldots \ldots, \underline{26}, \underline{47}$

Armadillos .....................

ARS ................. $\underline{55}, \underline{68}, \underline{101}$

Arson ......................... . . . . .

Artificial insemination . . . . . . . . 25, 26, $\underline{60}$

Asian elephants ...................

Aspca .................. 20. $\underline{\underline{60}}$

Audads ....................... $\frac{51}{26}$

Avian depredation $\ldots \ldots \ldots \ldots \ldots \ldots \ldots \ldots . \ldots \ldots$

Avian medicine ................ . 89

Avian physical . . . . . . . . . . . . $\frac{89}{89}$

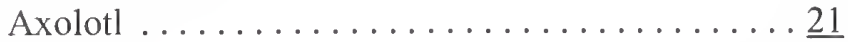

Baboons ................. $\underline{63}, \underline{102}$

Bacterial diseases . . . . . . . . . . . . 64,75

Baiting techniques ............. $\underline{26}, \underline{27}$

Bandaging and Splinting $\ldots \ldots \ldots \ldots . \ldots \ldots$

Barn Construction ................. 27

Barns ......................... . . . . . . .

Basic anatomy $\ldots \ldots \ldots \ldots \ldots \ldots \ldots \ldots, \underline{96}$ 
Basic management ................

Bats $\frac{81}{89}$

Battery systems

$\underline{36}, \underline{79}$

Bears

$\underline{28}, \underline{34}, \underline{63}, \underline{68}, \underline{89}$

Bedding Materials

$\underline{33}$

Beef cattle industry

Behavior $. \ldots . \underline{20}, \underline{21}, \underline{22}, \underline{23}, \underline{24}, \underline{25}, \underline{27}, \underline{28}, \underline{30}, \underline{31}$,
$\underline{32}, \underline{35}, \underline{36}, \underline{38}, \underline{40}, \underline{41}, \underline{42}, \underline{44}, \underline{45}, \underline{46}, \underline{47}, \underline{49}$,

$\underline{50}, \underline{51}, \underline{52}, \underline{54}, \underline{55}, \underline{56}, \underline{57}, \underline{61}, \underline{62}, \underline{63}, \underline{64}, \underline{65}$,

$\underline{67}, \underline{71}, \underline{75}, \underline{76}, \underline{77}, \underline{78}, \underline{79}, \underline{80}, \underline{83}, \underline{84}, \underline{85}, \underline{87}$.

$\underline{88}, \underline{89}, \underline{91}, \underline{92}, \underline{93}, \underline{94}, \underline{97}, \underline{98}, \underline{99}, \underline{100}, \underline{102}$,

$\underline{104}, \underline{105}, \underline{106}$

Behavior modification

$\underline{100}$

Behavioral research

$\underline{44}, \underline{45}, \underline{81}$

Biogenetics . . . . . . . . . . . . . 105

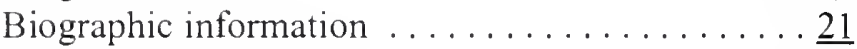

Biography ............... $\underline{54}, \underline{56}, \underline{59}$

Biological diversity . . . . . . . . . $\underline{36}, \underline{80}$

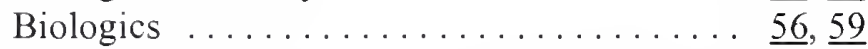

Biomedical research . . 19 19, 20, 21, 23, 24, 25, $\underline{34}, \underline{39}$, $\underline{48}, \underline{52}, \underline{54}, \underline{58}, \underline{76}, \underline{94}, \underline{95}, \underline{96}, \underline{103}, \underline{105}, \underline{106}$

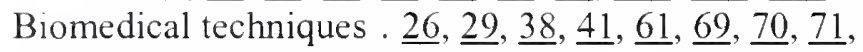
$\underline{87}, \underline{90}, \underline{93}, \underline{94}, \underline{95}, \underline{96}, \underline{102}$

Biomethodology .............. $28, \underline{29}$

Biometry ................... . . . .

Biopharmaceuticals .......... $78, \underline{100}, \underline{101}$

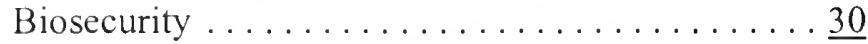

Biotechnology . . . 25, $\underline{30}, \underline{32}, \underline{37}, \underline{55}, \underline{56}, \underline{60}, \underline{63}, \underline{78}$, $\underline{80}, \underline{95}, \underline{100}, \underline{101}, \underline{105}$

Birds . . . . . . $\underline{8}, \underline{13}, \underline{20}, \underline{22}, \underline{26}, \underline{30}, \underline{33}, \underline{37}, \underline{40}, \underline{63}$, $\underline{66}, \underline{72}, \underline{76}, \underline{89}$

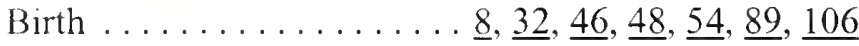

Birth management ............

Birth process ..............

Birute galdikas-brindamour . . . . . . . . . . . $\frac{79}{92}$

Bison .................. $44, \frac{92}{92}$

Bitches .................... $\frac{22}{23}$

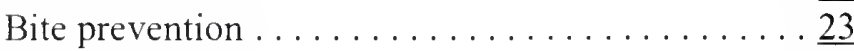

Black rhino . . . . . . . . . . . . . . . . . . 97

Blood

$\underline{27}, \underline{28}, \underline{29}, \underline{30}, \underline{31}, \underline{37}, \underline{38}, \underline{42}, \underline{45}$,

$\underline{47}, \underline{48}, \underline{49}, \underline{61}, \underline{69}, \underline{70}, \underline{71}, \underline{78}, \underline{82}, \underline{84}, \underline{85}, \underline{88}$,

$\underline{93}, \underline{94}, \underline{96}, \underline{99}, \underline{100}, \underline{104}$

Blood collection and sampling .... 28, 29, $\underline{29}, \underline{30}, \underline{38}$, $\underline{45}, \underline{61}, \underline{69}, \underline{70}, \underline{82}, \underline{85}, \underline{88}, \underline{93}, \underline{96}, \underline{99}$

Blood collection and preservation ........

Blood gas analyzer . . . . . . . . . . . $\underline{48}, \underline{49}$

Blood sampling and anesthesia $\ldots \ldots \ldots \ldots \underline{82}$

Borneo .................. $\underline{65}, \underline{78}$

Bovine restraint $\ldots \ldots \ldots \ldots \ldots \ldots \ldots \ldots \ldots \ldots \ldots$

Bovine somatotropin . . . . . . . . . $\underline{32}, \underline{73}, \underline{95}$

Brain . . . . . . . . . . . . . . $\underline{40}, \underline{54}$
Breeding . . . . 20 $20, \underline{21}, \underline{25}, \underline{26}, \underline{31}, \underline{33}, \underline{45}, \underline{47}, \underline{49}, \underline{57}$, $\underline{58}, \underline{64}, \underline{68}, \underline{71}, \underline{76}, \underline{78}, \underline{84}, \underline{86}, \underline{94}, \underline{95}, \underline{101}, \underline{105}$

Broilers ...................... . . . . .

Broodmares .............. $31, \underline{45}, \underline{78}$

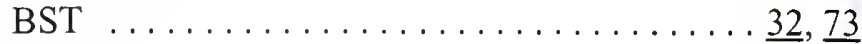

Buddhism ...................... $\frac{25}{55}$

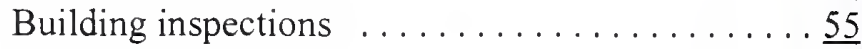

Bull hooks ..................

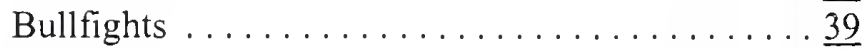

Bulls .......................... $\frac{39}{96}$

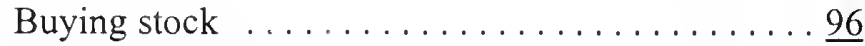

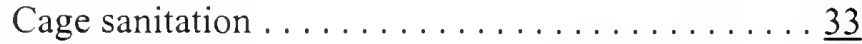

Cages ............. $\underline{32}, \underline{33}, \underline{50}, \underline{81}, \underline{100}$

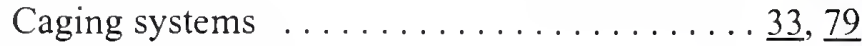

Calf Management . . . . . . . . . . . . . . . . . . . . . . . . . . . .

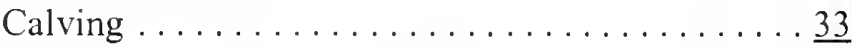

Cancer $\ldots \ldots \ldots \ldots \ldots \ldots \ldots \ldots \ldots \ldots \ldots \ldots, \underline{95}$

Canine structure and movement $\ldots \ldots \ldots \ldots .41$

Captive animals . . . . . . . . 25, $\underline{61}, \underline{89}, \underline{106}$

Cardiac puncture ................69, $\frac{69}{34}$

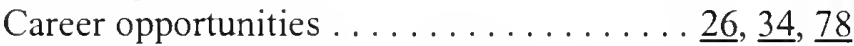

Careers . . . . . . 17, $\underline{19}, \underline{26}, \underline{33}, \underline{34}, \underline{53}, \underline{78}, \underline{106}$

Carnivore restraint $\ldots \ldots \ldots \ldots \ldots \ldots \ldots \ldots$

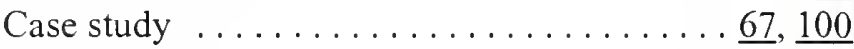

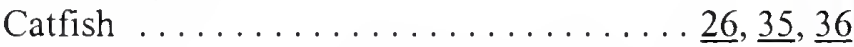

Cats . . . . . 22, 28, $\underline{29}, \underline{31}, \underline{34}, \underline{35}, \underline{40}, \underline{44}, \underline{63}$, $\underline{65}, \underline{76}, \underline{77}, \underline{81}, \underline{86}, \underline{87}, \underline{88}, \underline{89}, \underline{90}, \underline{97}, \underline{104}$

Cattle ....... 22, $\underline{27}, \underline{28}, \underline{31}, \underline{32}, \underline{33}, \underline{35}, \underline{38}, \underline{39}$, $\underline{43}, \underline{45}, \underline{47}, \underline{48}, \underline{52}, \underline{54}, \underline{57}, \underline{60}, \underline{62}, \underline{64}, \underline{66}, \underline{67}$,

$\underline{75}, \underline{91}, \underline{102}, \underline{103}, \underline{104}, \underline{106}$

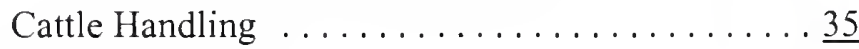

Cattle Judging . . . . . . . . . . . . . $\frac{28}{28}$

Cattle parturition ...............

Cayo santiago ................... 62

Celebes Macaques . . . . . . . . . . . . . . . . $\frac{71}{78}$

Cell culture . . . . . . . . . . . . . . . . . 2, $\underline{28}, \underline{78}$

Cesarean section $\ldots \ldots \ldots \ldots \ldots \ldots \ldots \ldots \ldots \ldots$

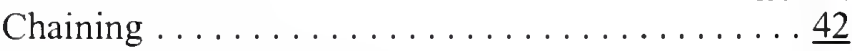

Chemical immobilization . . . . . . . . . 34 , $\underline{42}$

Chemo and Mechano Receptors .........

Chest .................... . . .

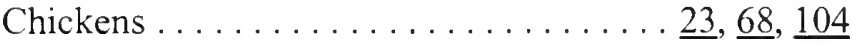

Children .............. 23, $\underline{79}, \underline{83}$

Chimeras ................

Chimpanzees $\underline{21}, \underline{25}, \underline{31}, \underline{40}, \underline{50}, \underline{56}, \underline{62}, \underline{71}, \underline{80}, \underline{89}, \underline{91}$

Chinchillas ....................

Christianity ..................

Circus ......................

Clam .......................... . . . . . .

Clinical signs $\ldots \ldots \ldots \ldots \ldots \underline{38}, \underline{73}, \underline{74}, \underline{94}, \underline{95}$

Coaptation splints $\ldots \ldots \ldots \ldots \ldots \ldots \ldots$

Cognitive neuropsychology .......... 
Cold shoeing $\underline{27}, \underline{97}$

Colic

$\underline{51}, \underline{105}$

Common diseases

$\underline{74}, \underline{86}, \underline{96}$

Communication . . . . 19 $, \underline{22}, \underline{28}, \underline{42}, \underline{55}, \underline{80}, \underline{87}, \underline{88}$, $\underline{97}, \underline{98}, \underline{99}, \underline{102}$

Comparative anatomy $\underline{34}, \underline{58}, \underline{64}, \underline{75}, \underline{78}, \underline{79}, \underline{83}, \underline{86}$,

Compliance $\underline{88}, \underline{107}, \underline{109}$

Composition of milk $\underline{32}, \underline{73}$

Composting 37

Conferences .......2 23, $\underline{57}, \underline{59}, \underline{64}, \underline{78}, \underline{100}, \underline{101}$

Conference on animal welfare $\ldots \ldots \ldots \ldots \ldots 57$

Conformation ............. $\underline{36}, \underline{37}, \underline{41}, \underline{49}$

Congresses ............. $\underline{56}, \underline{58}, \underline{100}, \underline{101}$

Conservation ....21 $\underline{21}, \underline{35}, \underline{43}, \underline{57}, \underline{65}, \underline{67}, \underline{72}, \underline{73}, \underline{85}$, $\underline{92}, \underline{97}, \underline{102}, \underline{106}$

Construction $\underline{27}, \underline{35}, \underline{76}$

Containment facilities ...............

Contraceptives ................. $\underline{98}$

Control . 19, 26, 27, $\underline{30}, \underline{33}, \underline{36}, \underline{37}, \underline{38}, \underline{39}, \underline{44}, \underline{47}, \underline{49}$, $\underline{55}, \underline{57}, \underline{61}, \underline{63}, \underline{64}, \underline{65}, \underline{71}, \underline{78}, \underline{83}, \underline{89}, \underline{90}, \underline{94}$

Control of bird pests

Controls . 26

Cosmetics $\underline{34}, \underline{36}, \underline{84}, \underline{86}, \underline{105}$

Cow Handling $\underline{63}, \underline{84}$

Cows

Crayfish $\underline{22}, \underline{24}, \underline{31}, \underline{32}, \underline{38}, \underline{62}, \underline{73}, \underline{95}, \underline{102}$

Crocodiles $\underline{39}$

Cryptosporidium and Cryptosporidiosis $\ldots . \frac{77}{38}$

Cultural values . . . . . . . . . . . . $\underline{55}, \underline{88}, \underline{93}$

Curare .....................

Cynomologus monkeys .............. $\frac{\underline{81}}{2 .}$

Daily activities ................. . . . . . . . . .

Dairy cattle . . . . . . $\underline{32}, \underline{38}, \underline{43}, \underline{48}, \underline{62}, \underline{102}, \underline{106}$

Dairy cattle behavior .............. 102

Dairy cows ................. 22, 24, $\underline{102}$

Dairy farming ................

Data processing .................62

Databases ................... $\underline{79}, \underline{83}$

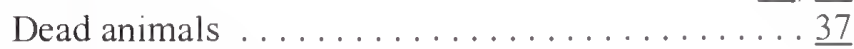

Deafferentation ..................

Deer ...................... . . . . . .

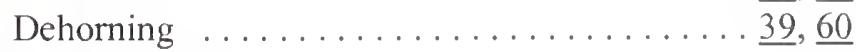

Depo provera ........................

Depression ..................... $\underline{98}$

Design .............. 27 $\underline{32}, \underline{32}, \underline{36}, \underline{43}, \underline{46}$

Diabetic orangutans ............... 100

Diagnosis . . . . . . . 42 $\underline{42}, \underline{44}, \underline{73}, \underline{74}, \underline{89}, \underline{93}, \underline{94}$, $\underline{95}, \underline{101}, \underline{102}, \underline{105}$

Diagnostic reagents ............... . . . . . . . . . . . .

Diane Fossey . . . . . . . . . . . . . . . $\frac{78}{78}$

Diarrhea .................... . . .
Disease control ................. $\underline{39}, \underline{64}$ Diseases . . 22 $2, \underline{26}, \underline{34}, \underline{39}, \underline{42}, \underline{47}, \underline{49}, \underline{54}, \underline{55}, \underline{56}, \underline{61}$, $\underline{64}, \underline{68}, \underline{72}, \underline{73}, \underline{74}, \underline{75}, \underline{78}, \underline{80}, \underline{86}, \underline{92}, \underline{93}, \underline{94}$, $\underline{95}, \underline{96}, \underline{100}, \underline{101}, \underline{102}, \underline{105}$

Disinfection $\underline{26}, \underline{33}, \underline{49}$

Disposal ...........................

Dissection $\underline{22}, \underline{39}, \underline{40}, \underline{87}, \underline{91}$

DNA $\underline{60}, \underline{80}, \underline{95}$

Doctor Fox $\frac{90}{23}$

Dog Attacks .................. $\frac{23}{23}$

Dogs . . . 19 19, 20, 22 $, \underline{23}, \underline{27}, \underline{29}, \underline{32}, \underline{34}, \underline{38}, \underline{41}, \underline{42}$, $\underline{44}, \underline{49}, \underline{50}, \underline{52}, \underline{58}, \underline{65}, \underline{76}, \underline{81}, \underline{83}, \underline{87}, \underline{88}, \underline{89}$, $\underline{90}, \underline{98}, \underline{99}, \underline{104}$

Dolphins $\underline{40}, \underline{61}, \underline{80}$

Domestic cats ... $\underline{35}, \frac{87}{89}$

Dominance .............................

Downed animals ................ . . .

Draize test ...............

Drug administration . . . . . . . 28, $\underline{29}, \underline{56}, \underline{69}, \underline{70}$

Drug approval process .............

Drugs .... 211, $\underline{48}, \underline{54}, \underline{56}, \underline{61}, \underline{63}, \underline{68}, \underline{72}, \underline{75}, \underline{76}, \underline{101}$

Ducks ....................

East africa, .......................

Echolocation ................... . . . . . . .

Ecology . . . . . . . . . . . . . $37, \underline{44}, \underline{80}$

Education ..... 22, 28, $\underline{33}, \underline{34}, \underline{39}, \underline{41}, \underline{47}, \underline{66}, \underline{67}$, $\underline{75}, \underline{79}, \underline{89}, \underline{104}, \underline{106}$

Educational requirements . . . . . . . . . 106

Elementary school ............... . . $\underline{105}$

Elephants ................ $\underline{42}, \underline{60}$

Elk .........................

Embryo.................... $40, \underline{40}, \underline{60}$

Emergency Care ..................

Emu ................ $42, \underline{43}, \underline{102}$

Endangered species $\ldots \ldots \ldots \ldots \underline{16}, \underline{49}, \underline{65}, \underline{73}, \underline{97}$

Environmental Assurance Program .........

Environmental engineering . . . . . . . . . . $\underline{43}$

Environmental enrichment . . . . . 28 $, \underline{31}, \underline{43}, \underline{50}, \underline{61}$, $\underline{80}, \underline{89}, \underline{99}$

Environmental factors ............ $\underline{33}, \underline{75}$

Enzootic simian viruses ...............

Equipment $\ldots . \underline{26}, \underline{27}, \underline{33}, \underline{35}, \underline{48}, \underline{49}, \underline{52}, \underline{62}, \underline{63}, \underline{66}$, $\underline{71}, \underline{75}, \underline{81}, \underline{85}$

Ethical ....... $\underline{31}, \underline{36}, \underline{41}, \underline{52}, \underline{53}, \underline{59}, \underline{60}, \underline{63}, \underline{64}$, $\underline{80}, \underline{81}, \underline{93}, \underline{102}$

Ethics .... 19 $, \underline{20}, \underline{23}, \underline{24}, \underline{36}, \underline{52}, \underline{55}, \underline{59}, \underline{60}, \underline{73}, \underline{77}$, $\underline{79}, \underline{80}, \underline{83}, \underline{84}, \underline{90}, \underline{98}, \underline{99}, \underline{104}, \underline{105}, \underline{106}$

Ethograms .....................

Ethology ................... . . . . . . . . . .

Europe $\ldots \ldots \ldots \ldots \ldots \ldots \ldots \ldots \ldots \ldots \ldots \ldots$

European Pork Production ............ $\underline{43}$ 
Euthanasia $\underline{28}, \underline{29}, \underline{43}, \underline{57}, \underline{58}, \underline{69}, \underline{70}, \underline{75}, \underline{78}, \underline{90}, \underline{92}$, $\underline{93}, \underline{94}, \underline{95}, \underline{96}, \underline{103}, \underline{104}, \underline{105}$

Evaluation $\underline{58}, \underline{63}, \underline{94}$

Evolution

Ewes $\underline{58}, \underline{77}$

Experimental psychologists . . . . . . . . . 19 Experimental techniques . . . . $\underline{90}, \underline{91}, \underline{92}, \underline{94}, \underline{95}, \underline{96}$ Experimentation $20,23,24, \underline{25}, \underline{37}, \underline{41}, \underline{51}, \underline{52}, \underline{53}, \underline{60}$, $\underline{81}, \underline{83}, \underline{84}, \underline{89}, \underline{98}, \underline{104}$

External parasites ........... $\underline{44}, \underline{60}, \underline{80}$

Extinction ............... $\underline{49}, \underline{71}, \underline{73}$

Eye ................ $\underline{38}, \underline{40}, \underline{42}$

Factory farming $\ldots \ldots \ldots \ldots \ldots \ldots \ldots \ldots, \underline{22}, \underline{67}, \underline{102}$

Farm animal behavior .......... $\underline{44}, \underline{45}, \underline{102}$

Farm animals $\ldots \ldots \underline{23}, \underline{25}, \underline{44}, \underline{45}, \underline{55}, \underline{62}, \underline{84}, \underline{88}, \underline{91}$, $\underline{95}, \underline{101}, \underline{102}$

FDA $\ldots \ldots \ldots \ldots \ldots \ldots \ldots \ldots, \underline{21}, \underline{6}, \underline{60}, \underline{68}, \underline{98}, \underline{100}$

Feces ..................... 100

Feed utilization efficiency . . . . . . . . . . 37

Feeding . . . . . 27, 28, $\underline{32}, \underline{34}, \underline{42}, \underline{45}, \underline{46}, \underline{47}, \underline{51}$, $\underline{55}, \underline{56}, \underline{57}, \underline{61}, \underline{64}, \underline{65}, \underline{74}, \underline{76}, \underline{95}$

Feeding and watering in markets $\ldots \ldots \ldots \ldots . .51$

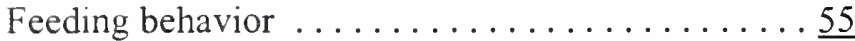

Feeds .............. 27, $\underline{45}, \underline{46}, \underline{68}$

Feedyard .................. . 47

Females ...............19, $\underline{66}, \underline{71}$

Feminists .................... 19

Feral cats ...............

Ferrets ............. $28, \underline{34}, \underline{47}$

Fertilization $\ldots \ldots \ldots \ldots \ldots \ldots \ldots \ldots \ldots, \underline{65}$

Fetal pig ...............

Fish . . . . . 26 $, \underline{30}, \underline{32}, \underline{35}, \underline{36}, \underline{39}, \underline{40}, \underline{45}, \underline{47}, \underline{54}$, $\underline{63}, \underline{65}, \underline{101}$

Five steps .84

Flamingos .................. . . . .

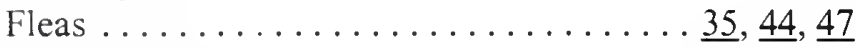

Foal handling $\ldots \ldots \ldots \ldots \ldots \ldots \ldots \ldots \ldots \ldots$

Foal management ............

Foaling .............

Foals ...........19, $\underline{41}, \underline{42}, \underline{48}, \underline{50}, \underline{54}, \underline{98}$

Food animal products ..............

Food safety . . . 또요 $\underline{55}, \underline{68}, \underline{73}, \underline{75}, \underline{79}, \underline{100}, \underline{101}, \underline{103}$

Food Safety and Animal Drugs .........

Footcare ................

Foreign Genes ................ . .

Foxes .................

Frogs ................

Future ..... 23, $\underline{26}, \underline{36}, \underline{42}, \underline{54}, \underline{57}, \underline{91}, \underline{100}, \underline{105}$

Gait .................... 41,49

Gastric disorders ................

Genetic engineering . . $30, \underline{37}, \underline{56}, \underline{59}, \underline{63}, \underline{64}, \underline{78}, \underline{80}$, $\underline{81}, \underline{84}, \underline{101}, \underline{105}$
Genetically engineered food $\ldots \ldots \ldots \ldots \ldots 54$

Genetics ..............25, $\underline{60}, \underline{60}, \underline{80}, \underline{94}$

Gerbils .............. $\underline{26}, \underline{\underline{50}}, \underline{72}, \underline{94}$

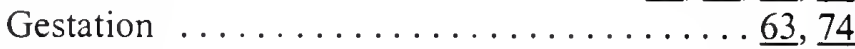

Gibbons .................. $\underline{50}, \underline{71}$

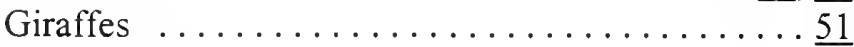

Gnotobiotics ....................

Goat Breeding ...............

Gorillas . . . . . . . . $\underline{49}, \underline{50}, \underline{71}, \underline{78}, \underline{79}, \underline{80}, \underline{99}$

Granby's Primates ................ $\underline{50}$

Grass tetany ...............

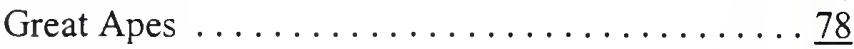

Great britain ................ $\underline{45}, \underline{79}$

Grooming ............27, $\underline{42}, \underline{56}, \underline{78}$

Ground handling $\ldots \ldots \ldots \ldots \ldots \ldots \ldots \ldots \ldots \ldots$

Group and family behavior ............. $\frac{55}{20}$

Guide dogs ................. 20

Guidelines .... 21 $, \underline{22}, \underline{24}, \underline{34}, \underline{53}, \underline{68}, \underline{74}, \underline{76}, \underline{78}$, $\underline{90}, \underline{103}, \underline{107}, \underline{108}$

Guinea Pigs . $\underline{26}, \underline{29}, \underline{50}, \underline{65}, \underline{69}, \underline{72}, \underline{82}, \underline{87}, \underline{88}, \underline{91}, \underline{92}$ Habitat . . . . . . . . . $\underline{37}, \underline{61}, \underline{65}, \underline{83}, \underline{99}$ Haemobartonellosis .............. Halothane ...................

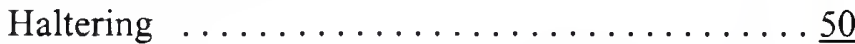
Hamsters $\ldots \ldots \ldots \ldots \ldots \ldots \underline{26}, \underline{50}, \underline{69}, \underline{72}, \underline{92}, \underline{95}$ Handling . . . . 19, $\underline{20}, \underline{27}, \underline{28}, \underline{31}, \underline{34}, \underline{35}, \underline{37}, \underline{38}, \underline{42}$, $\underline{43}, \underline{47}, \underline{48}, \underline{50}, \underline{51}, \underline{52}, \underline{58}, \underline{60}, \underline{61}, \underline{62}, \underline{64}, \underline{68}$, $\underline{69}, \underline{70}, \underline{71}, \underline{72}, \underline{73}, \underline{76}, \underline{77}, \underline{78}, \underline{79}, \underline{81}, \underline{82}, \underline{85}$, $\underline{87}, \underline{88}, \underline{89}, \underline{90}, \underline{92}, \underline{93}, \underline{94}, \underline{95}, \underline{96}, \underline{98}, \underline{102}, \underline{106}$, $\underline{107}, \underline{108}$

Handling and restraint . $\underline{27}, \underline{50}, \underline{61}, \underline{70}, \underline{71}, \underline{79}, \underline{82}, \underline{90}$, $\underline{92}, \underline{94}, \underline{95}, \underline{96}$

Handling and sexing $\underline{51}$

Handling livestock ............... $\underline{\underline{51}}$

Handling transport $\ldots \ldots \ldots \ldots \ldots \ldots . \ldots \ldots 5$

Healing Touch techniques . . . . . . . . . 97

Health . . . 21 $, \underline{23}, \underline{24}, \underline{26}, \underline{30}, \underline{32}, \underline{34}, \underline{37}, \underline{39}, \underline{43}, \underline{44}$, $\underline{45}, \underline{48}, \underline{50}, \underline{51}, \underline{53}, \underline{59}, \underline{62}, \underline{67}, \underline{68}, \underline{70}, \underline{72}, \underline{73}$,

$\underline{74}, \underline{81}, \underline{82}, \underline{86}, \underline{88}, \underline{90}, \underline{91}, \underline{92}, \underline{95}, \underline{96}, \underline{98}, \underline{99}$, $\underline{102}, \underline{103}, \underline{105}, \underline{106}$

Health care ... $\underline{23}, \underline{45}, \underline{72}, \underline{86}, \underline{90}, \underline{92}, \underline{95}, \underline{96}, \underline{98}, \underline{106}$ Heart . . . . . . . . . . . 23, $\underline{40}, \underline{65}, \underline{93}$

Heart valve prosthesis $\ldots \ldots \ldots \ldots \ldots \ldots$

Heart valve replacement $\ldots \ldots \ldots \ldots \ldots \ldots \underline{65}$

Herbicides ...................

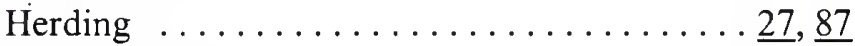

Herpes $b$ virus $\ldots \ldots \ldots \ldots \ldots \ldots \ldots \ldots$

Hiking $\ldots \ldots \ldots \ldots \ldots \ldots \ldots \ldots \ldots \ldots \ldots \ldots, 21$

Hinduism ...................

History . . . . $\underline{20}, \underline{21}, \underline{28}, \underline{32}, \underline{40}, \underline{58}, \underline{65}, \underline{88}, \underline{89}$, $\underline{92}, \underline{93}, \underline{94}, \underline{96}, \underline{99}, \underline{106}$

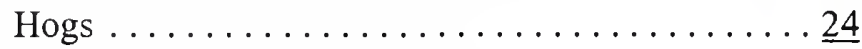


Hoof care $\underline{47}, \underline{48}$

Hoof problems $\underline{105}$

Hoof structure and trimming . . . . . . 27, $\underline{42,48}$ Horns $\ldots \ldots .39$

Horse behavior $\underline{20}, \underline{46}, \underline{50}, \underline{54}$

Horse breeding

$\underline{31}, \underline{47}, \underline{84}$

Horse care 27,51

Horse handling $\underline{16}, \underline{98}$

Horse training $\underline{27}, \underline{52}, \underline{77}$

Horsemanship

$\underline{9}, \underline{37}, \underline{87}$

Horses . 19, 20, 22, 27, 28, $\underline{31}, \underline{33}, \underline{37}, \underline{38}, \underline{42}, \underline{43}, \underline{45}$, $\underline{46}, \underline{47}, \underline{48}, \underline{50}, \underline{51}, \underline{52}, \underline{63}, \underline{64}, \underline{67}, \underline{78}, \underline{80}, \underline{83}$, $\underline{84}, \underline{87}, \underline{96}, \underline{97}, \underline{98}, \underline{101}, \underline{102}, \underline{104}, \underline{105}$

Horseshoeing .........16, 27, 4ㅗ, $\underline{80}, \underline{96}, \underline{97}$

Horticulture .................. 26

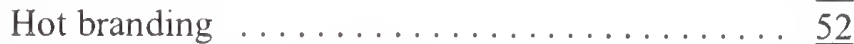

Housing $28, \underline{33}, \underline{34}, \underline{36}, \underline{43}, \underline{45}, \underline{47}, \underline{51}, \underline{57}, \underline{62}, \underline{63}, \underline{68}$, $\underline{71}, \underline{72}, \underline{74}, \underline{79}, \underline{86}, \underline{90}, \underline{91}, \underline{93}, \underline{95}, \underline{96}, \underline{103}, \underline{104}$

Human health . . . ...... 23, $\underline{32}, \underline{37}, \underline{98}, \underline{103}, \underline{106}$ Human-animal communication ........ $\underline{80}, \underline{87} 91$ Human-Animal relations . . . . . . . . . . . . . 19,49 Humane care . . . . . . . $\underline{53}, \underline{90}, \underline{91}, \underline{95}, \underline{96}, \underline{106}$ Humane Care and Use ..... $\underline{53}, \underline{90}, \underline{91}, \underline{95}, \underline{96}, \underline{106}$ Humane education ............... 41,79 Humane handling . . . . . . . . . . $\underline{69}, \underline{70}, \underline{72}$ Humane methods . . . . . . . . . . . . . $\underline{43}, \underline{90}$ Humane principles . . . . . . . . . . . . . . . . 53 Humane slaughter . . . . . . . . . . . . . Humane Society $\underline{19}, \underline{33}, \underline{42}, \underline{53}, \underline{59}, \underline{64}, \underline{67}, \underline{79}, \underline{83}, \underline{105}$ Humans and animals . . . . . . $\underline{19}, \underline{36}, \underline{104}, \underline{106}$ Hunting ........... 20, $\underline{41}, \underline{44}, \underline{89}, \underline{92}, \underline{99}$

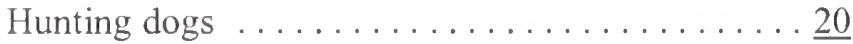
Husbandry .... 21, 23, 24, 28, $\underline{39}, \underline{43}, \underline{51}, \underline{57}, \underline{62}$, $\underline{64}, \underline{70}, \underline{71}, \underline{74}, \underline{75}, \underline{77}, \underline{79}, \underline{86}, \underline{90}, \underline{91}, \underline{92}, \underline{93}$, $\underline{94}, \underline{95}, \underline{96}, \underline{103}$

Hyenas $\underline{34}$

IACUC's history . . . . . . . . . . . . . $\underline{88}$ Identification . . . 24 $\underline{24}, \underline{27}, \underline{29}, \underline{30}, \underline{34}, \underline{37}, \underline{47}, \underline{50}, \underline{54}$, $\underline{55}, \underline{60}, \underline{61}, \underline{64}, \underline{67}, \underline{71}, \underline{78}, \underline{80}, \underline{94}, \underline{96}$

Illnesses common to the young horse . . . . . 47 Immobilization . . . . . . . . . . $\underline{34}, \underline{42}, \underline{50}, \underline{77}$ Immunological adjuvants . . . . . . . . . . . $\frac{53}{24}$

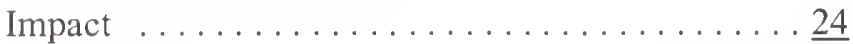
Imprinting $\ldots \ldots \ldots \ldots \ldots \ldots \ldots \ldots \ldots \ldots$ In vitro $\ldots \ldots \ldots \ldots \ldots \ldots \ldots \ldots, \underline{54}, \underline{59}, \underline{60}$ Industry $\ldots . \underline{21}, \underline{22}, \underline{23}, \underline{26}, \underline{28}, \underline{33}, \underline{34}, \underline{35}, \underline{36}, \underline{43}, \underline{47}$, $53, \underline{56}, \underline{60}, \underline{65}, \underline{66}, \underline{67}, \underline{73}, \underline{79}, \underline{100}, \underline{103}, 104$ Infections ................ Infectious diseases $\ldots \ldots \ldots \ldots \ldots \ldots, \underline{54}, \underline{68}, \underline{95}$
Information $\ldots \underline{20}, \underline{21}, \underline{24}, \underline{26}, \underline{27}, \underline{30}, \underline{33}, \underline{34}, \underline{35}, \underline{38}$, $\underline{39}, \underline{40}, \underline{45}, \underline{49}, \underline{51}, \underline{52}, \underline{53}, \underline{58}, \underline{62}, \underline{64}, \underline{67}, \underline{79}$, $\underline{82}, \underline{83}, \underline{86}, \underline{87}, \underline{90}, \underline{91}, \underline{93}, \underline{95}, \underline{96}, \underline{103}, \underline{105}$, $107, \underline{108}$

Injecting $\ldots \ldots \ldots \ldots \ldots \ldots \ldots \ldots \ldots, \underline{54}, \underline{76}$ Injection . . . . . 28 $\underline{28}, \underline{29}, \underline{54}, \underline{60}, \underline{69}, \underline{70}, \underline{74}, \underline{76}, \underline{88}$ Injection Techniques ........... Injuries . . . . . . 23, 28, $\underline{42}, \underline{51}, \underline{85}, \underline{99}, \underline{102}, \underline{105}$ Injuries in Horses . . . . . . . . . . . . . . . . 28 Injury . . . . . . . . . . 54 Inspection . . 26 $6, \underline{47}, \underline{54}, \underline{55}, \underline{59}, \underline{68}, \underline{100}, \underline{101}, \underline{103}, \underline{105}$ Instruction $\ldots \ldots \ldots \ldots \ldots \ldots \ldots \underline{26}, \underline{49}, \underline{69}, \underline{92}$ Integrated control . . . . . . . . . . . . . . . 19 Integrated pest management $\ldots \ldots \ldots \ldots 19, \underline{55}$ Intelligence . . . . . . . . . . $40, \underline{40}, \underline{41}, \underline{50}, \underline{57}$ Intensive care unit $\ldots \ldots \ldots \ldots \ldots \ldots \ldots 6$ Intensive housing ............. $36, \underline{79}$ Intensive livestock farmi묭, 24 $, \underline{35}, \underline{36}, \underline{80}, \underline{89}, \underline{96}, \underline{103}$

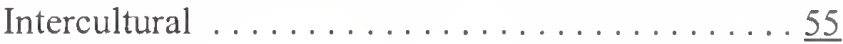
Interviews . . . . . . . . . . 21 $21, \underline{23}, \underline{24}, \underline{33}, \underline{59}, \underline{89}$ Intubation ................ $\underline{68}, \underline{69}, \underline{70}$ Investigators ................ $86, \underline{86}$ Isolation bubbles . . . . . . . . . . . . . . . . 49 Jane Goodall .............. 21 $, \underline{56}, \underline{62}$ Judaism ......................... . 25 Juvenile films . . . . . . . . . . . . . . . $\underline{33}, \underline{53}$ Kangaroos ........................ . . . . . .

Kennel worker ...................

Ketamine hydrochloride ........... $\underline{70}, \underline{81}$

Kid rearing ................. $\frac{49}{49}$

Koalas ...................... . . . . . . . . .

Konrad Lorenz . . . . . . . . . . . . . . . . . . . . . . . . . . .

Labeling .............. 21, $\underline{54}, \underline{55}, \underline{73}$

Laboratory animal . 19, 24, 26 $, \underline{31}, \underline{33}, \underline{34}, \underline{39}, \underline{49}, \underline{50}$, $\underline{51}, \underline{53}, \underline{58}, \underline{60}, \underline{63}, \underline{64}, \underline{70}, \underline{73}, \underline{74}, \underline{75}, \underline{80}, \underline{81}$, $\underline{90}, \underline{91}, \underline{95}, \underline{96}, \underline{99}, \underline{106}$

Laboratory animal facilities . . . $\underline{31}, \underline{33}, \underline{49}, \underline{58}, \underline{75}, \underline{80}$ Laboratory animal medicine ........ $\underline{39}, \underline{58}, \underline{73}$ Laboratory animal workers ............ Laboratory animals $\underline{19}, \underline{20}, \underline{21}, \underline{22}, \underline{23}, \underline{24}, \underline{25}, \underline{29}, \underline{31}$, $\underline{34}, \underline{39}, \underline{49}, \underline{50}, \underline{51}, \underline{52}, \underline{53}, \underline{58}, \underline{60}, \underline{64}, \underline{65}, \underline{68}$, $\underline{69}, \underline{70}, \underline{72}, \underline{74}, \underline{76}, \underline{78}, \underline{80}, \underline{81}, \underline{82}, \underline{83}, \underline{87}, \underline{89}$, $\underline{90}, \underline{91}, \underline{92}, \underline{93}, \underline{94}, \underline{95}, \underline{96}, \underline{98}, \underline{99}, \underline{100}, \underline{104}$, 106

Laboratory research . . . . . . . . . . . . 94, 105

Laboratory techniques . . . . . . $\underline{69}, \underline{70}, \underline{71}, \underline{82}$

Lagomorphs .................... . . . . . .

Lamb survival . . . . . . . . . . . . . . . . $\frac{58}{58}$

Lambs ...................... . . . . . . . .

Lameness . . . . . . . . . . . . . . . $\underline{83}, \underline{96}$

Language ............... 
Law and legislation ..... 21, $\underline{24}, \underline{53}, \underline{63}, \underline{68}, \underline{74}, \underline{89}$, $\underline{90}, \underline{99}, \underline{103}, \underline{107}, \underline{108}$

LD 50 $\ldots \ldots \ldots \ldots \ldots \ldots \ldots$

Leakey

Legislation $\quad 24,44,53,60,83,86,89,90,103, \underline{105}$ Lemurs ......................... . . . . . . . Library ......... 24, $\underline{50}, \underline{64}, \underline{88}, \underline{91}, \underline{107}, \underline{108}$ Licenses $\underline{56}, \underline{59}$ Lincoln Park Zoo $\underline{19}, \underline{55}, \underline{60}, \underline{68}, \underline{99}$ Linda Tellington Jones . . . . . . . . . . . . . . . $\frac{97}{55}$ Livestock . . 20 $\underline{20}, \underline{24}, \underline{35}, \underline{36}, \underline{43}, \underline{44}, \underline{45}, \underline{46}, \underline{47}, \underline{51}, \underline{55}$, $\underline{57}, \underline{59}, \underline{63}, \underline{64}, \underline{66}, \underline{71}, \underline{72}, \underline{73}, \underline{80}, \underline{84}, \underline{85}, \underline{88}$, $\underline{89}, \underline{91}, \underline{96}, \underline{100}, \underline{101}, \underline{102}, \underline{103}, \underline{105}, \underline{106}$

Livestock behavior . . . . . . . . . . . 64 Livestock handling . . . . . . . . . . . 51, $\underline{73}$ Livestock marketing . . . . . . . . . . 51, Lizards $70,75,77$ Llamas $\underline{20}, \underline{21}, \underline{28}, \underline{60}$

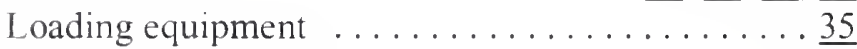

Lung lobectomy ...............

Lungs ....................... . . . . . . . .

Macaca mulatta .............. 25, 100 Macaques ............. $31, \underline{70}, \underline{71}, \underline{76}$ Madagascar .................. $\frac{83}{38}$ Magnesium sulfate ................ . . . . . . Maintenance ....... $\underline{31}, \underline{32}, \underline{49}, \underline{60}, \underline{62}, \underline{66}, \underline{81}, \underline{90}$ Male genitilia ................. 22 Mammal ...................40, $\underline{103}$ Man's Rest Friends . . . . . . . . . . . . . . . . $\underline{60}$ Management 19, 20, 24, 28, 30, 31, 33, 35, 36, 38, $\underline{39}$, $\underline{43}, \underline{45}, \underline{46}, \underline{47}, \underline{48}, \underline{49}, \underline{55}, \underline{58}, \underline{60}, \underline{62}, \underline{63}, \underline{64}$, $\underline{65}, \underline{68}, \underline{74}, \underline{79}, \underline{80}, \underline{84}, \underline{86}, \underline{99}, \underline{103}$

Management Practices . . $\underline{24}, \underline{46}, \underline{60}, \underline{62}, \underline{68}, \underline{79}, \underline{80}, \underline{86}$ Mares $\underline{31}, \underline{45}, \underline{48}, \underline{78}, \underline{84}$ Marine Mammals . . . . . . . . . . . $\underline{61}, \underline{103}$ Marketing ... $\underline{43}, \underline{45}, \underline{51}, \underline{58}, \underline{62}, \underline{78}, \underline{88}, \underline{91}, \underline{99}, \underline{101}$ Marmosets 31,71 Marsupial $\frac{61}{63}$

Mass media ..................

Massachusetts referendum . . . . . . . . . . 66 Massage ............... Mathematical models .............. Meat inspection ............. $26, \underline{55}$ Medical advances ............. . $52, \underline{90}$ Medical research $\underline{19}, \underline{24}, \underline{25}, \underline{31}, \underline{36}, \underline{48}, \underline{60}, \underline{72}, \underline{80}, \underline{83}$, $\underline{93}, \underline{94}, \underline{98}, \underline{99}, \underline{104}, \underline{106}$

Meriones unguiculatus . . . . . . . . . . . . 994 Methods ...2020,25, 26, 27, $\underline{31}, \underline{34}, \underline{37}, \underline{38}, \underline{39}, \underline{41}, \underline{43}$, $\underline{49}, \underline{50}, \underline{51}, \underline{52}, \underline{57} . \underline{58}, \underline{59}, \underline{60}, \underline{61}, \underline{62}, \underline{65}, \underline{69}$, $\underline{71}, \underline{72}, \underline{75}, \underline{76}, \underline{77}, \underline{79}, \underline{81}, \underline{82}, \underline{84}, \underline{85}, \underline{87}, \underline{90}$, $\underline{98}, \underline{101}, \underline{107}, \underline{108}, \underline{109}$

Metro Washington Park Zoo
Mice $. \underline{29}, \underline{31}, \underline{36}, \underline{39}, \underline{50}, \underline{55}, \underline{57}, \underline{60}, \underline{61}, \underline{69}, \underline{72}$ $\underline{80}, \underline{81}, \underline{82}, \underline{94}, \underline{95}, \underline{101}$

Milk ............ $\underline{32}, \underline{73}, \underline{75}, \underline{95}, \underline{101}, \underline{102}$

Milk production ............. $\underline{32}, \underline{95}, \underline{102}$

Milking ....................

Minks ........................

Modoc Nat'l Forest $\ldots \ldots \ldots \ldots \ldots \ldots \ldots \ldots$

Molecular modeling ................ $\frac{62}{62}$

Molecular structure ...............

Mongolian gerbil ................. . . . .

Mongooses ..................... . . . . . . . .

Monkeys . . . . . . 25 $\underline{25}, \underline{29}, \underline{62}, \underline{63}, \underline{70}, \underline{81}, \underline{99}, \underline{100}$

MoorComfort Gestation System .......... 63

Moral and ethical . . . . . . . . 52, $\underline{59}, \underline{64}, \underline{93}$

Moscow Circus ................... $\frac{97}{84}$

Motivation ..................... . . . . . . .

Mountain gorillas . . . . . . . . . . . . . . . 49

Mouse . . . . . 29 $\underline{29}, \underline{36}, \underline{39}, \underline{57}, \underline{60}, \underline{69}, \underline{80}, \underline{82}, \underline{94}, \underline{95}$

Mouse Embryos ................

Mouse pox ................

Movement ... 23ㄴ $\underline{24}, \underline{41}, \underline{49}, \underline{54}, \underline{59}, \underline{63}, \underline{96}, \underline{97}, \underline{105}$

Moving animals ...............

Mules .......................

Murine respiratory mycoplasmosis $\ldots \ldots \ldots \ldots \underline{93}$

Muscle relaxants ..................63

Musk oxen ................22, $\underline{76}$

Muskrats ....................... $\frac{81}{63}$

Mustangs ..................

Myelin basic protein $\ldots \ldots \ldots \ldots \ldots \ldots \ldots$

Myths and Facts ..................

Nasal gastric gavage ................ 29

Neck region and medial thigh $\ldots \ldots \ldots \ldots \ldots \underline{85}$

Nervous system . . . . . . . . . . . . 19

Neurology . . . . . . . . . . . . . . . . $\frac{81}{63}$

Neuromuscular blocking agents $\ldots \ldots \ldots \ldots \underline{63}$

Neuron ..................... . . . . . .

Neutering $\ldots \ldots \ldots \ldots \ldots \ldots \underline{35}, \underline{41}, \underline{42}, \underline{66}, \underline{90}$

Newts .......................21

$\mathrm{NIH} \ldots \ldots \ldots \ldots \ldots \ldots \ldots \ldots \ldots \ldots, \underline{61}, \underline{103}$

Nitrous oxide .................... . . . . .

Nonhuman Primates . . . . . . . . . $\underline{64}, \underline{70}, \underline{96}$

Normal and abnormal delivery $\ldots \ldots \ldots \ldots \underline{48}$

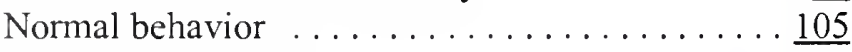

Normal conditions ............ 20, 2 , 97

Novice technologists barrier ........... 51

Nutrition . . . . 28 $\underline{28}, \underline{45}, \underline{46}, \underline{47}, \underline{55}, \underline{62}, \underline{65}, \underline{71}, \underline{72}, \underline{74}$, $\underline{90}, \underline{91}, \underline{92}, \underline{94}, \underline{95}, \underline{96}$

Nutritional requirements . . . . . . . . . 65 , $\underline{92}, \underline{93}$

Obedience ...................

Observation ................ $\underline{\underline{32}}, \underline{73}$

Occlusion ...................

Occupational health and safety $\ldots \ldots \ldots \ldots \underline{\underline{70}}$ 
Okapis

Opossums $\underline{31}, \underline{61}$

Orangutans $\underline{50}, \underline{65}, \underline{71}, \underline{78}, \underline{79}, \underline{100}$

Organic farming .37

Organic fertilizer

Organizations $\ldots \ldots 37$

Origin of man $\underline{79}, \underline{83}, \underline{108}$

Ostriches $\frac{59}{66}$

Outdoor pig production .$\underline{66}$

Ovariohysterectomy

Overpopulation

Oyster Production

Packing . .

Pain and Distress

Palpation

Parasites

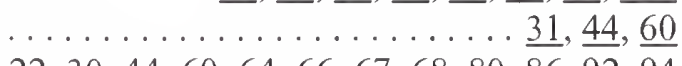
$\underline{22}, \underline{30}, \underline{44}, \underline{60}, \underline{64}, \underline{66}, \underline{67}, \underline{68}, \underline{80}, \underline{86}, \underline{92}, \underline{94}$

Patenting ..........

Pathogenesis $\underline{39}, \underline{93}, \underline{94}, \underline{95}$

PAWS $\frac{67}{51}$

Peccaries .................

Personnel safety ................

Pest control ........ 26, 27, $\underline{36}, \underline{47}, \underline{55}, \underline{61}, \underline{71}$

Pesticide application ............... 71

Pesticides ............... $37, \underline{80}, \underline{81}$

Pests ............ 19, 26, $\underline{36}, \underline{44}, \underline{55}, \underline{65}$

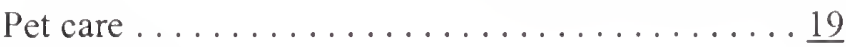

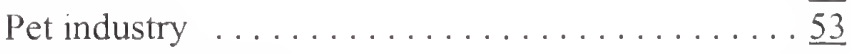

Pet overpopulation ..............

PETA . . . . . . . . . 31 $, \underline{36}, \underline{60}, \underline{81}, \underline{102}, \underline{103}$

Peter Singer ...............11, $\underline{54}, \underline{99}$

Pets $\underline{19}, \underline{20}, \underline{28}, \underline{33}, \underline{36}, \underline{72}, \underline{79}, \underline{83}, \underline{89}, \underline{90}, \underline{91}, \underline{104}, \underline{105}$

Pfiesteria ....................67

Pharmaceuticals ............ $72, \underline{84}, \underline{98}$

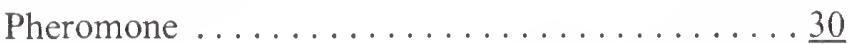

Philosophy . . . . . . . . 24, 25, $\underline{54}, \underline{88}, \underline{89}, \underline{93}$

Physical examination ....... $\underline{42}, \underline{44}, \underline{89}, \underline{90}, \underline{94}, \underline{96}$

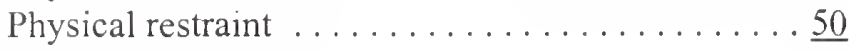

Physiological aspects . . . . . . . . . . $\frac{28}{28}$

Physiology . . . . . $\underline{30}, \underline{36}, \underline{39}, \underline{40}, \underline{41}, \underline{55}, \underline{62}, \underline{74}$, $\underline{91}, \underline{92}, \underline{93}, \underline{101}$

Pig handling $\underline{52}, \underline{72}$

Pigs . . . 26 $\underline{6}, \underline{29}, \underline{43}, \underline{45}, \underline{49}, \underline{50}, \underline{52}, \underline{55}, \underline{64}, \underline{65}, \underline{69}, \underline{72}$, $\underline{76}, \underline{81}, \underline{82}, \underline{85}, \underline{87}, \underline{88}, \underline{91}, \underline{92}, \underline{101}, \underline{102}, \underline{104}$

Pinniped .................... . . . . . .

Plum Island . . . . . . . . . . . . . . . . . . $\frac{68}{27}$

Plywood splints $\ldots \ldots \ldots \ldots \ldots \ldots \ldots \ldots \ldots$

Pneumonia .................... . . . . . .

Poaching . . . . . . . . . . . . 42, 97

Poisonous snakes ................ . . . . . . . . . . . .

Polar bears . . . . . . . . . . . . . . $28, \underline{89}$

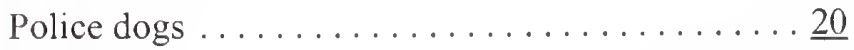

Policies . . . . . . . . . . . . . . . . $\underline{59}, \underline{103}, \underline{108}$

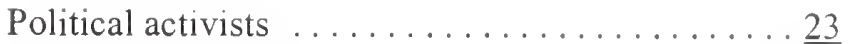

Population control ............. $57, \underline{89}$

Porcupines ........................

Pork industry and trade ..........21, $\underline{43}$

Pork producers .. $\underline{21}, \underline{23}, \underline{37}, \underline{43}, \underline{54}, \underline{61}, \underline{68}, \underline{72}, \underline{73}, \underline{85}$

Pork quality ............ $\underline{54}, \underline{61}, \underline{68}, \underline{73}, \underline{85}$

Positive interaction techniques ........

Postnatal care ................ $48, \underline{48}, \underline{58}$

Poultry ...... 24, $\underline{36}, \underline{37}, \underline{45}, \underline{67}, \underline{68}, \underline{79}, \underline{81}, \underline{100}$

Poultry production ............... . 79

Pound animals ............ 23, $\underline{60}, \underline{99}$

Pounds ....................... . 19

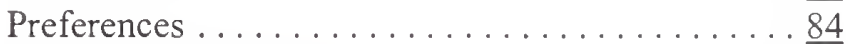

Preferred techniques $\ldots \ldots \ldots \ldots \ldots \ldots \underline{81}, \underline{82}$

Preventative measures .............. 22

Prevention ....... 20. $20, \underline{23}, \underline{28}, \underline{34}, \underline{41}, \underline{54}, \underline{68}$, $\underline{70}, \underline{74}, \underline{75}, \underline{86}, \underline{93}, \underline{96}$

Primate behavior $\underline{62}, \underline{71}$

Primate handling and restraint $\ldots \ldots \ldots \ldots \ldots \underline{70}$

Primates . 16, 25, 29, $\underline{31}, \underline{50}, \underline{63}, \underline{64}, \underline{70}, \underline{71}, \underline{81}, \underline{96}, \underline{99}$

Product safety and testing ....... $20, \underline{58}, \underline{60}, \underline{98}$

Production . 19, 20, 22, 24 $, \underline{30}, \underline{32}, \underline{34}, \underline{35}, \underline{36}, \underline{41}, \underline{42}$, $\underline{43}, \underline{44}, \underline{46}, \underline{47}, \underline{49}, \underline{54}, \underline{58}, \underline{59}, \underline{60}, \underline{62}, \underline{63}, \underline{64}$, $\underline{70}, \underline{73}, \underline{74}, \underline{75}, \underline{77}, \underline{78}, \underline{79}, \underline{80}, \underline{81}, \underline{83}, \underline{85}, \underline{86}$, $\underline{88}, \underline{95}, \underline{96}, \underline{97}, \underline{98}, \underline{100}, \underline{101}, \underline{102}, \underline{104}, \underline{105}$

Production systems ...............63

Proper research . . . . . . . . . . . . $\frac{67}{67}$

Pseudomonas aeruginosa . . . . . . . . . . . . . . . . . . . . .

Psittacosis . . . . . . . . . . . . . . . . $\frac{22}{22}$

Public health .... 26 $, \underline{34}, \underline{39}, \underline{53}, \underline{90}, \underline{91}, \underline{95}, \underline{96}, \underline{103}$

Public Health Service . . . . . . . . . . 26, $\underline{53}, \underline{103}$

Public opinion ..............

Puerto Rico .................. 62

Pulmonary function tests $\ldots \ldots \ldots \ldots \ldots \ldots$

Pupillary response .............. 44

Puppy .................. 52, $\underline{105}$

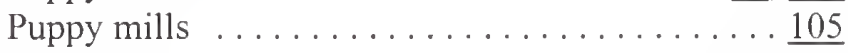

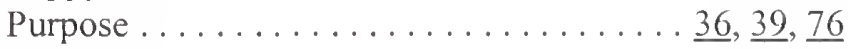

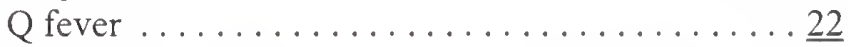

Quality Assurance ....... $\underline{54}, \underline{61}, \underline{68}, \underline{73}, \underline{75}, \underline{85}$

Rabbits . 29 $, \underline{31}, \underline{65}, \underline{66}, \underline{68}, \underline{69}, \underline{72}, \underline{73}, \underline{74}, \underline{82}, \underline{91}, \underline{96}$

Raccoons ...................... . . . . .

Race horses .................

Raising chickens $\ldots \ldots \ldots \ldots \ldots \ldots \ldots \ldots$

Ranching ................. $\frac{65}{65}$

Ratites ................66 6 , 74

Rats ... $\underline{29}, \underline{36}, \underline{50}, \underline{54}, \underline{55}, \underline{60}, \underline{69}, \underline{70}, \underline{72}, \underline{81}, \underline{82}$, $\underline{93}, \underline{94}, \underline{95}, \underline{96}$

Recombinant vaccines .............. . 59

Record keeping ..............

Regulations $\underline{21}, \underline{22}, \underline{25}, \underline{26}, \underline{34}, \underline{53}, \underline{60}, \underline{68}, \underline{76}, \underline{86}, \underline{89}$, $\underline{90}, \underline{91}, \underline{92}, \underline{95}, \underline{96}, \underline{100}, \underline{103}, \underline{105}$ 
Regulatory Issues . . . . . . . . . . . . . 78

Regulatory policies

.$\underline{59}$

Religion

Reproduction $\underline{93}, \underline{94}, \underline{101}$

$\underline{24}, \underline{25}, \underline{55}, \underline{88}, \underline{104}$ $\underline{28}, \underline{39}, \underline{48}, \underline{49}, \underline{55}, \underline{86}, \underline{91}, \underline{92}$,

Reproductive anatomy .$\underline{22}$

Reproductive cycle .$\frac{48}{77}$

Reptiles

$\underline{70}, \underline{75}, \underline{77}$

Research animals

$\underline{51}, \underline{74}, \underline{75}, \underline{81}, \underline{103}$

Research methods

$\underline{13}, \underline{75}$

Residues

$\underline{48}, \underline{68}, \underline{73}, \underline{75}$

Respiratory disease .............

Restraining . . . 25 $\underline{28}, \underline{28}, \underline{34}, \underline{38}, \underline{50}, \underline{60}, \underline{61}, \underline{69}, \underline{76}, \underline{77}$

Restraint . . 27, 28, 29, $30, \underline{31}, \underline{34}, \underline{37}, \underline{38}, \underline{39}, \underline{42}, \underline{50}$,

$\underline{51}, \underline{60}, \underline{61}, \underline{69}, \underline{70}, \underline{71}, \underline{76}, \underline{77}, \underline{78}, \underline{79}, \underline{80}, \underline{81}$,

$\underline{82}, \underline{83}, \underline{85}, \underline{87}, \underline{90}, \underline{92}, \underline{93}, \underline{94}, \underline{95}, \underline{96}, \underline{98}, \underline{106}$

Restraint and handling . . $\underline{34}, \underline{50}, \underline{69}, \underline{70}, \underline{76}, \underline{77}, \underline{81}, \underline{85}$

Rheas ...................

Rhesus . . . . . . . . 25, $\underline{29}, \underline{62}, \underline{81}, \underline{99}, \underline{100}$

Rhinoceros ................ 51,97

Rodent behavior ................. $\frac{55}{71}$

Rodent control . . . . . . 26, 27, $\underline{36}, \underline{55}, \underline{61}, \underline{71}$

Rodents .... 26 $, \underline{27}, \underline{33}, \underline{36}, \underline{50}, \underline{55}, \underline{60}, \underline{61}, \underline{65}, \underline{72}$, $\underline{77}, \underline{78}, \underline{82}, \underline{95}$

Rotational grazing ............... 56

Russell and Birch . . . . . . . . . . . . . 24,

Saboteurs ................... . . $\underline{89}$

Safety . . . . 20. $\underline{20}, \underline{23}, \underline{27}, \underline{32}, \underline{48}, \underline{50}, \underline{55}, \underline{60}, \underline{64}, \underline{68}$,

$\underline{70}, \underline{73}, \underline{75}, \underline{78}, \underline{79}, \underline{90}, \underline{92}, \underline{95}, \underline{96}, \underline{98}, \underline{100}$,

$\underline{101}, \underline{103}, \underline{106}$

Salamanders

.$\underline{21}$

Sampling methods ...............

Scientists . . 24 $, \underline{58}, \underline{79}, \underline{90}, \underline{91}, \underline{95}, \underline{96}, \underline{102}, \underline{104}, \underline{105}$

Sea lions ..................61, $\underline{67}, \underline{80}$

Sealman ....................63

Seals ..................... $\underline{61}, \underline{67}$

Searching the literature $\ldots \ldots \ldots \ldots \ldots \ldots \ldots$

Serological diagnosis . . . . . . . . . . . 102

Shark .................... . . . . .

Sheep . . . . . . . $\underline{40}, \underline{45}, \underline{55}, \underline{58}, \underline{65}, \underline{79}, \underline{80}, \underline{87}$

Shiverer Mouse . . . . . . . . . . . . . . . . . . $\underline{80}$

Shoeing $\ldots \ldots \ldots \ldots \ldots \ldots \ldots \ldots \ldots, \underline{44}, \underline{80}, \underline{97}$

Silver Spring Monkeys ............

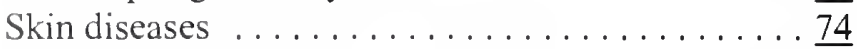

Slaughter .............. $\underline{59}, \underline{66}, \underline{102}$

Small Animal ICU . . . . . . . . . . . . . . $\underline{66}$

Small animals ................... . . . . .

Smuggling ................... . . . . . .

Snakes ................ $\underline{70}, \underline{75}, \underline{77}$

Social attitudes .................. $\frac{90}{57}$

Social order .................

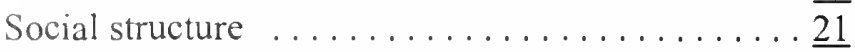

Sodium pentobarbital ................. $\underline{81}$

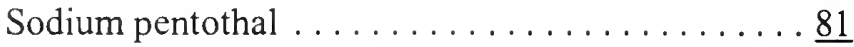

Sources of information $\ldots \ldots \ldots \ldots \ldots \ldots \ldots$

Sows ........................ .63

Spaying $\ldots \ldots \ldots \ldots \ldots \ldots \ldots \ldots \ldots \ldots \ldots \ldots \ldots \ldots, \underline{31}, \underline{89}$

Special exhibit ................

Splitbrain operations $\ldots \ldots \ldots \ldots \ldots \ldots \ldots, \frac{41}{20}$

Sport .....................

Sportsmedicine ...................

Squirrel monkeys . . . . . . . . . . . . . $\frac{70}{70}$

Stables ..................... . $\frac{27}{84}$

Stallions .................. $\underline{78}, \underline{84}$

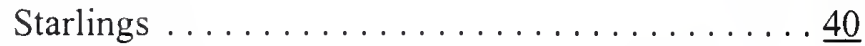

Statistics ..................... $\frac{76}{30}$

Stereoscopic vision $\ldots \ldots \ldots \ldots \ldots \ldots \ldots \ldots \ldots$

Stereotypic behaviors . . . . . . . . . . $31, \underline{64}$

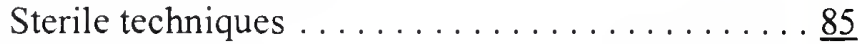

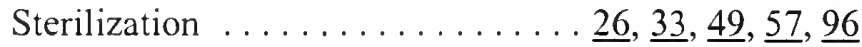

Stimulus response $\ldots \ldots \ldots \ldots \ldots \ldots \ldots$. . . . . . .

Stockyards ...................... $\frac{91}{38}$

Stomach tube . . . . . . . . . . . . . 29, $\underline{\underline{38}}$

Stranding Data . . . . . . . . . . . . . 103

Stress . . . . . 31 $, \underline{35}, \underline{51}, \underline{60}, \underline{62}, \underline{70}, \underline{99}, \underline{100}, \underline{102}$

Striped Bass ................. 45

Structure . . . . . 21 $, \underline{22}, \underline{41}, \underline{44}, \underline{48}, \underline{49}, \underline{62}, \underline{104}$

Succinyl choline . . . . . . . . . . . . . 70

Suffer ................. $84, \frac{99}{96}$

Surgery . . . . . 26 $, \underline{32}, \underline{38}, \underline{41}, \underline{49}, \underline{61}, \underline{65}, \underline{83}, \underline{85}, \underline{96}$, $\underline{99}, \underline{102}, \underline{106}$

Surgical ..... 26 $, \underline{41}, \underline{42}, \underline{53}, \underline{60}, \underline{65}, \underline{66}, \underline{83}, \underline{85}, \underline{98}$

Surgical equipment $\ldots \ldots \ldots \ldots \ldots \ldots$

Surgical procedure . . . . . . . . $41, \underline{65}, \underline{66}, \underline{98}$

Surgical techniques .............

Sustainable agriculture . . . . . . . . . $25, \underline{37}$

Suxamethonium .................. $\frac{63}{68}$

Swine . . . . . 26 $\underline{37}, \underline{37}, \underline{40}, \underline{43}, \underline{44}, \underline{45}, \underline{52}, \underline{54}, \underline{68}$, $\underline{71}, \underline{72}, \underline{73}, \underline{76}, \underline{85}, \underline{86}, \underline{100}, \underline{101}$

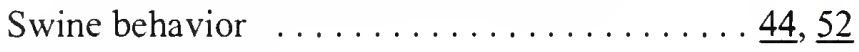

Swine breeding $\ldots \ldots \ldots \ldots \ldots \ldots \ldots \ldots \ldots \ldots \ldots$

Swine diseases $\ldots \ldots \ldots \ldots \ldots \ldots \ldots, \underline{68}, \underline{86}$

Swine handling $\ldots \ldots \ldots \ldots \ldots \ldots \ldots \ldots \ldots, \underline{52}, \underline{76}, \underline{85}$

Swine management $\ldots \ldots \ldots \ldots \ldots \ldots \ldots 6$

Swine surgery $\ldots \ldots \ldots \ldots \ldots \ldots \ldots \ldots$

Symposium . . . . . $\underline{34}, \underline{58}, \underline{64}, \underline{75}, \underline{78}, \underline{79}, \underline{83}, \underline{86}, \underline{88}$

T.E.A.M. or T Touch . . . . . $\underline{28}, \underline{42}, \underline{50}, \underline{77}, \underline{78}, \underline{87}$, $\underline{88}, \underline{97} \underline{99}, \underline{101}$

Tadpoles ...................... 21

Tanzania .................. . $\underline{56}, \underline{62}$

Taoism .....................

Tarsiers ....................

Tattooing .............. $29, \underline{43}, \underline{54}$

Taxonomy . . . . . 21 $, \underline{42}, \underline{50}, \underline{64}, \underline{71}, \underline{74}, \underline{92}, \underline{93}, \underline{94}$ 
Teaching .... 25, $\underline{50}, \underline{58}, \underline{75}, \underline{76}, \underline{82}, \underline{83}, \underline{84}, \underline{87}, \underline{105}$ Technician training ............

Technicians $\ldots \ldots \underline{19}, \underline{27}, \underline{28}, \underline{29}, \underline{47}, \underline{53}, \underline{58}, \underline{70}, \underline{90}$, $\underline{91}, \underline{95}, \underline{96}, \underline{100}$

Techniques ..... 20. $\underline{21}, \underline{24}, \underline{26}, \underline{27}, \underline{28}, \underline{29}, \underline{30}, \underline{32}$, $\underline{33}, \underline{34}, \underline{35}, \underline{37}, \underline{38}, \underline{39}, \underline{41}, \underline{42}, \underline{44}, \underline{45}, \underline{47}, \underline{49}$, $50,51,52,54,58,60,61,666,68,69,70,71$, $\underline{72}, \underline{76}, \underline{77}, \underline{78}, \underline{80}, \underline{81}, \underline{82}, \underline{84}, \underline{85}, \underline{87}, \underline{88}, \underline{89}$, $\underline{90}, \underline{91}, \underline{92}, \underline{93}, \underline{94}, \underline{95}, \underline{96}, \underline{97}, \underline{100}, \underline{101}, \underline{102}$, $\underline{103}$

Technology $22, \underline{23}, \underline{36}, \underline{45}, \underline{62}, \underline{68}, \underline{81}, \underline{95}, \underline{100}$

Terrapins $\underline{70}, \underline{75}$

Terrorism $\underline{88}$

Test kits

Testing

The 3 R's $\underline{84}, \underline{89}, \underline{99}, \underline{102}, \underline{104}, \underline{106}$

Thoraco

Thoroughbred horse breeding $\ldots \ldots \ldots \ldots \underline{31}$

Ticks ........................ . . . . . . .

Tigers ....................

Tissue culture ................. . . . . . . . . . . . . .

TiterMax ................ .

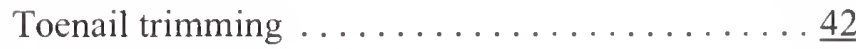

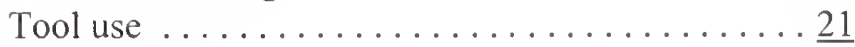

Toolmaking ..................

Tortoises ................... . . . . .

Toxicity ..................

Toxicology ..... $\underline{34}, \underline{58}, \underline{64}, \underline{75}, \underline{78}, \underline{79}, \underline{83}, \underline{86}, \underline{88}$

Training ..... $19, \underline{20}, \underline{24}, \underline{26}, \underline{27}, \underline{28}, \underline{29}, \underline{31}, \underline{32}$,

$\underline{33}, \underline{34}, \underline{35}, \underline{36}, \underline{37}, \underline{38}, \underline{40}, \underline{41}, \underline{42}, \underline{47}, \underline{50}, \underline{51}$,

$\underline{52}, \underline{53}, \underline{54}, \underline{55}, \underline{58}, \underline{60}, \underline{61}, \underline{63}, \underline{64}, \underline{65}, \underline{66}, \underline{68}$,

$\underline{69}, \underline{70}, \underline{71}, \underline{74}, \underline{76}, \underline{77}, \underline{78}, \underline{81}, \underline{82}, \underline{84}, \underline{85}, \underline{86}$,

$\underline{87}, \underline{88}, \underline{90}, \underline{91}, \underline{93}, \underline{95}, \underline{96}, \underline{97}, \underline{99}, \underline{100}, \underline{103}$

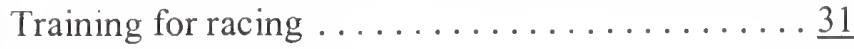

Training horses ............... $78, \underline{87}$

Training medical behaviors . . . . . . . . 100

Training methods ............. $\underline{52}, \underline{84}$

Training program ....... 27, $\underline{36}, \underline{47}, \underline{55}, \underline{61}, \underline{71}$

Training the horse for riding $\ldots \ldots \ldots \ldots$

Transgenic animals .......... $78, \underline{100}, \underline{101}$

Transgenic plants ..................101

Transportation ..... $\underline{35}, \underline{43}, \underline{51}, \underline{59}, \underline{62}, \underline{85}, \underline{91}, \underline{95}$

Trapping ............24, $61, \underline{65}, \underline{90}, \underline{104}$

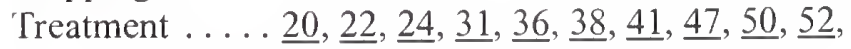

$\underline{53}, \underline{62}, \underline{67}, \underline{72}, \underline{74}, \underline{75}, \underline{79}, \underline{81}, \underline{83}, \underline{86}, \underline{89}, \underline{93}$,

$\underline{96}, \underline{100}, \underline{101}, \underline{102}, \underline{106}$

Triggerfish

Trout diseases $\ldots \ldots \ldots \ldots \ldots \ldots \ldots \ldots \ldots 10 \ldots \ldots$

Tuberculin testing ........... $71, \underline{81}, \underline{102}$

Tumors
Turtles ................

United States ‥ 19 $\underline{19}, \underline{26}, \underline{33}, \underline{35}, \underline{38}, \underline{42}, \underline{48}, \underline{53}, \underline{56}, \underline{59}$, $\underline{64}, \underline{67}, \underline{88}, \underline{98}, \underline{101}, \underline{103}, \underline{107}, \underline{108}$

US Bureau of Land Management . . . . . . . 63 USDA . . . . . . 24 $, \underline{26}, \underline{30}, \underline{38}, \underline{44}, \underline{53}, \underline{54}, \underline{55}, \underline{59}$, $\underline{60}, \underline{68}, \underline{75}, \underline{86}, \underline{89}, \underline{90}, \underline{91}, \underline{95}, \underline{96}, \underline{101}, \underline{102}$, $\underline{103}, \underline{105}, \underline{107}, \underline{108}$

Utilitarian philosophy .............. . 93

Vaccination and feeding programs ........ 47

Vaccination of fish . . . . . . . . . . . 54

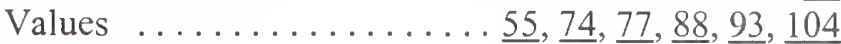

Veal calves ...... 22, $\underline{23}, \underline{62}, \underline{75}, \underline{79}, \underline{96}, \underline{103}, \underline{104}$

Veal Farming .................. 103

Veal industry ............. 79, 103, 104

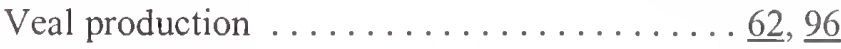

Vegetarianism ...............24, 41

Veterinarians ....... 21 $, \underline{23}, \underline{33}, \underline{57}, \underline{59}, \underline{81}, \underline{91}$

Veterinary ... 21 $, \underline{22}, \underline{26}, \underline{27}, \underline{28}, \underline{29}, \underline{32}, \underline{33}, \underline{34}, \underline{35}$,

$\underline{38}, \underline{39}, \underline{40}, \underline{42}, \underline{43}, \underline{44}, \underline{48}, \underline{50}, \underline{56}, \underline{58}, \underline{59}, \underline{61}$,

$\underline{63}, \underline{64}, \underline{65}, \underline{66}, \underline{68}, \underline{69}, \underline{70}, \underline{75}, \underline{76}, \underline{77}, \underline{81}, \underline{83}$,

$\underline{85}, \underline{87}, \underline{89}, \underline{91}, \underline{92}, \underline{93}, \underline{94}, \underline{95}, \underline{96}, \underline{98}, \underline{99}, \underline{100}$,

$\underline{102}, \underline{103}, \underline{104}, \underline{105}$

Veterinary biologicals ............. . . . . . .

Veterinary care . . . . . . $\underline{35}, \underline{39}, \underline{42}, \underline{65}, \underline{99}, \underline{105}$

Veterinary drug residues ............

Veterinary drugs ....... $21, \underline{48}, \underline{56}, \underline{61}, \underline{68}, \underline{75}$

Veterinary equipment $\ldots \ldots \ldots \ldots \ldots \ldots \ldots 6, \ldots \ldots \ldots$

Veterinary hematology .............

Veterinary medicine . . . . 21 $, \underline{22}, \underline{26}, \underline{27}, \underline{28}, \underline{32}$,

$\underline{33}, \underline{34}, \underline{38}, \underline{43}, \underline{44}, \underline{50}, \underline{56}, \underline{58}, \underline{66}, \underline{75}, \underline{76}, \underline{77}$,

$\underline{81}, \underline{85}, \underline{89}, \underline{91}, \underline{92}, \underline{93}, \underline{94}, \underline{95}, \underline{96}, \underline{98}, \underline{102}, \underline{103}$, $\underline{104}$

Veterinary nurse . ................

Veterinary pharmacology ........... $\underline{11}, \underline{58}$

Veterinary physical therapies $\ldots \ldots \ldots \ldots \ldots \underline{83}$

Veterinary procedure $\ldots \ldots \ldots \ldots \ldots \ldots \ldots 6 . \ldots \ldots 6$

Veterinary techniques .......... $\underline{58}, \underline{76}$

Veterinary training ... 26 26, 28, $\underline{29}, \underline{32}, \underline{33}, \underline{63}, \underline{64}, \underline{66}$, $\underline{68}, \underline{69}, \underline{70}, \underline{76}, \underline{81}, \underline{85}, \underline{93}, \underline{96}$

Veterinary treatment .............. 100

View of animals ............ $\underline{15}, \underline{88}$

Visual and tactile evaluation ..........

Vitamin E . . . . . . . . . . . . . . 16, 103, 104

Vocational education ............. $34, \underline{39}$

Vocational guidance ........ $19, \underline{26}, \underline{33}, \underline{34}, \underline{53}$

Vocations ..................

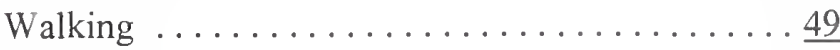

Wallabies ..................

Washoe ..................... . . . . .

Weaning $\ldots \ldots \ldots \ldots \ldots \ldots \ldots \ldots \ldots \ldots \ldots \ldots \ldots, \underline{45}, \underline{48}, \underline{104}$

Weanlings 
Welfare . . . . . . . 19, $\underline{20}, \underline{21}, \underline{22}, \underline{23}, \underline{24}, \underline{25}, \underline{28}$, $\underline{34}, \underline{36}, \underline{37}, \underline{39}, \underline{42}, \underline{43}, \underline{44}, \underline{45}, \underline{51}, \underline{53}, \underline{57}, \underline{58}$, $\underline{59}, \underline{60}, \underline{63}, \underline{64}, \underline{66}, \underline{72}, \underline{74}, \underline{75}, \underline{77}, \frac{78}{79}, \underline{79}, \underline{80}$,

$\underline{81}, \underline{83}, \underline{86}, \underline{88}, \underline{89}, \underline{90}, \underline{91}, \underline{93}, \underline{96}, \underline{98}, \underline{99}, \underline{100}$, $\underline{102}, 103, \underline{104}, \underline{105}, \underline{106}$

Western Horse . . . . . . . . . . . . . . . . . . 20

Whales ................. $\underline{61}, \underline{80}$

Wild animals ...............

Wild horses .................. 63

Wildlife $\ldots . \underline{30}, \underline{37}, \underline{42}, \underline{44}, \underline{56}, \underline{65}, \underline{71}, \underline{73}, \underline{92}, \underline{99}, \underline{104}$

Wildlife conservation ..............

Wildlife pests ................

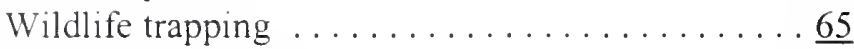

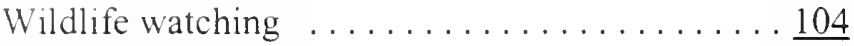

Wolves .....................

World Congress ............... 106

Wounds and injuries ............ 28

Yearlings ..............

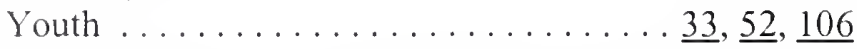

Zoo animals .... 24 $\underline{34}, \underline{42}, \underline{43}, \underline{50}, \underline{51}, \underline{61}, \underline{67}, \underline{71}$, $\underline{76}, \underline{81}, \underline{89}, \underline{91}, \underline{100}, \underline{102}$

Zoologists ......................

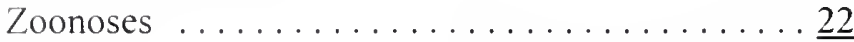

Zoos .......... $19, \underline{25}, \underline{28}, \underline{55}, \underline{89}, \underline{99}, \underline{106}$ 

NATIONAL AGRICULTURAL LIBRARY

Hilil

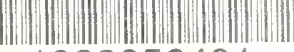

1023056401 
